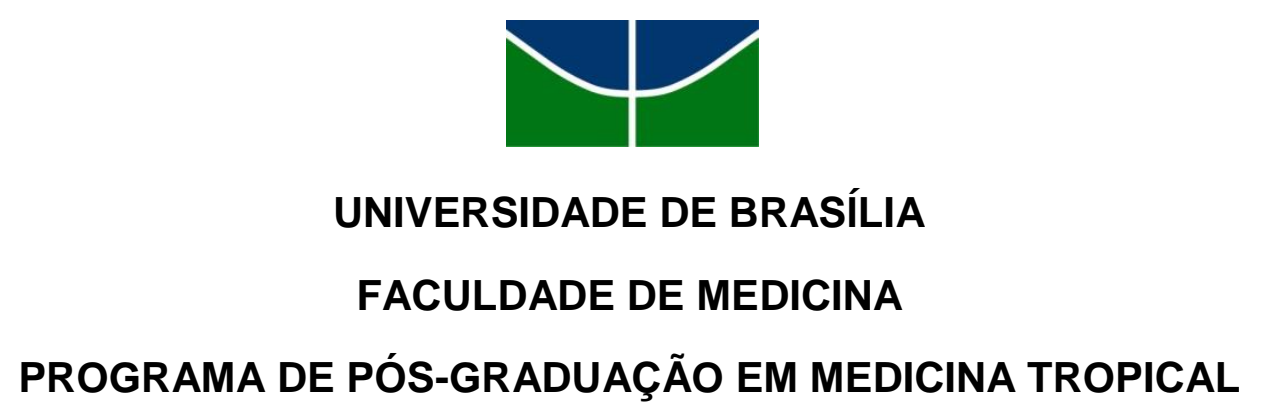

DOUGLAS DE ALMEIDA ROCHA

\title{
CARACTERIZAÇÃO DA SUSCETIBILIDADE DE PHLEBOTOMINAE (DIPTERA: PSYCHODIDAE) AO INSETICIDA ALFACIPERMETRINA
}

BRASÍLIA 


\section{CARACTERIZAÇÃO DA SUSCETIBILIDADE DE PHLEBOTOMINAE (DIPTERA: PSYCHODIDAE) AO INSETICIDA ALFACIPERMETRINA}

Douglas de Almeida Rocha

Dissertação apresentada ao Programa de PósGraduação em Medicina Tropical da Faculdade de Medicina da Universidade de Brasília para a obtenção do título de mestre em Medicina Tropical, na área de concentração: Biologia das doenças infecciosas e parasitárias.

Orientador: Prof. Dr. Marcos Takashi Obara

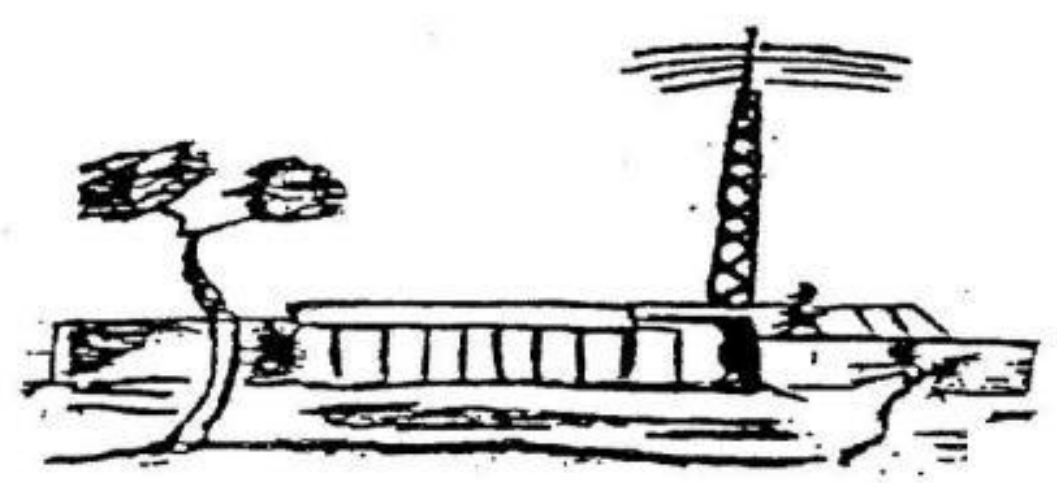

Brasília 
Ficha catalográfica elaborada automaticamente, com os dados fornecidos pelo(a) autor(a)

Rocha, Douglas de Almeida

Caracterização da suscetibilidade de Phlebotominae (Diptera: Psychodidae) ao inseticida

alfacipermetrina / Douglas de Almeida Rocha;

orientador Marcos Takashi Obara. -- Brasilia, 2016. $126 \mathrm{p}$.

Dissertação (Mestrado - Mestrado em Medicina Tropical) -- Universidade de Brasilia, 2016.

1. Flebotomíneos. 2. Leishmanioses. 3.

Resistência. 4. Piretróide. 5. Leishmania. I. Obara, Marcos Takashi, orient. II. Título. 
CARACTERIZAÇÃO DA SUSCETIBILIDADE DE

PHLEBOTOMINAE (DIPTERA: PSYCHODIDAE)

AO INSETICIDA ALFACIPERMETRINA

Universidade de Brasília

Banca Examinadora

Prof. Dr. Marcos Takashi Obara (Orientador) Universidade de Brasília - UnB

Dra. Grasielle Caldas D’Ávila Pessoa (Titular)

Centro de Pesquisas René Rachou - FIOCRUZ - MG

Prof. Dr. Rodrigo Gurgel Gonçalves (Titular) Universidade de Brasília - UnB

Prof. Dr. Wildo Navegantes de Araújo (Suplente)

Universidade de Brasília - UnB

\section{Brasília}


$\mathcal{N} a ̃ o$ diga não à vída que te espera Pra festejar a alegria de viver Pra agradecer a luz do seu caminho $\mathcal{E}$ você vaí com isso entender (Roberto Gómez Bolaños) 


\section{AGRADECIMENTOS}

A Deus... "Tudo é do Pai, toda honra e toda glória, é dele a vitória, alcançada em minha vida. Tudo é do Pai, se sou fraco e pecador bem mais forte é o meu Senhor, que me cura por amor".

A Mamãe do Céu... "Nas Ave Marias que hoje eu rezo, esqueço as palavras e adormeço. E embora cansado, sem rezar como eu devo, eu de Ti Maria não me esqueço".

Ao amor da minha vida, Maria Flor. Com você, os meus dias serão primavera. Amo você.

A minha esposa, Aline. Obrigado pela cumplicidade, companheirismo e apoio incondicional. Te amo.

A toda minha família, em especial ao meu pai, Hagamenon, minha mãe, Leide, meus irmãos Dennys e Danielle. Não consigo mensurar, nem descrever o quanto vocês são importantes para mim. Amo vocês.

Aos meus amigos que sempre torceram, comemoraram e choraram comigo esses anos todos. Obrigado.

Ao meu orientador, Prof. Marcos Takashi Obara, pela confiança, pelos conselhos, ensinamentos e principalmente pela amizade. Muito obrigado por acreditar em mim.

Ao meu coorientador, Prof. Andrey José de Andrade, pelo apoio em todas as etapas do projeto, pelas considerações na revisão do trabalho, por ser um mito, um amigo, um mestre, um exemplo de profissional e de pessoa. Muito obrigado.

A Luciana Reinaldo, pelo auxílio nas análises estatísticas do trabalho. 
Ao Prof. Rodrigo Gurgel Gonçalves, que abriu as portas do Laboratório de Parasitologia Médica e Biologia de Vetores da Faculdade de Medicina da UnB para mim, pela confiança e amizade durante estes últimos anos.

A Dra. Grasielle Caldas D'Ávila Pessoa, por ter-me "adotado", pelos ensinamentos, auxílio e críticas durante os bioensaios em Belo Horizonte e também por aceitar o convite em participar da minha banca.

Ao Prof. Wildo Navegantes de Araújo, pelos conselhos, ensinamentos e pelo aceite do convite em participar da minha banca.

Ao Jonatas Barbosa Cavalcante Ferreira, pela amizade, incentivo e por me apresentar o verdadeiro mundo científico.

Aos meus colegas do Núcleo de Medicina Tropical, que de alguma forma contribuiu na minha formação.

A Lúcia Martins, secretária do Núcleo de Medicina Tropical, pela competência e disposição em ajudar sempre que requisitada. Muito obrigado.

A equipe do Laboratório de Parasitologia e Biologia de Vetores da Faculdade de Medicina da UnB, pelos mais diversos auxílios durante estes anos.

Ao Dr. Nelder de Figueiredo Gontijo e ao César Nonato de Oliveira, da Universidade Federal de Minas Gerais, pela doação dos flebotomíneos utilizados no estudo.

A Gerência Regional de Saúde de Unaí-MG, especialmente ao Leontino Pereira do Amaral, Luiz Joaquim de Oliveira, Leila Faria e Daiane Vieira da Silva, pelo auxílio nas coletas de campo e disponibilização do laboratório para realização dos bioensaios. 
A Gerência Regional de Saúde de Paracatu-MG, especialmente ao Ediones Pires de Oliveira e Gislene Silva Couto, pelo auxílio nas coletas de campo e disponibilização do laboratório para realização dos bioensaios.

A Gerência Regional de Saúde de Belo Horizonte, especialmente ao Frank Wesley Vieira, pelo auxílio nas coletas de campo.

A Secretaria Estadual de Saúde de Minas Gerais, especialmente a Marcela Lencine Ferraz, por viabilizar o projeto nos municípios mineiros e ao motorista, José Ferreira de Arruda, pelo auxílio nas coletas de campo.

A Secretaria Estadual de Saúde de Goiás, especialmente a Maria Bárbara Helou Rodrigues, por viabilizar o projeto no município goiano de Pirenópolis.

A equipe do Laboratório Central de Saúde Pública de Goiás, especialmente ao Marcelo Santalucia, Belchior Cirino, Nair Mendes, pelo auxílio nas coletas de campo.

A Gerência Regional de Saúde de Pirenópolis, especialmente ao José Maurício, pelo auxílio nas coletas de campo e disponibilização do laboratório para realização dos bioensaios.

A Gerência Regional de Montes Claros, especialmente ao Edmarcos Xavier, pelo auxílio nas coletas de campo e disponibilização do laboratório para realização dos bioensaios.

A Gerência Regional de Januária, especialmente ao Givaldo Gomes de Menezes e Antônio Antunes da Mota, pelo auxílio nas coletas de campo e disponibilização do laboratório para realização dos bioensaios.

A todos aqueles, que direta ou indiretamente me apoiaram durante esta jornada. 


\section{LISTA DE FIGURAS}

Figura 1. Distribuição geográfica da leishmaniose visceral no Pág. 22 mundo, em 2013.

Figura 2. Distribuição geográfica da leishmaniose tegumentar Pág. 22 no mundo, em 2013.

Figura 3. Distribuição geográfica de casos e óbitos de Pág. 23 leishmaniose visceral no Brasil, em 2013.

Figura 4. Distribuição geográfica dos casos de leishmaniose Pág. 24 tegumentar americana no Brasil, em 2013.

Figura 5. Mapa dos estados de Minas Gerais e Goiás Pág. 42 mostrando a localização dos municípios selecionados para avaliação da suscetibilidade de flebotomíneos ao inseticida alfacipermetrina.

Figura 6. Armadilhas luminosas instaladas nos peridomicílios Pág. 43 dos diferentes municípios estudados. A: galinheiro em Unaí; B: chiqueiro em Paracatu; C: quintal em Belo Horizonte; D: curral em Pirenópolis; E: pombal em Montes Claros; F: galinheiro em Januária.

Figura 7. Cronograma das atividades de campo e laboratório Pág. 44 realizados nos diferentes municípios, em 2015.

Figura 8. Bioensaio de garrafa do CDC para a avaliação da Pág. 47 suscetibilidade de flebotomíneos ao inseticida alfacipermetrina. 1. Os flebotomíneos eram introduzidos nas garrafas impregnadas 
com auxílio de um capturador de castro. 2. A garrafa foi fechada e o tempo de exposição iniciado. 3. Em intervalos de 10 minutos, as garrafas foram examinadas e os flebotomíneos vivos e mortos contabilizados. 4. Os resultados das contagens foram anotados para cada intervalo de 10 minutos. 5. Após a queda de todos os flebotomíneos ou passados 120 minutos, a exposição era encerrada. 6. Todos os flebotomíneos da garrafa foram transferidos para potes com presença de algodão umedecido e solução açucarada, por 24 horas, para avaliação de possíveis efeitos "knock-down".

Figura 9. Curvas de sobrevivência de Kaplan-Meier para as Pág. 61 populações de flebotomíneos de colônia e dos municípios de Belo Horizonte, Januária, Montes Claros, Paracatu, Pirenópolis e Unaí.

Figura 10. Curvas de sobrevivência de Kaplan-Meier para as Pág. 62 dosagens do inseticida alfacipermetrina considerando as populações de flebotomíneos de colônia e dos municípios de Belo Horizonte, Januária, Montes Claros, Paracatu, Pirenópolis e Unaí.

Figura 11. Curvas de sobrevivência de Kaplan-Meier para a Pág. 63 Linhagem Referência de Suscetibilidade da Universidade Federal de Minas Gerais.

Figura 12. Curvas de sobrevivência de Kaplan-Meier para a Pág. 64 população de flebotomíneos de Unaí, Minas Gerais.

Figura 13. Curvas de sobrevivência de Kaplan-Meier para a Pág. 65 população de flebotomíneos de Paracatu, Minas Gerais. 
Figura 14. Curvas de sobrevivência de Kaplan-Meier para a Pág. 66 população de flebotomíneos de Belo Horizonte, Minas Gerais.

Figura 15. Curvas de sobrevivência de Kaplan-Meier para a Pág. 67 população de flebotomíneos de Pirenópolis, Goiás.

Figura 16. Curvas de sobrevivência de Kaplan-Meier para a Pág. 68 população de flebotomíneos de Montes Claros, Minas Gerais.

Figura 17. Curvas de sobrevivência de Kaplan-Meier para a Pág. 69 população de flebotomíneos de Januária, Minas Gerais. 


\section{LISTA DE TABELAS}

Tabela 1. Espécies de Leishmania e seus respectivos Pág. 20 reservatórios e vetores, no Brasil.

Tabela 2. Incriminação de espécies de flebotomíneos na Pág. 26 transmissão de Leishmania, no Brasil.

Tabela 3. Detalhes das capturas de flebotomíneos nos Pág. 45 municípios.

Tabela 4. Flebotomíneos coletados e utilizados nos Pág. 52 bioensaios de suscetibilidade de acordo com a espécie, origem e sexo.

Tabela 5. Estimativa de $\mathrm{DL}_{50}, \mathrm{RR}_{50}$ e slope da população de Pág. 54 referência e das populações de campo.

Tabela 6. $\mathrm{TL}_{50}$ e $\mathrm{TL}_{95}$ da população referência e das Pág. 56 populações de campo para os dois critérios de mortalidade (A e $B)$. 


\section{LISTA DE ABREVIATURAS E SIGLAS}

$\begin{array}{ll}\text { CDC } & \text { Centro de Controle e Prevenção de Doenças } \\ \text { DDT } & \text { Dietildicloro Difeniltricloroetano } \\ \text { DL } & \text { Dose Letal } \\ \text { KM } & \text { Kaplan-Meier } \\ \text { LRS } & \text { Linhagem Referência de Suscetibilidade } \\ \text { LT } & \text { Leishmaniose Tegumentar } \\ \text { LTA } & \text { Leishmaniose Tegumentar Americana } \\ \text { LV } & \text { Leishmaniose Visceral } \\ \text { OPAS } & \text { Organização Panamericana de Saúde } \\ \text { RR } & \text { Razão de Resistência } \\ \text { TL } & \text { Tempo Letal } \\ \text { UFMG } & \text { Universidade Federal de Minas Gerais }\end{array}$




\section{FINANCIAMENTO}

Apoio financeiro da Coordenação de Aperfeiçoamento de Pessoal de Nível Superior (CAPES). 


\section{ÍNDICE}

1 INTRODUÇÃO 19

$\begin{array}{lll}1.1 & \text { Leishmanioses } & 19\end{array}$

1.2 Os vetores de Leishmania 25

1.3 Aspectos de prevenção e controle das leishmanioses 27

1.3.1 Educação em saúde e combate ao vetor 28

1.3.2 Mosquiteiros tratados com inseticidas 29

1.3.3 Coleiras impregnadas 30

1.3.4 Manejo ambiental 30

1.3.5 Controle com plantas inseticidas 31

1.3.6 Controle biológico 32

1.3.7 Controle químico 32

1.4 Resistência e suscetibilidade de flebotomíneos a inseticidas 34

2 JUSTIFICATIVA 39

3 OBJETIVOS 40

3.1 Objetivo geral 40

3.2 Objetivos específicos 40

4 MATERIAL E MÉTODOS 41

4.1 Material biológico 41

4.2 Áreas de estudo 42

4.3 Inseticida e procedimentos dos bioensaios biológicos 45

4.4 Identificação dos flebotomíneos 48

4.5 Análise estatística 48

5 RESULTADOS 50 
$\begin{array}{lll}5.1 & \text { Flebotomíneos } & 50\end{array}$

5.2 Estimativa de $\mathrm{DL}_{50}, \mathrm{RR}_{50}$ e slope 53

5.3 Estimativa de Tempo Letal 54

5.4 Estimativas da curva de sobrevivência de Kaplan-Meier 57

$\begin{array}{lll}6 & \text { DISCUSSÃO } & 70\end{array}$

$\begin{array}{lll}7 & \text { CONCLUSÕES } & 78\end{array}$

8 REFERÊNCIAS BIBLIOGRÁFICAS 79

$\begin{array}{ll}\text { APÊNDICE } 1 & 91\end{array}$

APÊNDICE 2

$\begin{array}{ll}\text { APÊNDICE } 3 & 97\end{array}$

$\begin{array}{ll}\text { APÊNDICE } 4 & 98\end{array}$ 


\section{RESUMO}

ROCHA, Douglas A. Caracterização da suscetibilidade de Phlebotominae (Diptera: Psychodidae) ao inseticida alfacipermetrina. Dissertação (Mestrado em Biologia) - Programa de Pós-Graduação em Medicina Tropical, Universidade de Brasília, Brasília, 2016.

Introdução: As leishmanioses representam um conjunto de doenças infecciosas, sendo transmitidas principalmente pela picada de flebotomíneos fêmeas infectadas. Uma das medidas de controle dessas enfermidades trata-se do controle de vetores por meio de inseticidas químicos. Apesar das contínuas e intensivas campanhas de controle contra os flebotomíneos poucos estudos têm sido realizados para detectar mudanças na suscetibilidade de populações desses insetos. Objetivo: Caracterizar o perfil de suscetibilidade de populações naturais de flebotomíneos ao piretróide alfacipermetrina. Método: Flebotomíneos de seis municípios brasileiros e espécimes de laboratório classificados como "Linhagem Referência de Suscetibilidade" (LRS) foram avaliados pelo método de garrafas do Centro de Controle e Prevenção de Doenças para diferentes dosagens $(3 \mathrm{ug} / \mathrm{ml}, 5$ $\mathrm{ug} / \mathrm{ml}, 7 \mathrm{ug} / \mathrm{ml}$ e $9 \mathrm{ug} / \mathrm{ml}$ ) do inseticida alfacipermetrina. Acetona foi utilizada como controle. Resultados: Ao todo 2.198 flebotomíneos foram utilizados nos bioensaios. A espécie Lutzomyia longipalpis foi a mais capturada em todos os municípios. A dose ideal para diagnóstico nas alterações de suscetibilidade ao inseticida alfacipermetrina foi de 2,38 ug/ml. As curvas de sobrevivência de Kaplan-Meier apontaram que as populações de flebotomíneos de Montes Claros e Paracatu possuem maior tolerância a inseticidas, seguida da população de Pirenópolis, Unaí, Januária e Belo Horizonte. O tempo diagnóstico variou conforme as concentrações do inseticida sendo de 40 minutos para a dosagem de $9 \mathrm{ug} / \mathrm{ml}, 50$ minutos para a dosagem de $7 \mathrm{ug} / \mathrm{ml}, 60$ minutos para a dosagem de $5 \mathrm{ug} / \mathrm{ml}$ e 70 minutos para a dosagem de $3 \mathrm{ug} / \mathrm{ml}$. Conclusões: As populações de flebotomíneos oriundas dos municípios de Unaí, Paracatu, Belo Horizonte, Pirenópolis, Montes Claros e Januária, assim como a LRS apresentaram alterações nos perfis de suscetibilidade ao piretróide alfacipermetrina.

Palavras-chave: Flebotomíneos, Leishmanioses, Resistência, Bioensaios de garrafa, Piretróide, Leishmania. 


\section{ABSTRACT}

ROCHA, Douglas A. Caracterization of susceptibility of Phlebotominae (Diptera: Psychodidae) to the alpfacypermetrin insecticide. Dissertação (Mestrado em Biologia) - Programa de Pós-Graduação em Medicina Tropical, Universidade de Brasília, Brasília, 2016.

Introdution: Leishmaniases are a group of infectious diseases primarily transmitted by infected females of phlebotomine sand flies. Chemical insecticides are one of the control measures of these diseases used against vectors. Despite of the continuous and intensive control campaigns few studies have been carried out to detect changes in the susceptibility of sand flies by insecticides. Objective: Characterize the susceptibility profile of populations of sand flies to alphacypermetrin pyrethroid. Methods: Sand flies caught in six Brazilian municipalities and specimens of laboratory classified as Susceptibility Reference Lineage (SRL) were evaluated using CDC bottles trough different concentrations of alphacypermetrin $(3 \mathrm{ug} / \mathrm{ml}, 5 \mathrm{ug} / \mathrm{ml}, 7 \mathrm{ug} / \mathrm{ml}$ and $9 \mathrm{ug} / \mathrm{ml}$ ). Acetone P.A was used as control. Results: A total of 2,198 sand fly specimens were used in bioassays and Lutzomyia longipalpis was the species most caught in all municipalities. The ideal dose for diagnosing the susceptibility changes to alfacipermetrina insecticide was $2.38 \mathrm{ug} / \mathrm{ml}$. Kaplan-Meier survival curves showed that sand flies of Montes Claros and Paracatu municipalities had major tolerance by alphacypermetrin, then specimens of Pirenópolis, Unai Januária, and Belo Horizonte. Diagnosis time varied according to the insecticides concentrations: 40 minutes for $9 \mathrm{ug} / \mathrm{ml}$, $50 \mathrm{~min}$. for $7 \mathrm{ug} / \mathrm{ml}, 60 \mathrm{~min}$. for $5 \mathrm{ug} / \mathrm{ml}$ and $70 \mathrm{~min}$. for $3 \mathrm{ug} / \mathrm{ml}$. Conclusions: Sand fly populations of the municipalities of Unaí, Paracatu, Belo Horizonte, Pirenópolis, Montes Claros and Januária, as well as the SRL specimens showed changes in susceptibility profiles, indicating tolerance a alphacypermetrin.

Key words: Phlebotomine sand flies, Leishmaniases, Resistence, Bottle bioassay, Pyrethroid, Leishmania. 


\section{INTRODUÇÃO}

\subsection{Leishmanioses}

As leishmanioses representam um conjunto de doenças infecciosas, consideradas zoonoses, podendo manifestar-se no ser humano quando este entra em contato com o ciclo de transmissão do protozoário causador das doenças. Este espectro de enfermidades pode acometer pele, mucosas e/ou vísceras dependendo, principalmente, da espécie ou cepa do parasito e do estado imunológico do hospedeiro. As leishmanioses são resultantes da infecção por diferentes espécies de protozoários flagelados do gênero Leishmania Ross 1903, os quais apresentam ciclo de vida heteróxeno, vivendo alternadamente em hospedeiros vertebrados (mamíferos e répteis) e insetos vetores, estes últimos, responsáveis pela transmissão das leishmânias (Lainson e Shaw, 1973). O gênero Leishmania pertence a ordem Kinetoplastida família Trypanosomatidae. Os protozoários deste gênero apresentam duas formas morfológicas básicas: i) promastigota forma flagelada encontrada no intestino dos flebotomíneos vetores e ii) amastigota - forma circular e parasita intracelular obrigatória de células do sistema monocítico fagocitário (Shaw, 2002).

O gênero Leishmania compreende aproximadamente 30 espécies, das quais cerca de 20 são patogênicas para a espécie humana (Maroli et al. 2013; Ready, 2013). No Brasil, sete espécies de Leishmania causadoras da Leishmaniose Tegumentar Americana (LTA) foram identificadas: $L$. (Leishmania) amazonensis, L. (Viannia) braziliensis, L. (V.) guyanensis, L. (V.) lainsoni, $L .(V$.$) naiffi, L$. (V.) lindenberg e $L$. (V.) shawi. Até o momento 
somente a $L$. (L.) infantum é responsável pela Leishmaniose Visceral (LV) nas Américas (Maurício et al. 2000; Lainson e Rangel, 2005).

Os ciclos de transmissão das leishmanioses variam de acordo com a região geográfica, envolvendo uma diversidade de espécies de parasito, vetores e reservatórios (Brasil, 2006a; Brasil, 2010) (Tabela 1).

Tabela 1. Espécies de Leishmania e seus respectivos reservatórios e vetores, no Brasil.

\begin{tabular}{ccc}
\hline Parasitos & Reservatórios & Principais vetores \\
\hline Leishmania infantum & Cachorros & Lutzomyia longipalpis \\
Leishmania amazonensis & Roedores silvestres & Bichromomyia flaviscutellata \\
Leishmania braziliensis & Roedores silvestres & Psychodopygus wellcomei \\
Leishmania guyanensis & $\begin{array}{c}\text { Preguiças, tamanduás e } \\
\text { gambás }\end{array}$ & Nyssomyia umbratilis \\
Leishmania lainsoni & Pacas & Trichophoromyia ubiquitalis \\
Leishmania lindenberg & Desconhecido & Nyssomyia antunesi \\
Leishmania naiffi & Tatus & Psychodopygus ayrozai \\
Leishmania shawi & Macacos, quatis e & Nyssomyia whitmani \\
\hline
\end{tabular}

Fonte: Modificado de Brasil, 2010.

As leishmanioses apresentam duas formas clínicas clássicas, denominadas de tegumentar ou cutânea e visceral. A leishmaniose tegumentar (LT) caracteriza-se por feridas na pele que se localizam com maior frequência nas partes descobertas do corpo. Tardiamente, pode haver ulceração nas mucosas do nariz, da boca e da garganta, caracterizando-a como cutâneo-mucosa. Existe também uma forma rara de LT, a leishmaniose cutânea difusa, a qual se caracteriza por comprometimento dérmico maciço de natureza crônica e com recidivas frequentes. A LV é uma doença sistêmica, que acomete vários órgãos internos, principalmente 0 fígado, o baço e a medula óssea. Esse tipo de leishmaniose manifesta-se 
principalmente em crianças de até 10 anos; após esta idade se torna menos frequente. É caracterizada por febre de longa duração, perda de peso, astenia, adinamia e anemia, dentre outras manifestações. Quando não tratada, pode evoluir para óbito em mais de 90\% dos casos (Brasil, 2006a; Brasil, 2010).

A transmissão ocorre, principalmente por meio da picada de fêmeas de flebotomíneos (Diptera: Phlebotominae) infectadas. Porém, transmissões congênita, sexual (Turchetti et al. 2014), por transfusões de sangue (Dey e Singh, 2006), compartilhamento de agulhas entre usuários de drogas (Alvar et al. 2008), por vetores mecânicos como carrapatos (Dantas-Torres, 2011) e dípteros ceratopogonídeos (Diptera: Ceratopogonidae) (Dougall et al. 2011), tem sido relatadas $\mathrm{e}$, aparentemente, desempenhariam um papel significativo na epidemiologia, disseminação e manutenção das doenças, especialmente na ausência de flebotomíneos.

As leishmanioses representam um grave problema de saúde pública, sendo registradas em 98 países, onde 74 são endêmicos para LV (Figura 1) e 82 para LT (Figura 2), distribuídas por quatro continentes (Américas, Europa, África e Ásia). Países como o Brasil, Índia, Bangladesh e Sudão são responsáveis por $90 \%$ dos casos notificados de LV, com taxa de incidência anual de 400 mil casos. O Afeganistão, Brasil, Irã, Peru, Arábia Saudita e Síria são responsáveis por $90 \%$ dos casos de LT. As infecções humanas são encontradas também em 16 países da Europa. Estima-se que ocorram 1,5 milhões de novos casos para LT. Atualmente, cerca de 350 milhões de pessoas estão expostas a essas enfermidades em todo mundo (Alvar et al. 2012; OMS, 2013). 


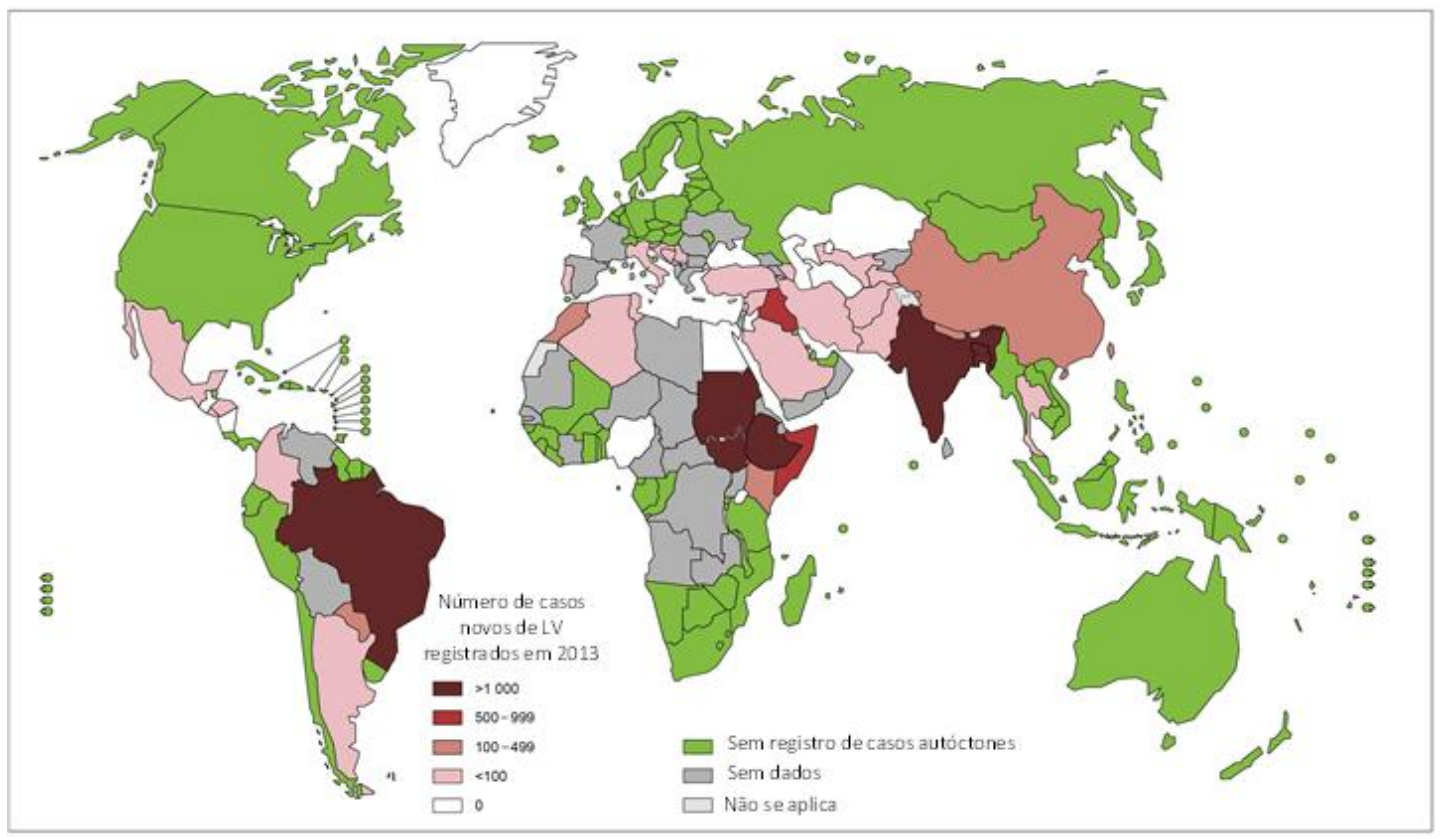

Figura 1. Distribuição geográfica da leishmaniose visceral no mundo, em 2013.

Fonte: Modificado de: Organização Mundial da Saúde, 2013.

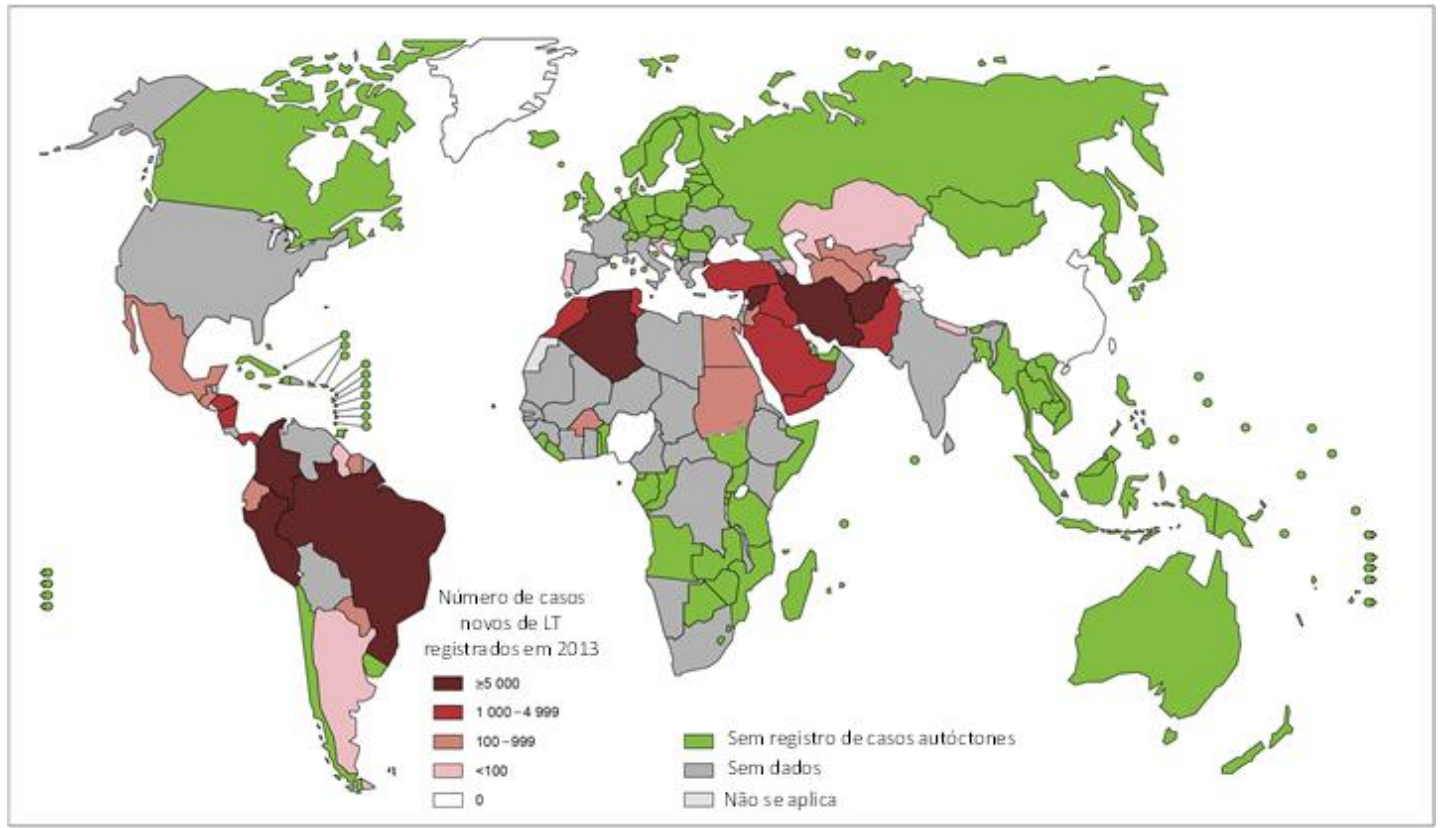

Figura 2. Distribuição geográfica da leishmaniose tegumentar no mundo, em 2013.

Fonte: Modificado de: Organização Mundial da Saúde, 2013. 
No continente americano, a LV distribui-se entre o México e a Argentina, porém $90 \%$ dos casos ocorrem no Brasil. Tradicionalmente, a LV ocorria em zonas rurais do nordeste brasileiro. No entanto, no início dos anos 80 ocorreram profundas alterações nos padrões de transmissões da LV, que devido à degradação ambiental, falta de saneamento básico e migrações e concentrações de grandes contingentes de pessoas infectadas nas periferias das grandes cidades, permitiram a "urbanização" dessa enfermidade. Ainda tais fatores promoveram a proliferação do vetor Lutzomyia longipalpis e com isso o aumento dos casos de LV nestes locais (Brasil, 2006a; Bern, et al. 2008; Ready, 2014). Atualmente a LV está distribuída por todas as regiões geográficas do Brasil causando em média 3 mil casos e 200 óbitos por ano, a maioria na região nordeste do país (Brasil, 2015a) (Figura 3).

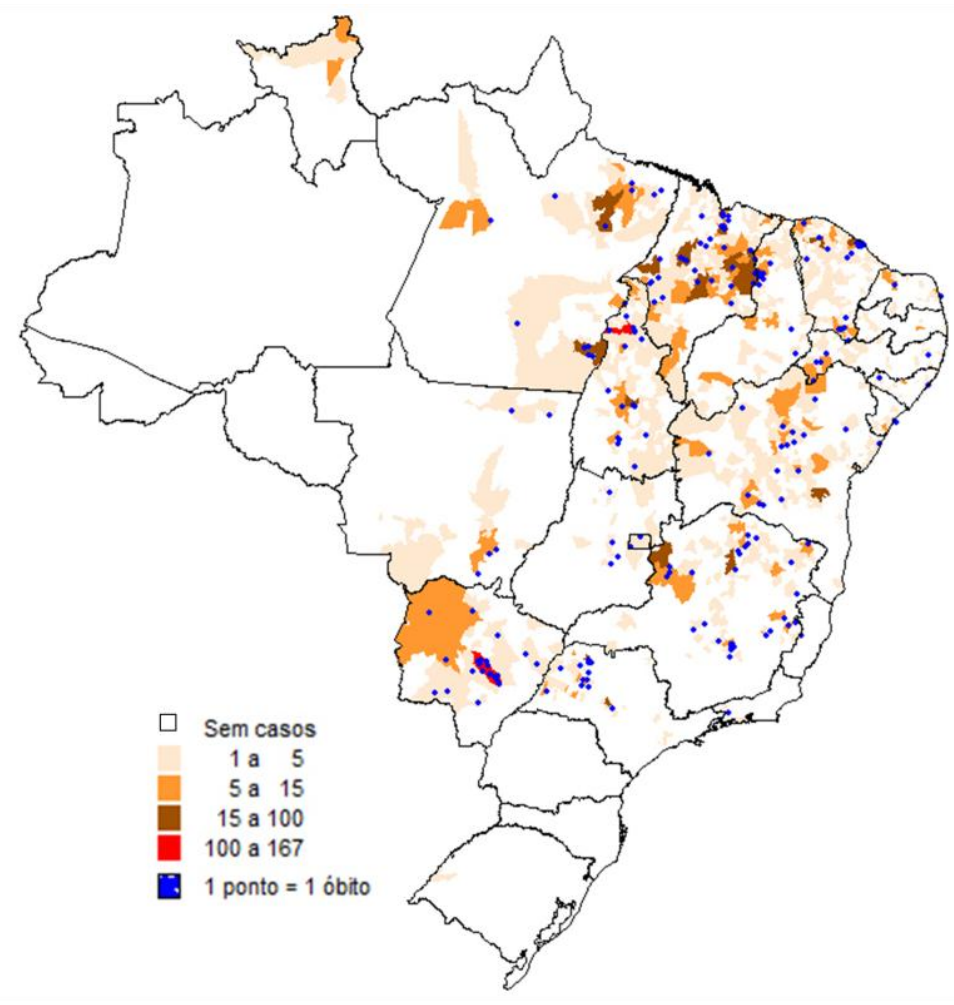

Figura 3. Distribuição geográfica de casos e óbitos de leishmaniose visceral no Brasil, em 2013.

Fonte: GT-Leishmanioses/UVTV/CGDT/SVS/MS,2013. 
A leishmaniose tegumentar americana (LTA), denominada assim, de acordo com sua distribuição geográfica, ocorre desde o sul dos Estados Unidos até o norte da Argentina, tendo o Brasil como o país mais acometido por essa enfermidade. Assim como a LV, a LTA também está em processo de transição. Inicialmente considerada uma zoonose de animais silvestres, que acometia ocasionalmente pessoas em contato com as florestas, a LTA começou a ocorrer em zonas rurais, já praticamente desmatadas, e em regiões periurbanas (Gontijo e Carvalho 2003; Alvar et al. 2012). Atualmente ocorre em todas as Unidades Federativas brasileiras com média de mais de 20 mil casos anuais, principalmente na região amazônica (Brasil, 2015b) (Figura 4).

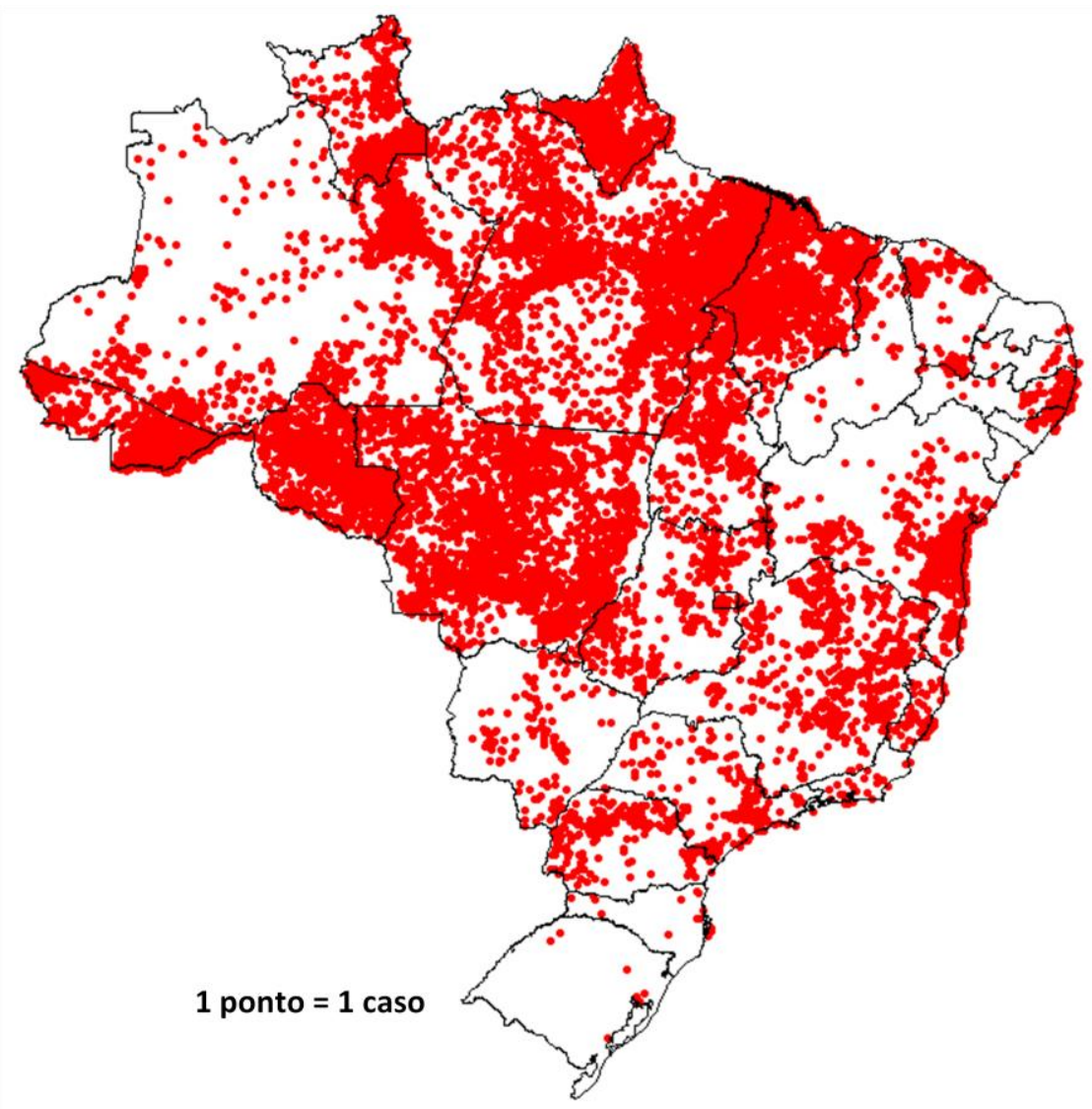

Figura 4. Distribuição geográfica dos casos de leishmaniose tegumentar americana no Brasil, em 2013.

Fonte: GT-Leishmanioses /UVTV/CGDT/SVS/MS, 2013. 


\subsection{Os vetores de Leishmania}

Os flebotomíneos são dípteros hematófagos pertencentes à família Psychodidae e subfamília Phlebotominae. Algumas espécies do gênero Lutzomyia, segundo a classificação de Young \& Duncan (1994), são os vetores comprovados e/ou suspeitos pela transmissão das leishmânias nas Américas. De acordo com a proposta de classificação de flebotomíneos da região Neotropical, com abordagem filogenética (Galati, 1995; 2003), o gênero Lutzomyia estaria subdividido em 19 gêneros dos quais algumas espécies estariam envolvidas na epidemiologia das leishmanioses. No Novo Mundo, 48 espécies de flebotomíneos são incriminadas como vetores potenciais de Leishmania, outras 38 espécies são suspeitas de transmitir o protozoário causador das leishmanioses. No Brasil, esses números são de 16 espécies incriminadas e 14 suspeitas (Tabela 2) (Maroli et al. 2013; Ready, 2013).

Alguns critérios são sugeridos para incriminar uma determinada espécie de flebotomíneo como vetora de Leishmania, tais como: isolar Leishmania, na fase promastigota, de fêmeas ingurgitadas de flebotomíneos do campo com menos de 36 horas de idade; encontrar Leishmania promastigotas no intestino ou na válvula estomodeal de flebotomíneos de campo infectados naturalmente, ou de colônia, infectados em xenodiagnóstico; antropofilia e interesse em picar hospedeiro-reservatórios de Leishmania; associação ecológica entre a espécie de flebotomíneo, o homem e o hospedeiro reservatório; hospedeiro natural infectado em condições de laboratório; por meio de dados retrospectivos ou por modelos matemáticos, demonstrar que o flebotomíneo mantém a transmissão do parasito, mesmo na presença de outro vetor e demonstração da relação da diminuição da incidência da doença com a queda da densidade populacional do flebotomíneo (Killick-Kendrick e Ward, 1981; Ready, 2013). 
Tabela 2. Incriminação de espécies de flebotomíneos na transmissão de Leishmania, no Brasil.

\begin{tabular}{|c|c|c|c|}
\hline Vetor & Espécie de Leishmania & Incriminação & $\begin{array}{l}\text { Forma } \\
\text { clínica }\end{array}$ \\
\hline Lutzomyia longipalpis & Leishmania infantum chagasi & Comprovado & LV \\
\hline Lutzomyia almerioi & Leishmania infantum chagasi & Suspeito & LV \\
\hline Lutzomyia cruzi & Leishmania infantum chagasi & Suspeito & LV \\
\hline Evandromyia sallesi & Leishmania infantum chagasi & Suspeito & LV \\
\hline Lutzomyia forattinii & Leishmania infantum chagasi & Suspeito & LV \\
\hline Migonemyia migonei & Leishmania infantum chagasi & Suspeito & LV \\
\hline Migonemyia migonei & Leishmania braziliensis & Comprovado & LTA \\
\hline Nyssomyia neivai & Leishmania braziliensis & Comprovado & LTA \\
\hline Nyssomyia whitmani & Leishmania braziliensis & Comprovado & LTA \\
\hline Pintomyia fischeri & Leishmania braziliensis & Comprovado & LTA \\
\hline Psychodopygus complexus & Leishmania braziliensis & Comprovado & LTA \\
\hline Psychodopygus wellcomei & Leishmania braziliensis & Comprovado & LTA \\
\hline Evandromyia edwardsi & Leishmania braziliensis & Suspeito & LTA \\
\hline Nyssomyia intermedia & Leishmania braziliensis & Suspeito & LTA \\
\hline Pintomyia pessoai & Leishmania braziliensis & Suspeito & LTA \\
\hline Psychodopygus paraensis & Leishmania braziliensis & Suspeito & LTA \\
\hline Nyssomyia anduzei & Leishmania guyanensis & Comprovado & LTA \\
\hline Nyssomyia whitmani & Leishmania guyanensis & Comprovado & LTA \\
\hline Nyssomyia umbratilis & Leishmania guyanensis & Comprovado & LTA \\
\hline Bichromomyia flaviscutellata & Leishmania amazonensis & Comprovado & LTA \\
\hline Bichromomyia olmeca nociva & Leishmania amazonensis & Comprovado & LTA \\
\hline Bichromomyia olmeca reducta & Leishmania amazonensis & Comprovado & LTA \\
\hline Lutzomyia longipalpis & Leishmania amazonensis & Comprovado & LTA \\
\hline Nyssomyia ubiquitalis & Leishmania lainsoni & Comprovado & LTA \\
\hline Nyssomyia whitmani & Leishmania shawi & Suspeito & LTA \\
\hline Psychodopygus ayrozai & Leishmania naiffi & Comprovado & LTA \\
\hline Psychodopygus amazonensis & Leishmania naiffi & Suspeito & LTA \\
\hline Psychodopygus paraensis & Leishmania naiffi & Suspeito & LTA \\
\hline Psychodopygus squamiventris & Leishmania naiffi & Suspeito & LTA \\
\hline Nyssomyia antunesi & Leishmania lindenbergi & Suspeito & LTA \\
\hline
\end{tabular}

LV: Leishmaniose visceral; LTA: Leishmaniose tegumentar americana.

Fonte: Modificado de: Maroli et al. 2013; Ready, 2013.

Como todo inseto pertencente à ordem Diptera, os flebotomíneos, são holometábolos (passam pelas fases de ovo, quatro estádios larvais, pupa e adulto). As formas imaturas possuem habitat terrestre, desenvolvendo-se em locais úmidos, sombreados e ricos em matéria orgânica em decomposição, especialmente de natureza vegetal. Os adultos são amarelados ou castanhos, com cerca de $2,5 \mathrm{~mm}$ de comprimento, possuem voo saltado e 
quando em repouso mantêm as asas eretas. A superfície corporal apresenta um revestimento quitinoso delgado, necessitando assim, abrigar-se em locais onde possam proteger-se de mudanças de temperatura e pluviosidade que ocorrem no ambiente (Aguiar e Medeiros, 2003).

Distribuem-se por quase todas as regiões do mundo, sendo mais diversos na Região Neotropical, com maior número de espécies e densidade que flutuam de acordo com a estação climática (Sherlock, 2003). Em todo o mundo são conhecidas 966 espécies, das quais, mais de 515 estão presentes na região Neotropical e destas, 273 foram registradas no Brasil, representando $28,26 \%$ do total e $53 \%$ das que ocorrem na Região Neotropical (Galati, 2015; Shimabukuro et al. 2016).

Os flebotomíneos iniciam suas atividades no crepúsculo. Ambos os sexos se alimentam de sucos vegetais, néctar de flores, frutos e soluções açucaradas. As fêmeas, além da alimentação de açúcares, também são hematófagas, pois necessitam de sangue para a maturação dos ovos. Por meio deste hábito, pode se infectar e/ou transmitir agentes patogênicos para mamíferos e répteis (Sherlock, 2003).

\subsection{Aspectos de prevenção e controle das leishmanioses}

As medidas de controle das leishmanioses, preconizadas pela Organização Mundial de Saúde (OMS), constam de diagnóstico precoce e tratamento dos casos humanos, controle dos vetores e realização de inquéritos sorológicos nas populações caninas seguidos da eliminação dos animais soropositivos (Brasil, 2006a). No Brasil, essas ações foram descontínuas por diversas razões, tais como problemas orçamentários e escassez de recursos humanos adequadamente treinados. Com isso, essas medidas não têm atingido os efeitos esperados, ocorrendo reinfestações dos 
ambientes e ressurgimentos dos casos humanos e caninos (Gontijo e Melo, 2004; Romero e Boelaert, 2010).

Com o contínuo aumento das infecções das leishmanioses, o controle destas enfermidades requer a adoção de diferentes estratégias para a interrupção da transmissão humana. Dentre essas ações podemos citar a educação em saúde, mosquiteiros e coleiras impregnadas com inseticidas, manejo ambiental, controle com plantas inseticidas, biológico e com uso de substâncias químicas, comumente denominadas de inseticidas.

\subsubsection{Educação em saúde e combate ao vetor}

Educação em saúde é um elemento central na implementação de qualquer método de prevenção e controle de doenças (OMS, 2010) e segundo Killick-Kendrick (2010), é a chave para controlar a LV.

Os manuais de LV e LTA recomendam as atividades de educação em saúde, devendo-se inseri-las em todos os serviços que desenvolvem as ações de controle das leishmanioses, requerendo o envolvimento efetivo das equipes multiprofissionais e multi-institucionais com vistas ao trabalho articulado nas diferentes unidades de prestação de serviços (Brasil, 2006a; 2010). Sherlock (1996) observou que na Bahia e em outras regiões do Brasil, a pobreza, a desnutrição e a alta densidade de flebotomíneos estão associadas à elevada presença de animais domésticos e péssimas condições sanitárias em áreas de transmissão da LV. Em Montes Claros, Minas Gerais, Monteiro et al. (2005) observaram as mesmas condições apontadas por Sherlock (1996), onde as habitações tinham, em sua maioria deficiência na coleta de lixo e de saneamento básico, em algumas áreas muitos moradores viviam em locais com baixos índices socioeconômicos, a convivência com animais domésticos era bastante elevada, resultando em acúmulo de matéria orgânica, proporcionando condições favoráveis para a ocorrência da transmissão da doença. Esse quadro tem se expandido 
também para população de bom nível socioeconômico, tendo sido também observado em Várzea Grande, Mato Grosso (Mestre e Fontes, 2007) e em Belo Horizonte, Minas Gerais, onde um estudo sobre o conhecimento da LV verificou que metade dos indivíduos acometidos pela doença desconhecia-a completamente quando foram infectados e apenas $1,2 \%$ reconheciam 0 vetor, além disso, pessoas não alfabetizadas tinham oito vezes mais chance de serem acometidas pela doença (Borges et al. 2008).

A falta de informação da população sobre as leishmanioses é devido aos poucos trabalhos de divulgação dessas doenças, seja por meios impressos ou audiovisuais. Além disso, Luz et al. (2003) alertaram para um processo de imposição de discursos e reprodução de preconceitos a partir de desenhos e fotografias de materiais educativos sobre as leishmanioses. Assim sendo, seja nos contextos dos serviços de saúde ou nas áreas de educação e comunicação, a escassez e a baixa qualidade do material remetem à necessidade de uma reflexão crítica sobre a possibilidade de propor novas abordagens sobre as leishmanioses.

\subsubsection{Mosquiteiros tratados com inseticida}

Alexander e Maroli (2003) sugeriram que mosquiteiros impregnados com inseticida poderiam ser uma forma mais eficiente e barata do que a borrifação intradomiciliar para controle de flebotomíneos. Em estudos realizados por Courtenay et al. (2007), na llha de Marajó, Pará, os mosquiteiros impregnados reduziram a quantidade de flebotomíneos em comparação com redes não tratadas. Porém, o hábito dos moradores de jantarem nos horários de pico das atividades de Lu. longipalpis dificultaria o controle do vetor por esse método. Na Índia, Dinesh et al. (2008) não encontraram diferenças significativas nos bioensaios com redes impregnadas com o inseticida permetrina para controle de Phlebotomus argentipes. Bray e Hamilton (2013) avaliaram a eficácia de mosquiteiros 
impregnados com lambda-cialotrina no controle de Lu. longipalpis, em condições de laboratório. Apesar dos bons resultados alcançados no controle dos flebotomíneos, os autores sugerem que testes em condições de campo sejam realizados, principalmente em galinheiros e outros abrigos de animais.

\subsubsection{Coleiras impregnadas}

O uso de coleiras impregnadas pode proteger os cachorros contra infecção por leishmânia como também reduzir o risco de transmissão do parasito e substituir a controversa eutanásia de cães adotados pelos programas de controles das leishmanioses.

Em áreas endêmicas para LV na Itália (Maroli et al. 2001) e no Irã (Mazloumi Gavgani et al. 2002) foi demonstrado que cães usando coleiras impregnadas com deltametrina apresentaram menor risco de infecção. Contudo, por meio de modelo matemático simulou-se comparativamente o controle da LV por meio do uso da coleira impregnada com a eutanásia de cães por um período de cinco anos, observando-se que não houve diferença significativa entre os dois tratamentos (Reithinger et al. 2004). Assim, a decisão de incluir a aplicação em massa das coleiras nos programas de controle das leishmanioses no Brasil dependerá da sua aplicabilidade prática no campo, a fim de interromper o ciclo de transmissão doméstico, sendo necessária para isso a implementação de estudos longitudinais que demonstrem sua efetividade como medida de controle (Brasil, 2006a).

\subsubsection{Manejo ambiental}

Mudanças ambientais por meio de fenômenos naturais ou por intervenção humana (manejo ambiental), altera o equilíbrio ecológico e o 
contexto dentro dos quais vetores e parasitos se desenvolvem e transmitem doenças (Pessoa et al. 2007). O manejo ambiental é uma medida de controle que visa administrar o ambiente de forma a torná-lo inadequado ao vetor. Esta estratégia tem sido indicada para limpeza de quintais, terrenos e praças públicas, a fim de alterar as condições do meio, que propiciem o estabelecimento de criadouros de formas imaturas do vetor. Medidas simples como limpeza urbana, eliminação dos resíduos sólidos orgânicos e destino adequado dos mesmos, eliminação de fonte de umidade e cuidados com animais domésticos, entre outras, contribuem para evitar ou reduzir a proliferação do vetor (São Paulo, 2012).

\subsubsection{Controle com plantas inseticidas}

A necessidade de métodos mais eficazes e cada vez mais seguros no controle de insetos tem estimulado a busca de inseticidas em plantas. Alguns estudos têm estudado a ação de fitoquímicos contra as fases de desenvolvimento e no crescimento de insetos (Viegas-Júnior, 2003; Tare et al. 2004). Andrade-Coelho et al. (2009) avaliaram o efeito de frutas e folhas de nim (Azadirachta indica) e de amargozeira (Melia azedarach) contra o desenvolvimento de formas imaturas de Lu. longipalpis e demonstraram o potencial desta essência no controle deste vetor. Resultados similares foram encontrados por Maciel et al. (2010) avaliando o efeito do óleo de sementes nim contra larvas e adultos de Lu. longipalpis.

Os resultados disponíveis na literatura mostram que há um imenso potencial para as plantas e seus extratos para agirem como uma alternativa aos pesticidas químicos, porém mais estudos com diferentes plantas e diferentes metodologias devem ser realizados (Dinesh et al. 2014). 


\subsubsection{Controle biológico}

O controle biológico de flebotomíneos por meio da bactéria Bacillus thuringiensis foi testado, em condições de laboratório por Wahba et al. (1999) e Robert et al. (1997) e se mostrou bastante eficiente, tanto na mortalidade de larvas como na mortalidade de adultos. O fungo Beauveria bassiana também aumentou a mortalidade de flebotomíneos, em experimento realizado por Warburg (1991). O protozoário Ascogregarina chagasi é conhecido por reduzir tanto a longevidade como produção de ovos de Lu. longipalpis e pode efetivamente destruir colônias em laboratório (Dougherty \& Ward, 1991). Contudo, até que ponto este parasito poderia ser usado no controle biológico de flebotomíneos ainda é questionável (Lainson e Rangel, 2005). Atualmente, os estudos sobre controle biológico de flebotomíneos são escassos e a aplicação de biolarvicidas nas condições de campo é extremamente difícil. Devido à dificuldade de se encontrar os criadouros naturais destes insetos e a diversidade de habitat de procriação destes vetores, o controle químico ainda é o método mais eficiente.

\subsubsection{Controle químico}

Como mencionado anteriormente, no Brasil, as medidas de prevenção e controle são preconizadas pelo Ministério da Saúde e baseiam-se no diagnóstico precoce e tratamento adequado dos casos humanos; identificação e eliminação do reservatório doméstico e na redução do contato homem-vetor. Essa última estratégia é desenvolvida por meio de controle químico com aplicação periódica e sistemática de inseticida de ação residual, no intra e peridomicílio (Brasil, 2006a).

As primeiras tentativas de controle químico de flebotomíneos, no Brasil, ocorreram durante uma campanha no ano de 1953, por meio de 
pulverização residual com o inseticida organoclorado dietildicloro difeniltricloroetano (DDT) (Monteiro et al. 1994). Em 1954, Nery-Guimarães e Bustamante avaliaram o efeito da aplicação do DDT em um foco de LV, no estado do Rio de Janeiro. Este mesmo inseticida também foi usado nas ações de controle da espécie Lu. longipalpis no estados do Ceará e Minas Gerais nas décadas de 1950 e 1960 (Oliveira-Filho e Melo, 1994). A primeira avaliação do impacto do DDT foi realizada em quatro localidades do estado do Ceará (Deane et al. 1955).

Em 1964, o uso de inseticidas residuais foi interrompido, devido aos altos custos operacionais. Uma nova campanha recomeçou no início da década de 1980, quando um grande número de casos de LV foi notificado (Monteiro et al. 1994; Brasil, 1999).

O DDT, devido aos diversos questionamentos, tais como: elevada toxicidade para o ser humano e animais domésticos, custo operacional relativamente alto, necessidade de replicações frequentes e sua inativação pelo barro das paredes foi, gradativamente, sendo substituído pelo uso dos piretróides, desde o fim dos anos 1980 e início da década de 1990 (OliveiraFilho e Melo, 1994).

Um dos primeiros trabalhos analisando os efeitos de piretróides na mortalidade de flebotomíneos ocorreu em 1988, em Minas Gerais. Neste trabalho foi testado o inseticida deltametrina, em condição de laboratório, contra populações de Lu. longipalpis oriundos da gruta da Lapinha. Os resultados encontrados mostraram eficiência deste piretróide (Falcão et al. 1988).

Marcondes e Nascimento (1993) e De Silans et al. (1998) analisaram os efeitos de deltametrina e cipermetrina, respectivamente, em municípios do interior da Paraíba, Brasil. Ambos, avaliaram o número de flebotomíneos coletados após a borrifação de paredes com os piretróides. No primeiro estudo, as capturas se apresentaram irregulares e uma proteção de apenas quatro semanas foi notada. Em um segundo estudo, os resultados 
mostraram que o inseticida reduzia significativamente as populações de $L u$. longipalpis.

No ano de 2011, em Montes Claros, Minas Gerais, foi realizado um estudo com populações de Lu. longipalpis de campo. O inseticida utilizado no estudo foi o piretróide cipermetrina e uma redução significativa nas populações de flebotomíneos foi observada após as primeiras borrifações do inseticida.

\subsection{Resistência e suscetibilidade de flebotomíneos a inseticidas}

Apesar das contínuas e intensivas campanhas de controle contra os vetores de Leishmania, agentes causadores das leishmanioses, poucos estudos têm sido realizados para detectar mudanças na suscetibilidade de populações de flebotomíneos, em relação aos inseticidas utilizados no seu controle.

A resistência a inseticidas foi definida pela OMS como sendo uma característica herdável, portanto genética, que confere um aumento na tolerância a um pesticida, ou grupo de pesticidas, de modo que os indivíduos resistentes sobrevivem à concentração do(s) componente(s) que seria normalmente letal para a maioria dos indivíduos de uma população da mesma espécie (suscetível) (OMS, 1957; 1992).

A primeira evidência bem documentada de resistência de uma espécie de flebotomíneo foi para $P h$. papatasi para DDT e Dieldrin, detectada em Bihar e Arthala, ambos na Índia. Populações desta espécie foram expostos a DDT a $4 \%$ por 24 horas e houve apenas $67 \%$ de mortalidade (Kaul et al. 1978; Joshi et al. 1979; Rahman et al. 1982). Em seguida, Dhanda et al. (1983) confirmaram a elevada resistência de Ph. papatasi em Bihar, quando foi registrado 13,3\% de mortalidade para DDT a 
$8 \%$, durante $24 \mathrm{~h}$ de exposição. Nesse mesmo país, outras populações de Ph. papatasi também foram encontradas com elevados níveis de resistência em Gujarat (Thapar et al. 1993) e Rajastan (Bansal e Singh, 1996).

Ainda no Velho Mundo, Ph. argentipes também apresentou resistência ao organoclorado DDT, em áreas de Samastipur, distrito de Bihar e no vilarejo de Gulmehiya Bagh, localizado no distrito de Patna, Índia (Mukhopadhyay et al. 1992; Dinesh et al. 2011).

O primeiro relato de resistência a inseticidas em um gênero diferente foi para Sergentomyia, compreendendo a espécie Se. shortii em Assam, na Índia. Kaul et al. (1994) relataram $54 \%$ de mortalidade para os insetos expostos a DDT por 1 hora. A possível explicação da resistência foi atribuída à intensa pressão de inseticida das campanhas de malária, ocorridas desde 1958.

No Brasil, De Silans et al. (1998) realizaram a aplicação de cipermetrina em 180 unidades domiciliares localizadas no município de Conde, no estado da Paraíba com o intuito de analisar a eficácia e o poder residual desse composto no controle de Lu. longipalpis. Os resultados dos ensaios de campo confirmaram que a mortalidade após quatro meses de tratamento foi de apenas $36,2 \%$ e que a aplicação no peridomícilio apresentou-se ineficaz para diminuição da densidade populacional dessa espécie.

Alexander et al. (2009) demonstraram diferenças significativas entre a mortalidade de populações de Lu. longipalpis procedentes de Montes Claros e da gruta da Lapinha, ambas localizadas no estado de Minas Gerais. A sobrevivência da população da Lapinha foi de 3,3 \% para permetrina e 1,8\% para deltametrina. As populações de Montes Claros expostas aos inseticidas piretróides permetrina e deltametrina apresentaram valores de 38,9\% e $36,3 \%$ de sobrevivência, respectivamente. Estes resultados demonstraram alteração no perfil de suscetibilidade destas populações. 
$\mathrm{Na}$ Índia, populações de $P h$. argentipes provenientes de áreas endêmicas de leishmanioses, foram expostas aos inseticidas DDT, malation e deltametrina. Esses flebotomíneos se mostraram resistentes à DDT e malation e suscetíveis ao piretróide deltametrina (Singh e Kumar 2015).

A suscetibilidade de populações de Lu. longipalpis oriundas de área silvestre sem aplicação de inseticida, conhecida como gruta da Lapinha, Lagoa Santa, estado de Minas Gerais foi analisada por meio de papéis impregnados com oito diferentes concentrações de deltametrina $(0,25 ; 0,5$; $1 ; 2 ; 4 ; 6 ; 8$ e $10 \mathrm{mg} / \mathrm{m}^{2}$ ). A dosagem letal (DL) que matou $50 \%$ da população $\left(\mathrm{DL}_{50}\right)$ foi de $2,5 \mathrm{mg} / \mathrm{m}^{2}$ para deltametrina, demonstrando elevada suscetibilidade a essa substância química, conforme Falcão et al. (1988).

Em 1989, Le Pont et al. avaliaram o impacto da deltametrina, em populações de Lu. longipalpis na Bolívia, e constataram a eficiência deste inseticida no controle de flebotomíneos. Não houve registro de flebotomíneos durante os nove meses que seguiram o tratamento com deltametrina.

$\mathrm{Na}$ Venezuela foram realizados alguns estudos de suscetibilidade para as espécies de flebotomíneos. Pintomyia youngi apresentou resistência a organoclorado e carbamatos (Scorza et al. 1995), enquanto que populações de Lu. longipalpis procedentes de La Rinconada, estado de Lara apontaram baixo nível de resistência para fenitrotiona, pirimifós e permetrina, de acordo com Mazzari et al. (1997).

Os inseticidas permetrina e lambda-cialotrina (piretróides), além do DDT, foram avaliados por Maroli et al. (2002) em populações de $P h$. papatasi e Ph. perniciosus. Neste estudo, realizado em condição de laboratório, os flebotomíneos se mostraram mais suscetíveis a lambdacialotrina, seguidos da permetrina e DDT.

Em um estudo realizado com $P$. sergenti e $P$. papatasi provenientes de seis províncias endêmicas para leishmanioses, no Marrocos, mostraram 
a suscetibilidade dessas espécies aos inseticidas DDT, malation e lambdacialotrina (Faraj et al. 2012).

$\mathrm{Na}$ Colômbia, Lu. longipalpis oriundos de colônia se mostraram suscetíveis aos inseticidas malation, deltametrina e lambda-cialotrina. Estes resultados, segundo os autores, poderão ser utilizados no monitoramento de populações de flebotomíneos de campo (Marceló et al. 2014).

Dois métodos são utilizados para caracterizar perfis de suscetibilidade de flebotomíneos a inseticidas, em condições de laboratório. Ambos os métodos são preconizados para avaliação de resistência em mosquitos (Diptera: Culicidae) (Owusu et al. 2015). O método de bioensaios de garrafa, do Centro de Controle e Prevenção de Doenças (CDC) foi escolhido sobre o bioensaio da OMS por proporcionar uma análise de diferentes concentrações de inseticidas com confiabilidade e de forma barata. Destacase também que essa metodologia permite o contato do inseto em todas as partes impreganadas com inseticidas e as garrafas podem ser facilmente transportadas para diferentes locais e não exigem suporte laboratorial dispendioso e complexo.

Ressalta-se que as informações a respeito da ocorrência de resistência em espécies de flebotomíneos são escassas e quase inexistentes (Lins et al. 2008). No Brasil, os poucos estudos foram realizados com Lu. longipalpis e os resultados são incipientes visto que não se tem um conhecimento amplo e bem fundamentado sobre o potencial genético de resistência dessa importante espécie transmissora de Leishmania spp. ao homem. Nada se conhece a respeito da ação de inseticidas preconizada pelo MS do Brasil para as demais espécies de flebotomíneos (Pessoa et al. 2015).

Uma das grandes dificuldades em se desenvolver estudos de resistência e suscetibilidade a inseticidas tem sido determinar uma linhagem suscetível que possa ser utilizada como referência. Como preconizado da Organização Panamericana de Saúde (OPAS) (OPAS, 2005) entende-se por 
linhagem referência de suscetibilidade (LRS) aquela que: i) apresentar pelo menos mais de cinco gerações criados sob condições de laboratório, sem contato com inseticidas; ii) não ter acréscimo de novos insetos na colônia durante as últimas cinco gerações e iii) o local de origem não pode ter tido contato com inseticidas. A partir da LRS, é possível classificar as populações do campo, em suscetível ou resistente, e essa informação é essencial para tomadas de decisão no controle desses vetores. Pessoa et al. (2015a) indicaram a população de Lu. longipalpis provenientes da Gruta da Lapinha, Minas Gerais, Brasil como LRS. Essa população atendeu as recomendações da OPAS e se mostrou suscetível nos bioensaios realizados. 


\section{JUSTIFICATIVA}

A resistência de um inseto a compostos químicos foi descrita pela primeira vez em 1914 (Melander, 1914), despontando como um tema importante para a pesquisa e discussão em saúde pública e controle de pragas agrícolas, pois a sua presença trata-se de um dos principais obstáculos para o sucesso da interrupção das "arthropod borne diseases" (= doenças transmitidas por artrópodes) em países endêmicos. Nas últimas décadas, a resistência dos insetos vetores a inseticidas tem aumentado significativamente e continua a representar uma grande ameaça para 0 sucesso das intervenções de controle químico como um todo.

A sobreposição de endemias é outro fator que impacta, positivamente e negativamente, o controle de insetos vetores. A borrifação de inseticida para controle de mosquitos dos gêneros Aedes e Anopheles, por exemplo, pode extinguir focos pontuais de flebotomíneos em determinadas áreas. Ao mesmo tempo, pode selecionar organismos resistentes a inseticidas não utilizados especificamente para seu controle. Tal fato dificultaria escolhas futuras de pesticidas para controle de determinado vetor.

A falta de vacina segura e eficiente para combater as leishmanioses, torna o controle químico a ferramenta mais importante para reduzir os casos humanos das doenças. Com o aumento contínuo dos casos de leishmanioses, e um histórico de controle químico específico de mais de 60 anos, o monitoramento da suscetibilidade de flebotomíneos a inseticidas, principalmente em áreas endêmicas, torna-se fundamental para aprimorar as ações de controle vetorial, no Brasil.

Este é o primeiro trabalho, no Brasil, que visa caracterizar perfis de suscetibilidade de flebotomíneos, ao inseticida utilizado em seu controle, provenientes de diferentes municípios endêmicos para leishmanioses. 


\section{OBJETIVOS}

\subsection{Objetivo geral}

$\checkmark$ Caracterizar o perfil de suscetibilidade de populações naturais de flebotomíneos ao piretróide alfacipermetrina utilizado no controle das leishmanioses no Brasil.

\subsection{Objetivos específicos}

$\checkmark$ Avaliar o método de bioensaio com garrafa do CDC para análise de suscetibilidade de flebotomíneos;

$\checkmark$ Determinar o perfil de suscetibilidade de diferentes populações de flebotomíneos procedentes de áreas geograficamente separadas;

$\checkmark$ Recomendar a dose e tempo diagnóstico ideal para bioensaios de garrafa do CDC utilizados no monitoramento de suscetibilidade de populações de flebotomíneos; 


\section{MATERIAL E MÉTODOS}

\subsection{Material biológico}

Colônia de insetos suscetíveis - A população de flebotomíneos suscetíveis, da espécie Lu. longipalpis, foi proveniente de criações (mantida desde 2006) obtidas no Laboratório de Fisiologia de Insetos Hematófagos da Universidade Federal de Minas Gerais (UFMG) oriundas de Teresina, Piauí. Essa colônia apresenta os requisitos preconizados pela OPAS (2005) para ser uma LRS.

Populações de flebotomíneos para estudo - Os flebotomíneos foram capturados em áreas endêmicas tratadas com inseticidas, nas quais os Programas Estaduais de Controle das Leishmanioses realizam aplicações contínuas e sistemáticas com inseticidas de ação residual. A seleção dos municípios para as atividades de captura obedeceu aos seguintes critérios de inclusão: i) a realização de um programa específico de controle de flebotomíneos; ii) antecedentes de controle de outros vetores dentro da mesma área geográfica; iii) uso de inseticidas com finalidades agrícolas na mesma área, onde se localizam os vetores e/ou iv) uso doméstico de inseticidas. Documentos oficiais da Universidade de Brasília foram enviados para as Secretarias Estaduais de Saúde de Goiás (Apêndice 1) e Minas Gerais (Apêndice 2) oficializando as colaborações. 


\section{2 Áreas de estudo}

Para o estado de Minas Gerais foram selecionados os municípios de Belo Horizonte, Januária, Montes Claros, Paracatu e Unaí. No estado de Goiás, o município de Pirenópolis também foi escolhido como parte deste projeto (Figura 5). Os locais de coleta, em cada município, foram préselecionados pelos agentes de endemias da localidade, com base nos registros de casos humanos e caninos confirmados de LV e na probabilidade de maior ocorrência de flebotomíneos (Apêndice 3).

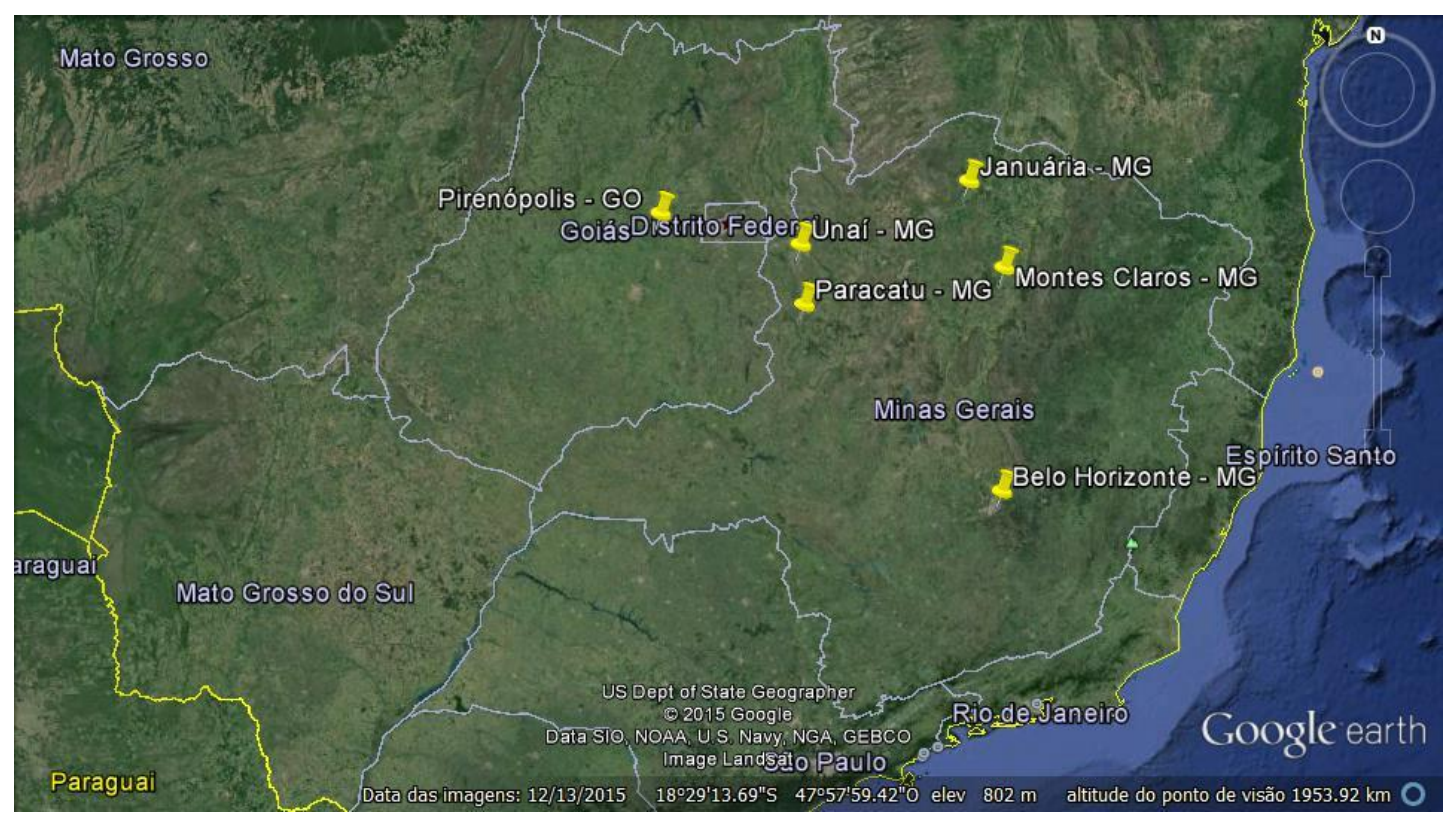

Figura 5. Mapa dos estados de Minas Gerais e Goiás mostrando a localização dos municípios selecionados para avaliação da suscetibilidade de flebotomíneos ao inseticida alfacipermetrina. Fonte: Google Earth, 2015.

Captura e acondicionamento dos flebotomíneos - Após a seleção dos municípios, as equipes de entomologia estaduais e municipais, juntamente com os pesquisadores envolvidos no projeto realizaram busca 
ativa em peridomicílio usando armadilhas luminosas dos tipos HP (Pugedo et al. 2005) e CDC (Sudia e Chamberlain, 1962) (Figura 6).
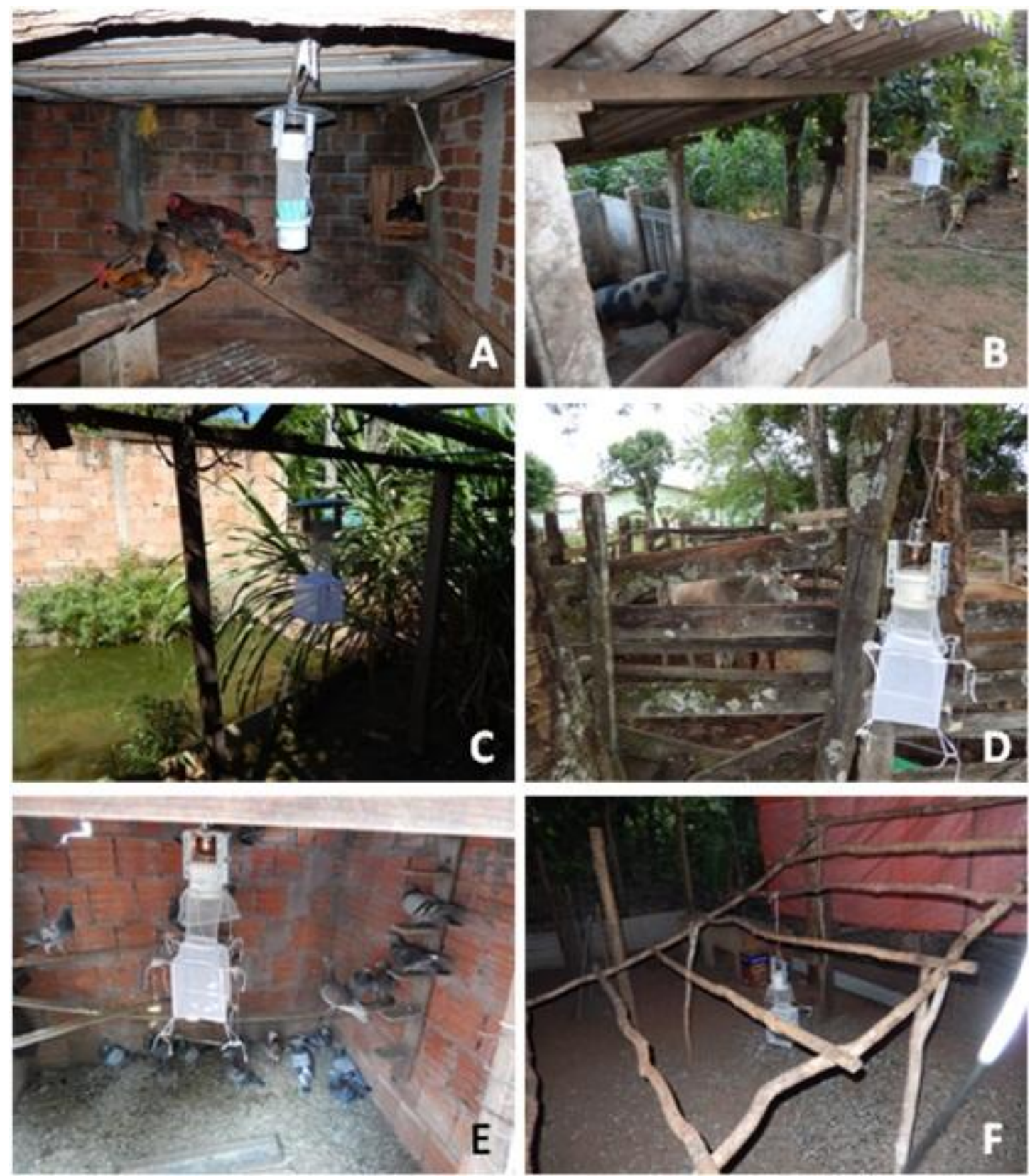

Figura 6. Armadilhas luminosas instaladas nos peridomicílios dos diferentes municípios estudados. A: galinheiro em Unaí; B: chiqueiro em Paracatu; C: quintal em Belo Horizonte; D: curral em Pirenópolis; E: pombal em Montes Claros; F: galinheiro em Januária. 
Em seguida, gaiolas de nylon foram acopladas às armadilhas e instaladas no crepúsculo e retiradas no início da manhã. Após a desmontagem das armadilhas, as gaiolas de nylon foram acondicionadas nos porta-malas dos veículos de campo sobre uma toalha umedecida e foram transportados para a os pontos de apoio disponíveis em cada um dos municípios estudados. Os flebotomíneos foram contados e separados em cinco capturadores de castro, fechados com algodão embebidos em água com açúcar (30\%) e mantidos no escuro por duas horas, para aclimatação dos insetos até o bioensaio (Figura 7).

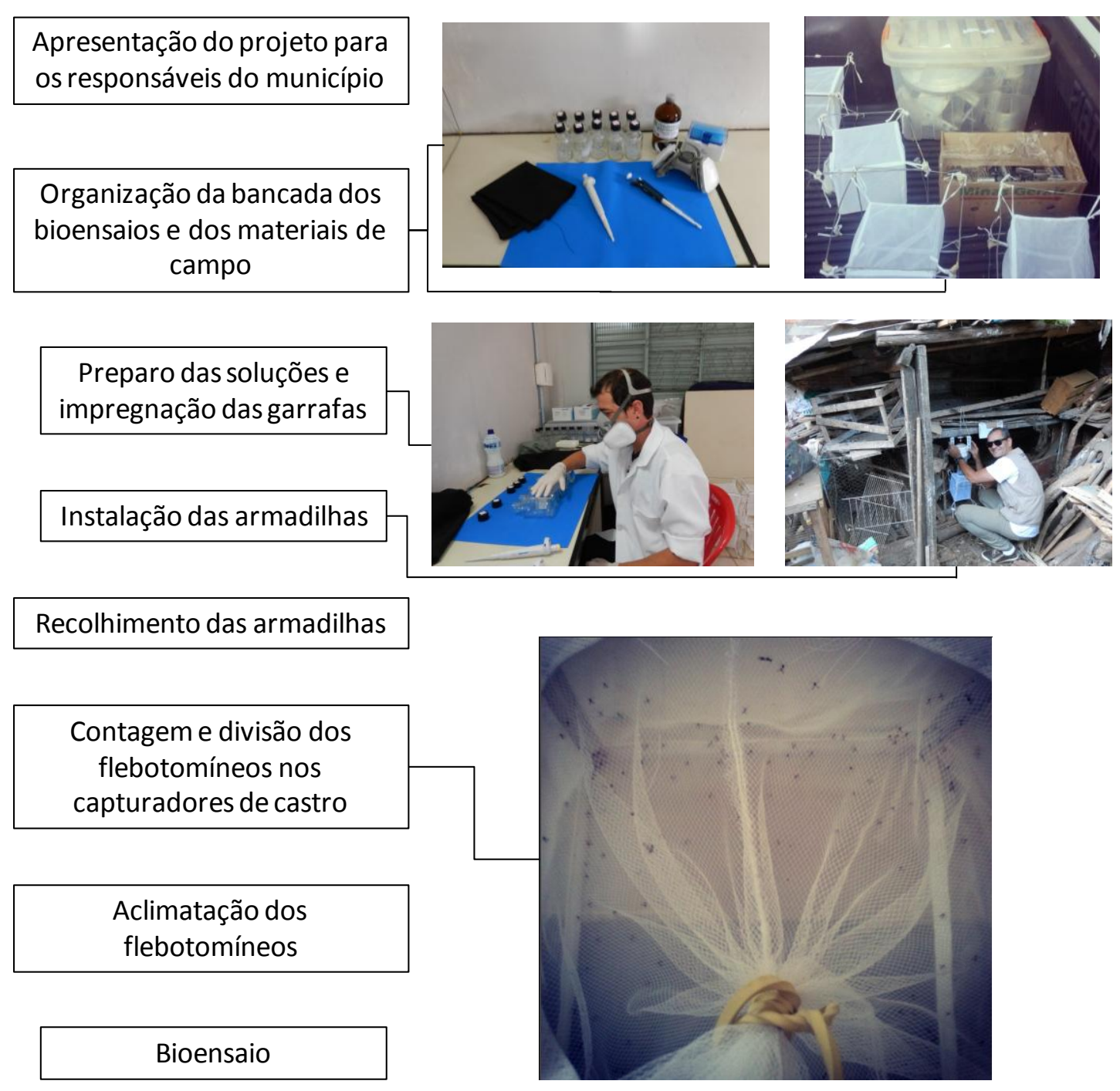

Figura 7. Cronograma das atividades de campo e laboratório realizados nos diferentes municípios, em 2015. 
As capturas de diferentes populações de flebotomíneos foram realizadas entre abril e outubro de 2015, conforme a disponibilidade de carros, técnicos de laboratório e campo, estrutura física e horários. De um modo geral, foram instaladas dez armadilhas luminosas do tipo HP entre 16 e 18 horas e retiradas na manhã seguinte, de acordo com a disponibilidade de veículos cedidos pelas Secretarias Municipais de Saúde.

As localidades específicas, coordenadas geográficas, períodos de capturas, número de armadilhas e horário de instalação e retirada podem ser obervados na Tabela 3 e Apêndice 3.

Tabela 3. Detalhes das capturas de flebotomíneos nos municípios.

\begin{tabular}{cccccc}
\hline Localidade & Período & $\begin{array}{c}\text { Número de } \\
\text { armadilhas }\end{array}$ & $\begin{array}{c}\text { Instalação das } \\
\text { armadilhas }\end{array}$ & $\begin{array}{c}\text { Retirada das } \\
\text { armadilhas }\end{array}$ & Bairros \\
\hline Unaí & $13-15$ de abril & 10 & $16-18 \mathrm{hs}$ & $07-09 \mathrm{hs}$ & 8 \\
Paracatu & $18-20$ de maio & 10 & $16-18 \mathrm{hs}$ & $07-09 \mathrm{hs}$ & 5 \\
Belo Horizonte & $\begin{array}{c}15-17 \text { de setembro } \\
28-30 \text { de setembro } \mathrm{n} \\
1^{0} \text { de outubro }\end{array}$ & 10 & $16-18 \mathrm{hs}$ & $8 \mathrm{~h} 30-10 \mathrm{hs}$ & 1 \\
Pirenópolis & 20 & $16-18 \mathrm{hs}$ & $06 \mathrm{~h} 30-08 \mathrm{~h} 30$ & 11 \\
Montes Claros & 13 e 14 de outubro & 10 & $16-18 \mathrm{hs}$ & $07-09 \mathrm{hs}$ & 3 \\
Januária & 16 e 17 de outubro & 10 & $16-18 \mathrm{hs}$ & $07-8 \mathrm{~h} 30$ & 4 \\
\hline
\end{tabular}

\subsection{Inseticida e procedimentos dos ensaios biológicos}

Inseticida Grau Técnico - O inseticida utilizado nos bioensaios foi o piretróide alfacipermetrina $\left(\mathrm{C}_{22} \mathrm{H}_{19} \mathrm{CL}_{2} \mathrm{NO}_{3}\right)$, com grau de pureza de 98,24\% e a acetona P. A. $\left(\mathrm{CH}_{3}\right)_{2} \mathrm{CO}$.

O inseticida, grau técnico (em pó), foi diluído em acetona (PA) para preparação da solução mãe. Nesta parte um total de 0,002 gramas de alfacipermetrina (ingrediente ativo) foi pesado em balança eletrônica de 
precisão, AG 200 GEHAKA, e misturado à 100ml de acetona (PA). Em seguida, a solução mãe foi fracionada em quatro sub concentrações de alfacipermetrina: $3 \mathrm{ug} / \mathrm{ml}, 5 \mathrm{ug} / \mathrm{ml}, 7 \mathrm{ug} / \mathrm{ml}$ e $9 \mathrm{ug} / \mathrm{ml}$.

Nesse estudo foi utilizada a metodologia de bioensaios com garrafa do CDC, descrita por Brogdon e Chan (2010). Para isso foram utilizadas garrafas do tipo Wheaton com volume de $250 \mathrm{ml}$, as quais foram revestidas internamente com acetona (controle) e diferentes concentrações do piretróide alfacipermetrina. Todos os frascos foram impregnados uniformemente nas partes laterais, superior e inferior por meio de rotação do recipiente e observação criteriosa da impregnação. Após a impregnação, as garrafas foram abertas, para evitar condensação, e ficaram armazenadas em locais protegidos da luz durante 24 horas.

Os flebotomíneos machos e fêmeas foram introduzidos nas garrafas com auxílio de pequenos funis para evitar o escape dos insetos. Em média, 18 insetos foram expostos por frasco, sendo uma com acetona (controle) e quatro diferentes concentrações do inseticida alfacipermetrina $(3 \mathrm{ug} / \mathrm{ml}, 5$ $\mathrm{ug} / \mathrm{ml}, 7 \mathrm{ug} / \mathrm{ml} \mathrm{e} 9 \mathrm{ug} / \mathrm{ml}$ ). Após a introdução dos insetos no frasco controle e em cada frasco teste, iniciou-se a contagem de duas horas de exposição. A cada 10 minutos, os frascos foram avaliados para contagem de quantos flebotomíneos permaneciam vivos. As informações a respeito da procedência das populações flebotomínicas, data do bioensaio, concentrações, tipo de inseticida, número de flebotomíneos mortos ou vivos foram registradas em fichas padronizadas, conforme Apêndice 4. Para cada localidade, os bioensaios foram repetidos três vezes e a leitura de mortalidade foi realizada por um único pesquisador.

Em quatro municípios (Belo Horizonte, Pirenópolis, Montes Claros e Januária) e na população de referência, após os bioensaios, os flebotomíneos foram transferidos para potes com presença de algodão umedecido e solução açucarada (30\%), por 24 horas, para avaliação de recuperação de efeito "knock-down" dos flebotomíneos (Figura 8). 
1.

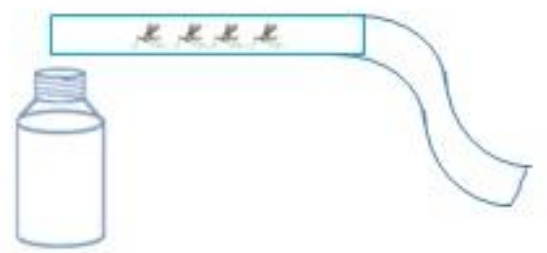

2.

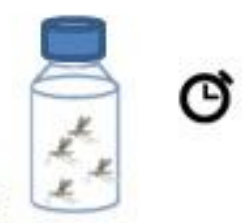

3.

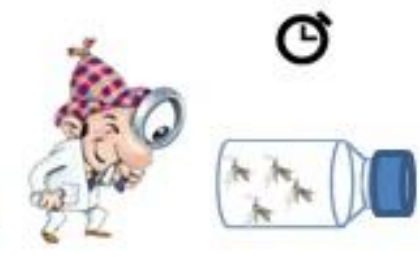

5.

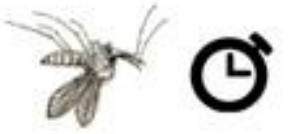

6.

4.
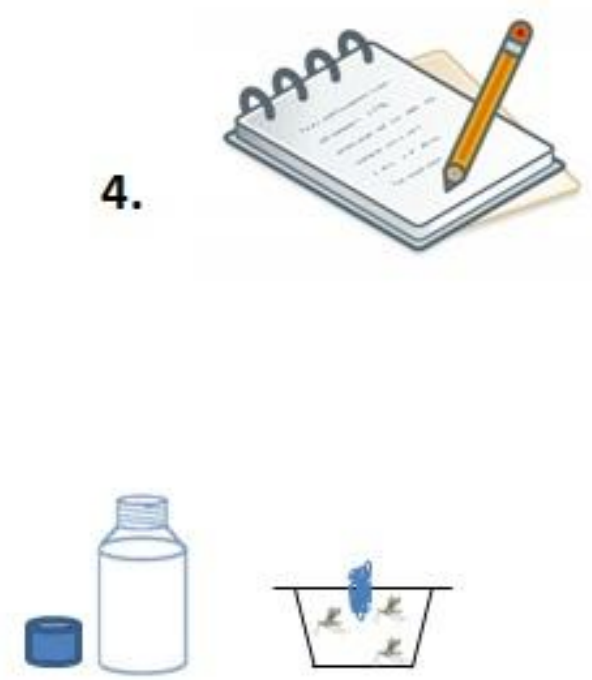

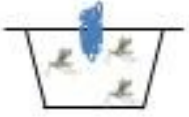

Figura 8. Bioensaio de garrafa do CDC para a avaliação da suscetibilidade de flebotomíneos ao inseticida alfacipermetrina. 1. Os flebotomíneos eram introduzidos nas garrafas impregnadas com auxílio de um capturador de castro. 2. A garrafa foi fechada e o tempo de exposição iniciado. 3. Em intervalos de 10 minutos, as garrafas foram examinadas e os flebotomíneos vivos e mortos contabilizados. 4. Os resultados das contagens foram anotados para cada intervalo de 10 minutos. 5. Após a queda de todos os flebotomíneos ou passados 120 minutos, a exposição era encerrada. 6 . Todos os flebotomíneos da garrafa foram transferidos para potes com presença de algodão umedecido e solução açucarada, por 24 horas, para avaliação de possíveis efeitos "knock-down". 


\subsection{Identificação dos flebotomíneos}

Os flebotomíneos capturados em campo, após a realização dos testes, foram armazenados em álcool 70\% e transportados ao Laboratório de Parasitologia Médica e Biologia de Vetores da Faculdade de Medicina da Universidade de Brasília para posterior identificação. Machos e fêmeas foram montados e clarificados, segundo Forattini (1973) e identificados utilizando a chave de Galati (2015). A abreviação dos gêneros seguiu a proposta de Marcondes (2007).

As fêmeas foram dissecadas e partes do corpo (asa, tórax, pernas e parte do abdômen) foram estocadas para futuras análises bioquímicas e genéticas de suscetibilidade a inseticida. Todos os espécimes encontram-se depositados no referido laboratório da UnB.

\subsection{Análise estatística}

Os dados de mortalidade das diferentes populações de flebotomíneos, obtidos nos bioensaios, foram utilizados para estimar a dose que mata uma determinada porcentagem da população. Esta dose é chamada de Dose Letal (DL). Neste trabalho foi estimada a $\mathrm{DL}_{50}$ (mortalidade de $50 \%$ ) das amostras estudadas. $\mathrm{O}$ cálculo da $\mathrm{DL}_{50}$ de cada população foi baseado na análise Probit realizado pelo programa Basic Probit Analisys.

A Razão de Resistência (RR) foi obtida por meio do quociente da $\mathrm{DL}_{50}$ da população de campo pela $\mathrm{DL}_{50}$ da linhagem suscetível. Quanto maior a Razão de Resistência, maior a magnitude da resistência.

Nesta análise também foi possível definir o coeficiente angular da curva dose resposta, também conhecido como slope. Esse parâmetro representa a homogeneidade da população. Os menores valores do coeficiente angular da curva indicam populações menos homogêneas. A elevada variação genética de uma determinada população pode aumentar a "probabilidade" 
de seleção de indivíduos que "carregam" os alelos de resistência, quando pressionados com inseticidas. Por outro lado, os maiores coeficientes angulares indicam menor variação genotípica na resposta da população ao inseticida.

O Tempo Letal (TL) foi estimado baseado na análise das taxas de mortalidade dos flebotomíneos durante os bioensaios. Quando morriam $50 \%$ dos flebotomíneos expostos, de qualquer localidade e qualquer dose, o $\mathrm{TL}_{50}$ era estimado. Assim também foi feito para a $\mathrm{TL}_{95}$, quando $95 \%$ dos insetos expostos morreram. Nesta fase, dois critérios de mortalidade foram usados.

Dois critérios de mortalidade foram adotados no estudo: critério $A$ - os flebotomíneos foram considerados mortos quando estavam totalmente imóveis; critério $B$ - os flebotomíneos foram considerados mortos quando apresentavam perda das pernas. $O$ critério de mortalidade $A$ foi utilizado nas análises de DL, RR e TL. O critério B foi utilizado somente na análise de TL.

As curvas de sobrevivência das populações de flebotomíneos foram inferidas pelo método de Kaplan-Meier (KM), que consiste em análise de sobrevida em que os intervalos de tempo não são fixos, mas determinados pela morte dos flebotomíneos (Bustamante-Teixeira et al. 2002). As estimativas foram calculadas utilizando o programa estatístico R 3.0.2. 


\section{RESULTADOS}

\subsection{Flebotomíneos}

Um total de 2.198 flebotomíneos foi utilizado nos bioensaios de garrafa do CDC. A população utilizada como LRS (colônia) apresentou 464 exemplares de Lu. longipalpis expostos aos bioensaios de garrafa, sendo 357 machos e 107 fêmeas. A população procedente de Montes Claros registrou 364 machos e 119 fêmeas da espécie Lu. longipalpis, além de um espécime não identificado, totalizando 484 exemplares utilizados no bioensaio. Para o município de Januária foram expostos 368 insetos, sendo 199 machos e 169 fêmeas. Em Unaí foram utilizados 302 flebotomíneos, sendo 220 machos e 82 fêmeas. A população procedente de Paracatu obteve um total de 265 insetos expostos com 231 machos e 34 fêmeas. Os flebotomíneos procedentes dos municípios de Pirenópolis e Belo Horizonte representaram um total geral de 175 e 140 espécimes, respectivamente (Tabela 4).

Dezesseis espécies de flebotomíneos, pertencentes a oito gêneros diferentes, foram coletadas no estudo. A espécie Lu. longipalpis foi a mais frequente, seguida de Lu. ischnacantha, Nyssomyia whitmani, Lu. renei e $\mathrm{Ny}$. intermedia. As espécies Evandromyia lenti, Ev. sallesi, Ev. bacula, Micropygomyia villelai, Mi. acanthopharynx, Pintomyia kuscheli, Martinsmyia oliveirai, Ny. neivai, Brumptomyia avellari e Psathyromyia sp. foram capturadas em menor número.

O município de Pirenópolis obteve o maior número de espécies capturadas, seguido por Januária, Unaí e Paracatu. Belo Horizonte apresentou duas espécies, sendo 98\% destas, Lu. longipalpis. Em Montes 
Claros, um espécime não pôde ser identificado, os demais foram da espécie Lu. longipalpis.

Por problemas na clarificação e montagem, 35 espécimes de flebotomíneos utilizados nos bioensaios não foram identificados. Destes 35 , 30 foram provenientes de Januária, três de Pirenópolis, um de Montes Claros e um de Paracatu. 
Tabela 4. Flebotomíneos coletados e utilizados nos bioensaios de suscetibilidade de acordo com a espécie, origem e sexo.

\begin{tabular}{|c|c|c|c|c|c|c|c|c|c|c|c|c|c|c|c|}
\hline \multirow{4}{*}{ Espécies } & \multicolumn{14}{|c|}{$\begin{array}{ll}\text { Estados e Municípios } \\
\end{array}$} & \multirow{4}{*}{ Total } \\
\hline & \multirow{2}{*}{\multicolumn{2}{|c|}{ Unaí }} & \multirow{2}{*}{\multicolumn{4}{|c|}{$\begin{array}{c}\text { Minas Gerais } \\
\text { Belo Horizonte }\end{array}$}} & \multirow{2}{*}{\multicolumn{2}{|c|}{ Montes Claros }} & & & \multirow{2}{*}{\multicolumn{2}{|c|}{$\begin{array}{c}\text { Goiás } \\
\text { Pirenópolis }\end{array}$}} & \multirow{2}{*}{\multicolumn{2}{|c|}{$\begin{array}{c}\text { Piauí } \\
\text { Colônia - UFMG }\end{array}$}} & \\
\hline & & & & & & & & & \multicolumn{2}{|c|}{ Januária } & & & & & \\
\hline & $0^{\lambda}$ & 우우 & $\partial^{\lambda}$ & 우우 & $\hat{0} 0^{\lambda}$ & 아 & ô & q 9 & $\hat{0} 0^{\lambda}$ & 우오 & $\partial^{\lambda} 0^{2}$ & 우우 & $0^{\lambda}$ & 우우 & \\
\hline Lutzomyia longipalpis & 176 & 56 & 223 & 19 & 99 & 39 & 364 & 119 & 116 & 71 & 106 & 30 & 357 & 107 & 1882 \\
\hline Lutzomyia ischnacantha & 0 & 0 & 0 & 0 & 0 & 0 & 0 & 0 & 47 & 33 & 0 & 0 & 0 & 0 & 80 \\
\hline Nyssomyia whitmani & 15 & 5 & 8 & 8 & 0 & 0 & 0 & 0 & 0 & 0 & 18 & 9 & 0 & 0 & 63 \\
\hline Lutzomyia renei & 0 & 0 & 0 & 0 & 0 & 0 & 0 & 0 & 18 & 32 & 0 & 0 & 0 & 0 & 50 \\
\hline Nyssomyia intermedia & 25 & 15 & 0 & 0 & 0 & 0 & 0 & 0 & 0 & 0 & 0 & 0 & 0 & 0 & 40 \\
\hline Evandromyia lenti & 2 & 1 & 0 & 3 & 0 & 0 & 0 & 0 & 2 & 6 & 0 & 2 & 0 & 0 & 16 \\
\hline Evandromyia sallesi & 0 & 5 & 0 & 2 & 0 & 2 & 0 & 0 & 0 & 0 & 0 & 0 & 0 & 0 & 9 \\
\hline Micropygomyia villelai & 0 & 0 & 0 & 0 & 0 & 0 & 0 & 0 & 7 & 2 & 0 & 0 & 0 & 0 & 9 \\
\hline Evandromyia bacula & 0 & 0 & 0 & 0 & 0 & 0 & 0 & 0 & 2 & 0 & 0 & 1 & 0 & 0 & 3 \\
\hline Micropygomyia acanthopharynx & 0 & 0 & 0 & 0 & 0 & 0 & 0 & 0 & 0 & 0 & 0 & 2 & 0 & 0 & 2 \\
\hline Pintomyia kuscheli & 0 & 0 & 0 & 0 & 0 & 0 & 0 & 0 & 0 & 0 & 2 & 0 & 0 & 0 & 2 \\
\hline Martinsmyia oliveirai & 0 & 0 & 0 & 0 & 0 & 0 & 0 & 0 & 0 & 0 & 1 & 1 & 0 & 0 & 2 \\
\hline Nyssomyia neivai & 2 & 0 & 0 & 0 & 0 & 0 & 0 & 0 & 0 & 0 & 0 & 0 & 0 & 0 & 2 \\
\hline Brumptomyia avellari & 0 & 0 & 0 & 0 & 0 & 0 & 0 & 0 & 2 & 0 & 0 & 0 & 0 & 0 & 2 \\
\hline Psathyromyia sp. & 0 & 0 & 0 & 1 & 0 & 0 & 0 & 0 & 0 & 0 & 0 & 0 & 0 & 0 & 1 \\
\hline Não identificados & 0 & 0 & 0 & 1 & 0 & 0 & 0 & 1 & 5 & 25 & 0 & 3 & 0 & 0 & 35 \\
\hline Total & 220 & 82 & 231 & 34 & 99 & 41 & 364 & 120 & 199 & 169 & 127 & 48 & 357 & 107 & \\
\hline Total geral & \multicolumn{2}{|c|}{302} & \multicolumn{2}{|c|}{265} & \multicolumn{2}{|c|}{140} & & & \multicolumn{2}{|c|}{368} & \multicolumn{2}{|c|}{175} & \multicolumn{2}{|c|}{464} & 2198 \\
\hline
\end{tabular}




\subsection{Estimativas de $\mathrm{DL}_{50}, \mathrm{RR}_{50}$ e slope}

A $\operatorname{DL}_{50}$ da população da LRS (UFMG) foi de $2,38 \mathrm{ug} / \mathrm{ml}$ de alfacipermetrina. A população de flebotomíneos procedente de Montes Claros obteve um valor de $\mathrm{DL}_{50}$ de $1,03 \mathrm{ug} / \mathrm{ml}$ por garrafa. Diferentemente a população de Pirenópolis demonstrou um valor de $\mathrm{DL}_{50}$ de $3,87 \mathrm{ug} / \mathrm{ml}$. Observou-se também que a população de flebotomíneos oriundos de Januária apresentou um valor de $\mathrm{DL}_{50}$ de $2,33 \mathrm{ug} / \mathrm{ml}$, seguidas das populações de Paracatu e Montes Claros com valores de $\mathrm{DL}_{50}$ de 1,31 e $1,03 \mathrm{ug} / \mathrm{ml}$, respectivamente.

Destaca-se a maior $\mathrm{RR}_{50}$ para a população procedente de Pirenópolis que apresentou um valor de 1,62 . A RR $R_{50}$ da população de Januária foi de 0,98 , seguida da população de Paracatu com um valor de 0,55 e Januária que mostrou um valor de 0,43.

As populações de flebotomíneos oriundas da Paracatu e Montes Claros apresentaram valores de coeficiente angular (slope) da curva de dose resposta de 1,40 e 1,47, respectivamente. Esses valores representam padrões de variações de mortalidade com pouca heterogeneidade em relação à população de referência $(1,37)$. O maior valor do slope foi para a população de Pirenópolis com 3,06, seguida da população de Januária que apresentou um valor de 2,53. Esses valores de coeficiente angular apontam maior heterogeneidade dessas populações, portanto, poderiam apresentar maior probabilidade de que os indivíduos dessas populações consigam tolerar maiores doses de inseticida. Os municípios de Unaí e Belo Horizonte não tiveram suas $D_{50}$ e $R R_{50}$ estimadas pelo programa por apresentarem doses menores matando mais indivíduos que doses maiores (Tabela 5). 
Tabela 5. Estimativa de $\mathrm{DL}_{50}, \mathrm{RR}_{50}$ e slope da população de referência e das populações de campo.

\begin{tabular}{ccccc}
\hline População & $\mathrm{n}$ & slope & DL50 & RR50 \\
\hline UFMG & 464 & 1,37 & $2,38(0,74 \pm 3,37)$ & 1 \\
Montes Claros & 384 & 1,47 & $1,03(0,00 \pm 2,14)$ & 0,43 \\
Paracatu & 265 & 1,40 & $1,31(0,00 \pm 2,50)$ & 0,55 \\
Januária & 368 & 2,53 & $2,33(0,99 \pm 3,18)$ & 0,98 \\
Pirenópolis & 175 & 3,06 & $3,87(0,25 \pm 5,80)$ & 1,62 \\
Unaí & 302 & - & - & - \\
Belo Horizonte & 140 & - & - & - \\
\hline
\end{tabular}

$\mathrm{DL}_{50}$ : Dose letal que mata $50 \%$ da população; $\mathrm{RR}_{50}$ : Razão de resistência entre a $\mathrm{DL}$ da população de campo sobre a DL da população de referência; IC: Intervalo de confiança; -: Dados não estimados.

\subsection{Estimativa de Tempo Letal}

O TL variou entre as dosagens para as populações e para os critérios de mortalidade. Na população da UFMG, os flebotomíneos alcançaram o $\mathrm{TL}_{50}$ entre 20 e 100 minutos, de exposição, dependendo da dose e do critério de mortalidade utilizado. Em Belo Horizonte, o TL $L_{50}$ variou entre 20 e 90 minutos. No município de Pirenópolis, a variação do $T L_{50}$ foi de 10 a 100 minutos. Em Montes Claros, o TL $L_{50}$ foi alcançado com 20 e 120 mintuos de exposição. Em Januária, essa variação foi de 10 a 100 minutos.

Pelo critério de mortalidade $A$, somente a população de Belo Horizonte alcançou o $\mathrm{TL}_{95}$ e este variou de 60 a 110 minutos de exposição. Avaliando os dois critérios, em Belo Horizonte, a variação do $T L_{95}$ foi de 40 a 110 minutos. A população de referência da UFMG, chegou ao $T L_{95}$, somente com a dose de $9 \mathrm{ug} / \mathrm{ml}$ com o critério de mortalidade B. Em Pirenópolis a variação do $T L_{95}$ foi de 20 a 40 minutos de exposição. Nos municípios de Montes Claros e Januária, a variação do $T L_{95}$ foi de 50 a 70 minutos e 30 a 120 minutos, respectivamente. 
Pelo critério de mortalidade $\mathrm{B}$, todos os municípios apresentaram valores de $\mathrm{TL}_{95}$, com exceção de Unaí e Paracatu que não foram testados para este critério (Tabela 6). 
Tabela 6. $T L_{50}$ e $T L_{95}$ da população referência e das populações de campo para os dois critérios de mortalidade (A e B).

\begin{tabular}{|c|c|c|c|c|c|}
\hline População & $\begin{array}{c}\text { Dose } \\
(\mathrm{ug} / \mathrm{ml})\end{array}$ & $\begin{array}{l}\text { TL50 A } \\
\text { (min) }\end{array}$ & $\begin{array}{l}\text { TL95 A } \\
\text { (min) }\end{array}$ & $\begin{array}{l}\text { TL50 B } \\
\text { (min) }\end{array}$ & $\begin{array}{l}\text { TL95 B } \\
(\mathrm{min})\end{array}$ \\
\hline \multirow{5}{*}{ UFMG } & Controle & - & - & - & - \\
\hline & 3 & 100 & - & 60 & - \\
\hline & 5 & 80 & - & 40 & - \\
\hline & 7 & 50 & - & 30 & - \\
\hline & 9 & 40 & - & 20 & 50 \\
\hline \multirow{5}{*}{ Belo Horizonte } & Controle & - & - & 90 & - \\
\hline & 3 & 50 & - & 30 & 60 \\
\hline & 5 & 40 & 90 & 20 & 40 \\
\hline & 7 & 30 & 110 & 20 & 40 \\
\hline & 9 & 20 & 60 & 20 & 40 \\
\hline \multirow{5}{*}{ Pirenópolis } & Controle & - & - & 30 & - \\
\hline & 3 & 100 & - & 40 & - \\
\hline & 5 & 70 & - & 10 & 40 \\
\hline & 7 & 60 & - & 30 & - \\
\hline & 9 & 40 & - & 10 & 20 \\
\hline \multirow{5}{*}{ Montes Claros } & Controle & - & - & 120 & - \\
\hline & 3 & 90 & - & 30 & 70 \\
\hline & 5 & 70 & - & 20 & 50 \\
\hline & 7 & 60 & - & 20 & 60 \\
\hline & 9 & 70 & - & 20 & - \\
\hline \multirow{5}{*}{ Januária } & Controle & - & - & 100 & - \\
\hline & 3 & 60 & - & 30 & 120 \\
\hline & 5 & 30 & - & 20 & 50 \\
\hline & 7 & 30 & - & 20 & 30 \\
\hline & 9 & 20 & - & 10 & 50 \\
\hline \multirow{5}{*}{ Unaí } & Controle & - & - & - & - \\
\hline & 3 & 50 & - & - & - \\
\hline & 5 & 50 & - & - & - \\
\hline & 7 & 60 & - & - & - \\
\hline & 9 & 60 & - & - & - \\
\hline \multirow{5}{*}{ Paracatu } & Controle & - & - & - & - \\
\hline & 3 & 50 & - & - & - \\
\hline & 5 & 90 & - & - & - \\
\hline & 7 & 70 & - & - & - \\
\hline & 9 & 70 & - & - & - \\
\hline
\end{tabular}

$\mathrm{TL}_{50}$ : Tempo para $50 \%$ dos flebotomíneos morrerem; $\mathrm{TL}_{95}$ : Tempo para $95 \%$ dos flebotomíneos morrerem; -: Dados não estimados. 


\subsection{Estimativas da curva de sobrevivência de Kaplan-Meier}

$\mathrm{Na}$ Figura 9 observam-se as curvas de sobrevivência de KM, em relação à somatória de todos os flebotomíneos expostos e as dosagens utilizadas. Com 20 minutos de exposição, as populações de Montes Claros, Pirenópolis e Paracatu apresentaram maiores taxas de sobrevivência, em relação à LRS. Em 40 minutos de exposição, a população de flebotomíneos de Montes Claros continuou com a maior taxa de sobrevivência, porém as populações de Paracatu e Pirenópolis apresentaram um aumento em sua mortalidade. Após 60 minutos de exposição, nota-se que a população de Montes Claros manteve a taxa de sobrevivência maior que a LRS, contudo todas as populações aumentaram suas taxas de mortalidade. Após 120 minutos de exposição a LRS obteve maior taxa de sobrevivência seguida das populações de Paracatu, Montes Claros, Pirenópolis, Unaí, Januária e Belo Horizonte. Durante todo o experimento, as populações de Januária e Belo Horizonte apresentaram uma taxa de mortalidade maior do que as demais populações.

Na Figura 10 estão representadas as taxas de sobrevivência de todas as populações, em relação às doses de $3,5,7$, e $9 \mathrm{ug} / \mathrm{ml}$, incluindo o grupo controle. De um modo geral, nota-se que a população controle apresentou uma variação na taxa de sobrevivência de 80 a 100\%. Ainda, nessa mesma figura, é possível observar um aumento gradativo da mortalidade, a medida que as dosagens elevam-se, validando o experimento. Esse comportamento das curvas se manteve por todo o período de exposição, havendo sobreposição das curvas em alguns momentos.

As curvas de sobrevivência de KM da população LRS apresentaram ordem de mortalidade conforme as doses de $3 \mathrm{ug} / \mathrm{ml}, 5 \mathrm{ug} / \mathrm{ml}, 9 \mathrm{ug} / \mathrm{ml}$ e 7 $\mathrm{ug} / \mathrm{ml}$ e controle com alta taxa de sobrevivência. Com 20 minutos de exposição, as concentrações de 7 e $9 \mathrm{ug} / \mathrm{ml}$ já apresentavam mortalidade elevada, em comparação com as doses de 3 e $5 \mathrm{ug} / \mathrm{ml}$. Essa diferença se 
mostrou constante durante 0 bioensaio. Ao final da exposição, aproximadamente $40 \%$ dos indivíduos, nas concentrações de 3 e $5 \mathrm{ug} / \mathrm{ml}$ estavam vivos. A taxa de sobrevivência para as dosagens de 7 e $9 \mathrm{ug} / \mathrm{ml}$ foi de aproximadamente $20 \%$ (Figura 11).

As curvas de sobrevivência de KM para população de flebotomíneos de Unaí apresentou o grupo controle matando poucos indivíduos, seguido das dosagens $7 \mathrm{ug} / \mathrm{ml}$, $3 \mathrm{ug} / \mathrm{ml}, 5 \mathrm{ug} / \mathrm{ml}$ e $9 \mathrm{ug} / \mathrm{ml}$. Neste município, desde os 20 primeiros minutos de exposição constata-se que a curva de sobrevivência da dose de $7 \mathrm{ug} / \mathrm{ml}$ variou pouco em relação as outras. Após os 120 minutos de bioensaio, nenhuma das dosagens matou 100\% dos flebotomíneos (Figura 12). A taxa de mortalidade para a população de Unaí foi de $69 \%$. Em comparação com as curvas de sobrevivência da LRS, esta população apresentou maior tolerância ao inseticida durante os primeiros 30 minutos de exposição. Após 60 minutos de exposição, a LRS apresentou alta taxa de sobrevivência nas concentrações de 3 e $5 \mathrm{ug} / \mathrm{ml}$, enquanto que a população de Unaí mostrou grande mortalidade para as doses de 3.5 e $9 \mathrm{ug} / \mathrm{ml}$. Ao final dos 120 minutos de exposição, a concentração de $7 \mathrm{ug} / \mathrm{ml}$ da população de Unaí obteve maior taxa de sobrevivência em comparação a LRS, nessa mesma dose. Para as outras concentrações a população da LRS apresentou maior taxa de sobrevivência.

Para a população de flebotomíneos de Paracatu, a análise das curvas de sobrevivência de $\mathrm{KM}$ apontou a dose controle com alta taxa de sobrevivência, seguida da dose de $3 \mathrm{ug} / \mathrm{ml}, 7 \mathrm{ug} / \mathrm{ml}, 5 \mathrm{ug} / \mathrm{ml}$ e $9 \mathrm{ug} / \mathrm{ml}$. Nos primeiros 60 minutos de exposição, a dose de $3 \mathrm{ug} / \mathrm{ml}$ apresentou a maior taxa de mortalidade, porém ao final do bioensaio registrou-se taxas menores que as demais doses. Não houve mortalidade de $100 \%$ para as dosagens, neste bioensaio (Figura 13). Aproximadamente $72 \%$ dos flebotomíneos expostos, neste município, morreram ao final das duas horas de exposição dos bioensaios. Quando comparada as curvas de sobrevivências desta população em relação à LRS, nota-se que desde os primeiros minutos a taxa de mortalidade dos flebotomíneos de Paracatu foi maior para todas as 
concentrações. Após 60 minutos de exposição, as concentrações de 3 e 9 $\mathrm{ug} / \mathrm{ml}$ propiciam maior mortalidade na população de Paracatu. Ao término da exposição as concentrações de 3, 5 e $9 \mathrm{ug} / \mathrm{ml}$ apresentaram maior taxa de mortalidade na população de Paracatu, enquanto que a dose de $7 \mathrm{ug} / \mathrm{ml}$ apresentou maior mortalidade na LRS.

As curvas de sobrevivência de KM para a população de Belo Horizonte, mostrou o controle matando poucos indivíduos, seguido das dosagens $3 \mathrm{ug} / \mathrm{ml}, 5 \mathrm{ug} / \mathrm{ml}, 7 \mathrm{ug} / \mathrm{ml}$ e $9 \mathrm{ug} / \mathrm{ml}$. A dose de $9 \mathrm{ug} / \mathrm{ml}$ alcançou $100 \%$ de mortalidade com 100 minutos de exposição. A dose de $7 \mathrm{ug} / \mathrm{ml}$ alcançou com 120 minutos. As demais doses não mataram 100\% dos flebotomíneos (Figura 14). Ao final das duas horas dos bioensaios, cerca de 83\% dos flebotomíneos, da população de Belo Horizonte morreram. Em comparação com as curvas de sobrevivência da população da UFMG (LRS), os flebotomíneos de Belo Horizonte apresentaram maior taxa de mortalidade durante os 120 minutos de exposição.

Na população de flebotomíneos procedentes de Pirenópolis, a análise das curvas de sobrevivência de KM, apontou a dose controle com taxa de sobrevivência maior do que as demais doses, porém próxima a $50 \%$. Em seguida registrou-se a dose de $3 \mathrm{ug} / \mathrm{ml}, 7 \mathrm{ug} / \mathrm{ml}, 5 \mathrm{ug} / \mathrm{ml}$ e $9 \mathrm{ug} / \mathrm{ml}$. A dose 9 $\mathrm{ug} / \mathrm{ml}$ mostrou uma taxa de mortalidade maior que as demais, desde os primeiros 20 minutos de exposição. Neste município, nenhuma das dosagens alcançou $100 \%$ de mortalidade (Figura 15). Nesta população, $69 \%$ dos flebotomíneos morreram ao final dos 120 minutos de exposição. Quando comparadas as curvas de sobrevivência entre as populações de Pirenópolis e da LRS, nota-se que após 30 minutos de exposição, as taxas de mortalidade para as concentrações de 3 e $5 \mathrm{ug} / \mathrm{ml}$ foram maiores na população de Pirenópolis, enquanto que a mortalidade das doses de 7 e 9 $\mathrm{ug} / \mathrm{ml}$ foram na LRS. Após 60 minutos de exposição, somente a concentração de $7 \mathrm{ug} / \mathrm{ml}$ apresentava maior mortalidade na LRS. Ao final dos 120 minutos, a população de Pirenópolis teve maior taxa de mortalidade nas concentrações de 3,5 e $9 \mathrm{ug} / \mathrm{ml}$. 
A análise das curvas de sobrevivência de $\mathrm{KM}$, apontou a dose controle com alta taxa de sobrevivência, seguida da dose de $3 \mathrm{ug} / \mathrm{ml}, 9$ $\mathrm{ug} / \mathrm{ml}, 5 \mathrm{ug} / \mathrm{ml}$ e $7 \mathrm{ug} / \mathrm{ml}$, na população de flebotomíneos de Montes Claros. Não houve mortalidade de $100 \%$ dos flebotomíneos para nenhuma das dosagens (Figura 16). Nos bioensaios desta população, aproximadamente $70 \%$ dos flebotomíneos morreram ao final das exposições de duas horas. Em comparação com as curvas de sobrevivências da LRS, a população de Montes Claros apresentou maior taxa de sobrevivência para as concentrações de 3 e $5 \mathrm{ug} / \mathrm{ml}$ no tempo de 30 minutos. Essa característica se repetiu com 60 minutos de exposição. Ao final dos 120 minutos, a LRS apresentou maior taxa de sobrevivência em todas as concentrações testadas.

As curvas de sobrevivência de KM para a população de flebotomíneos de Januária mostraram o grupo controle matando poucos indivíduos, seguido das dosagens $3 \mathrm{ug} / \mathrm{ml}, 5 \mathrm{ug} / \mathrm{ml}, 7 \mathrm{ug} / \mathrm{ml}$ e $9 \mathrm{ug} / \mathrm{ml}$. As dosagens de 5,7 e $9 \mathrm{ug} / \mathrm{ml}$ chegaram próximo a mortalidade de $100 \%$ dos insetos expostos, porém não alcançaram esta marca (Figura 17). A exposição dos flebotomíneos, neste município matou $77 \%$ da população em duas horas de bioensaio. Quando comparada com a LRS, a população de Januária apresentou maior taxa de mortalidade em todas as concentrações durante todo os 120 minutos de exposição. 


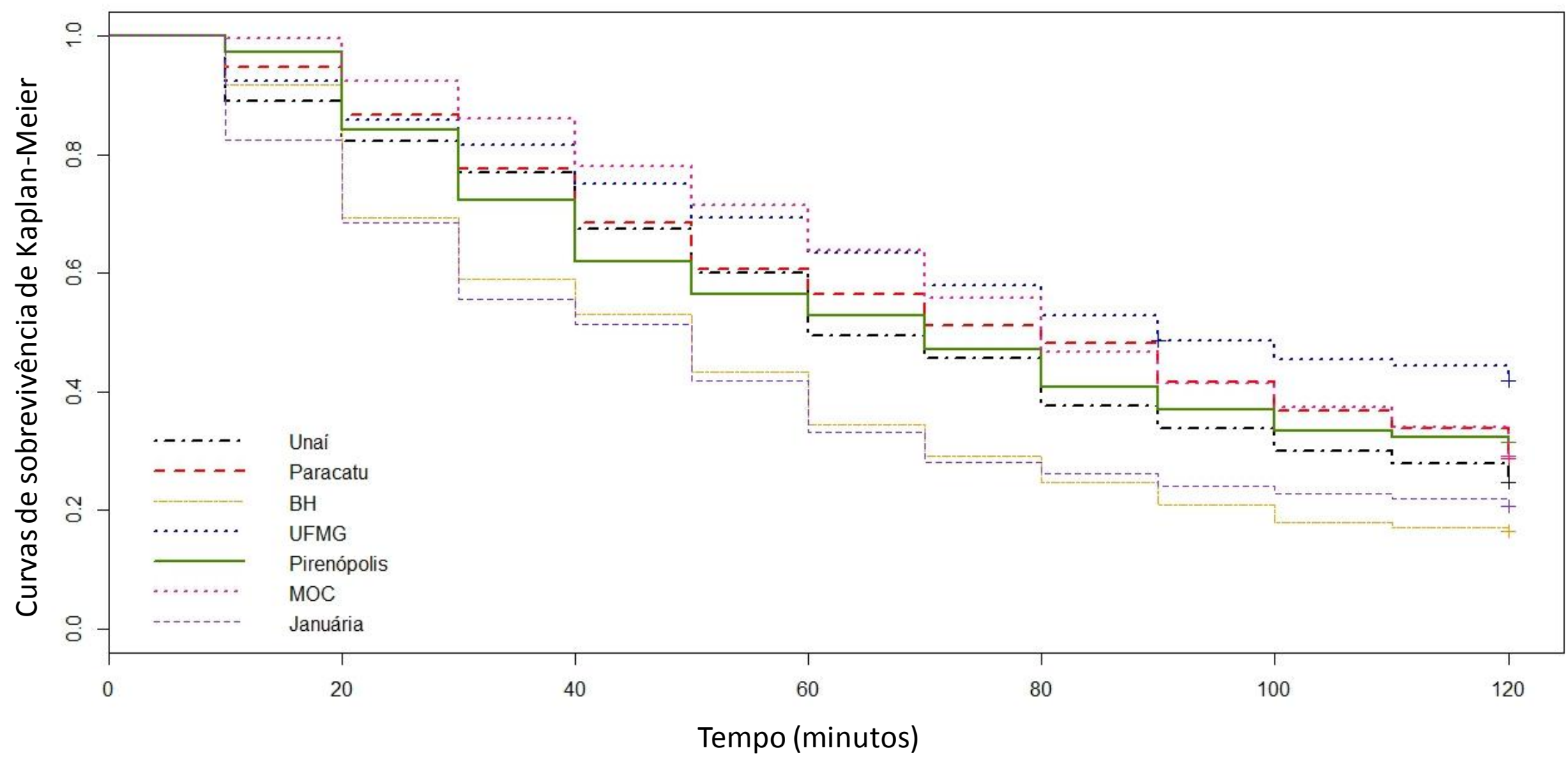

Figura 9. Curvas de sobrevivência de Kaplan-Meier para as populações de flebotomíneos de colônia e dos municípios de Belo Horizonte, Januária, Montes Claros, Paracatu, Unaí e Pirenópolis. 


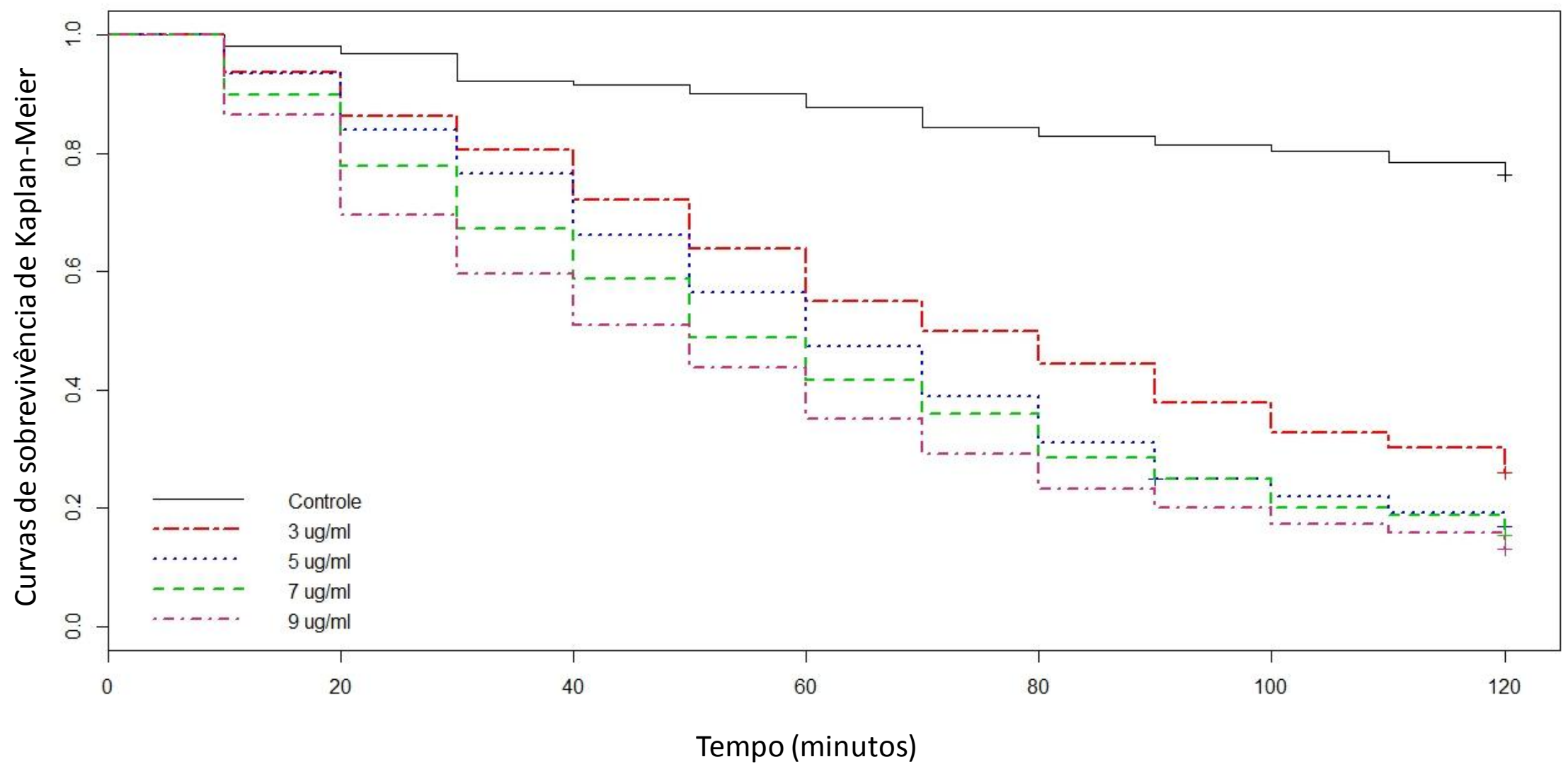

Figura 10. Curvas de sobrevivência de Kaplan-Meier para as dosagens do inseticida alfacipermetrina considerando as populações de flebotomíneos de colônia e dos municípios de Belo Horizonte, Januária, Montes Claros, Paracatu, Unaí e Pirenópolis. 


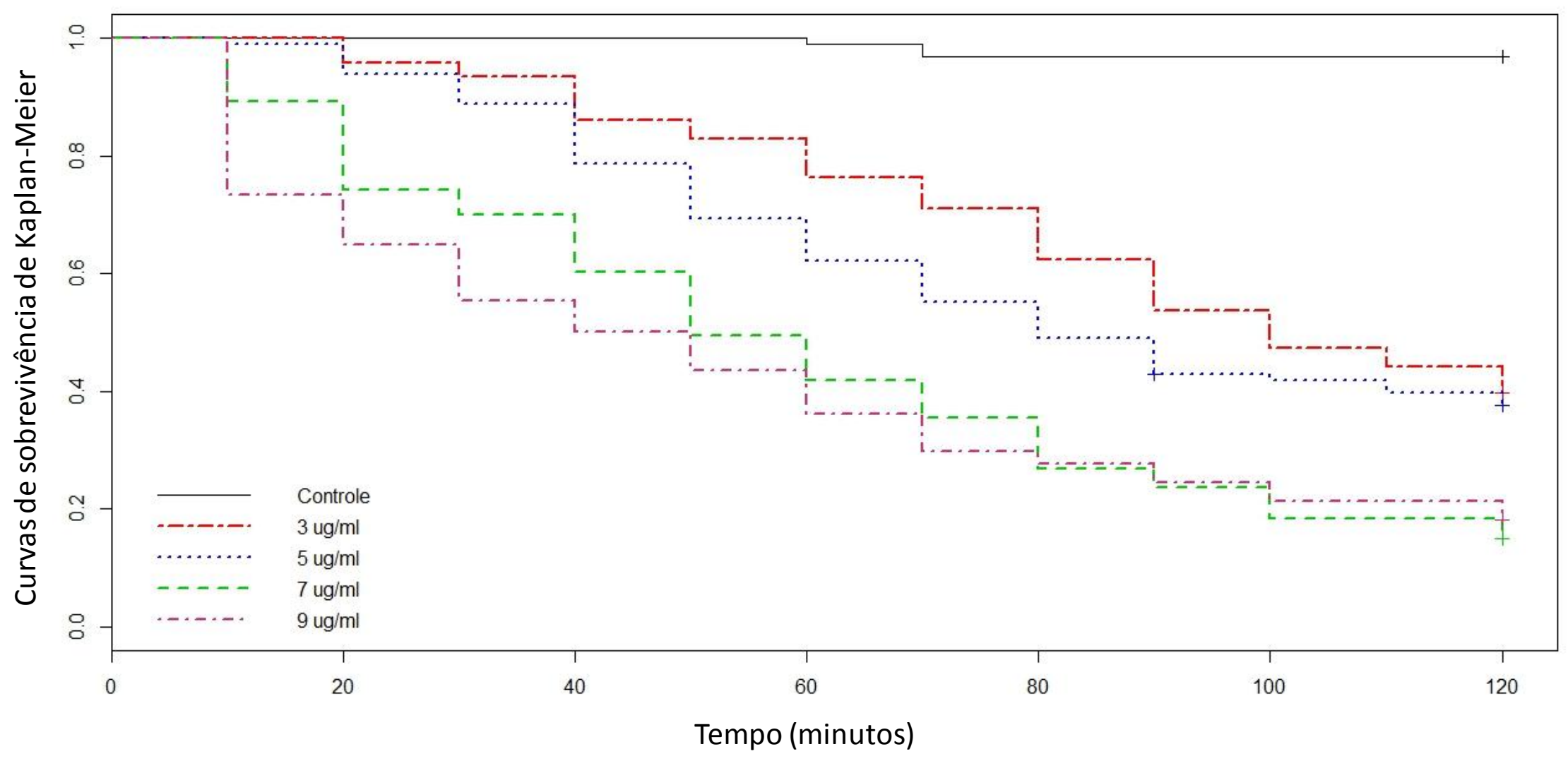

Figura 11. Curvas de sobrevivência de Kaplan-Meier para os flebotomíneos da Linhagem Referência de Suscetibilidade da Universidade Federal de Minas Gerais. 


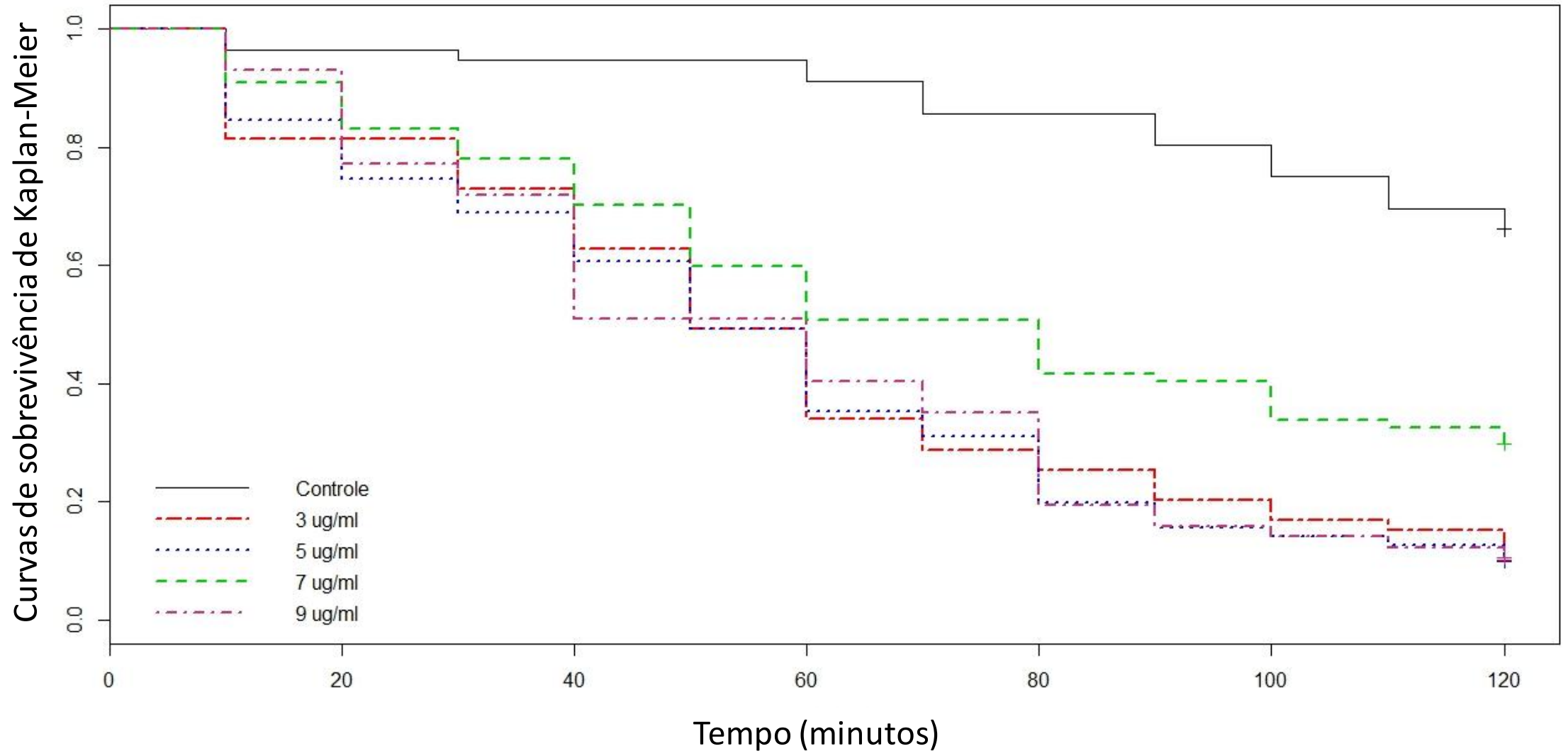

Figura 12. Curvas de sobrevivência de Kaplan-Meier para a população de flebotomíneos de Unaí, Minas Gerais. 


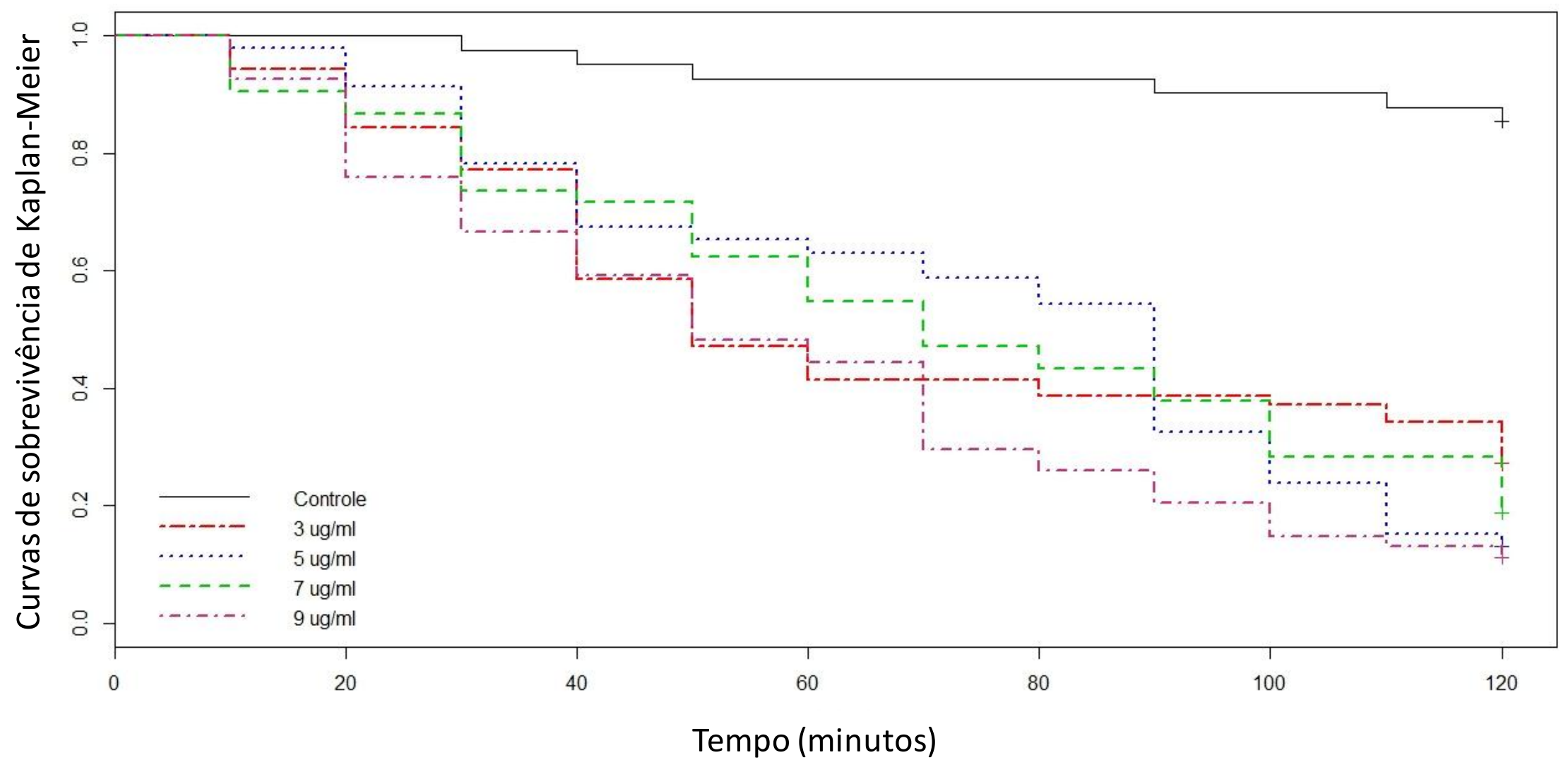

Figura 13. Curvas de sobrevivência de Kaplan-Meier para a população de flebotomíneos de Paracatu, Minas Gerais. 


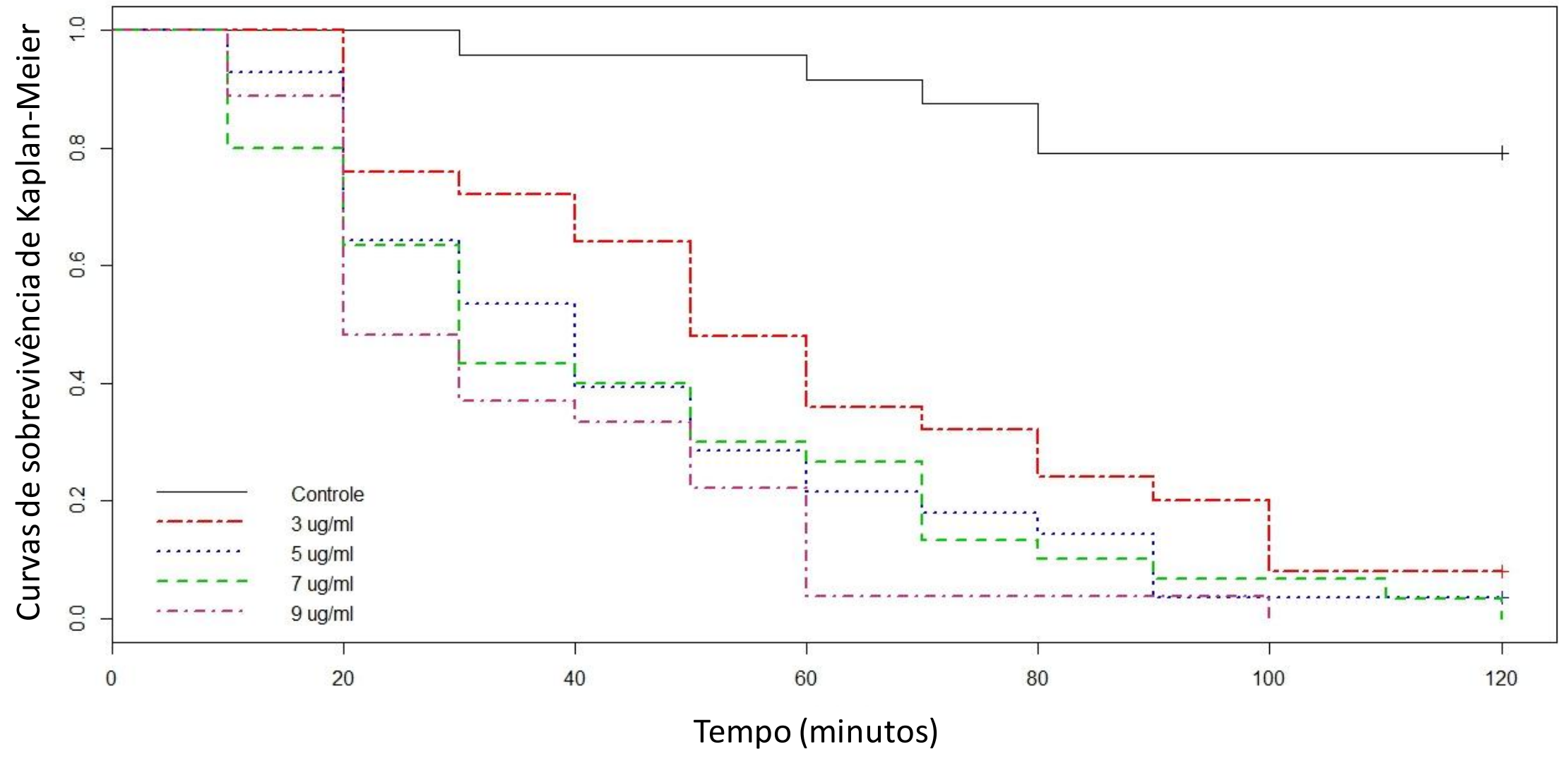

Figura 14. Curvas de sobrevivência de Kaplan-Meier para a população de flebotomíneos de Belo Horizonte, Minas Gerais. 


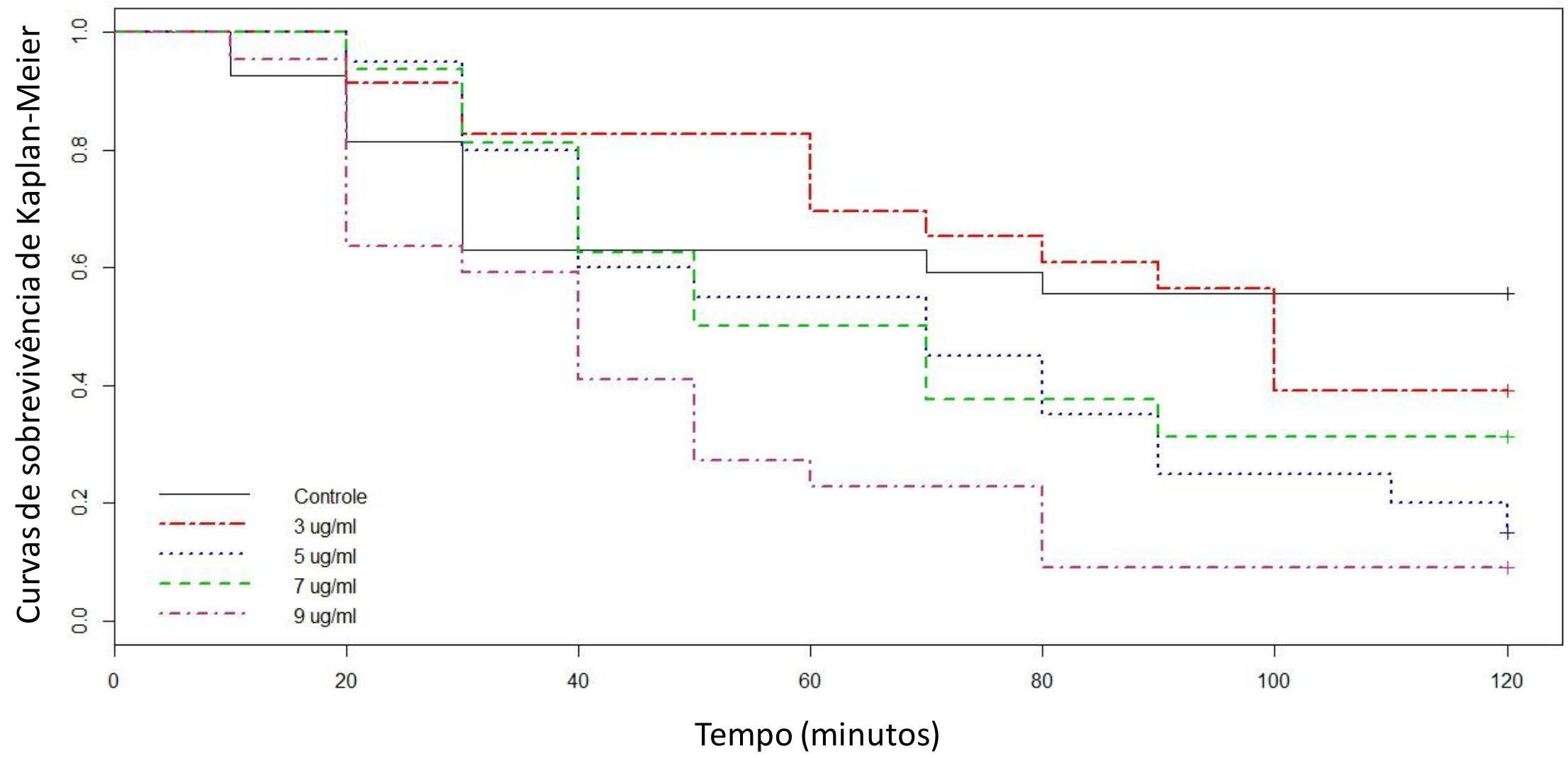

Figura 15. Curvas de sobrevivência de Kaplan-Meier para a população de flebotomíneos de Pirenópolis, Goiás. 


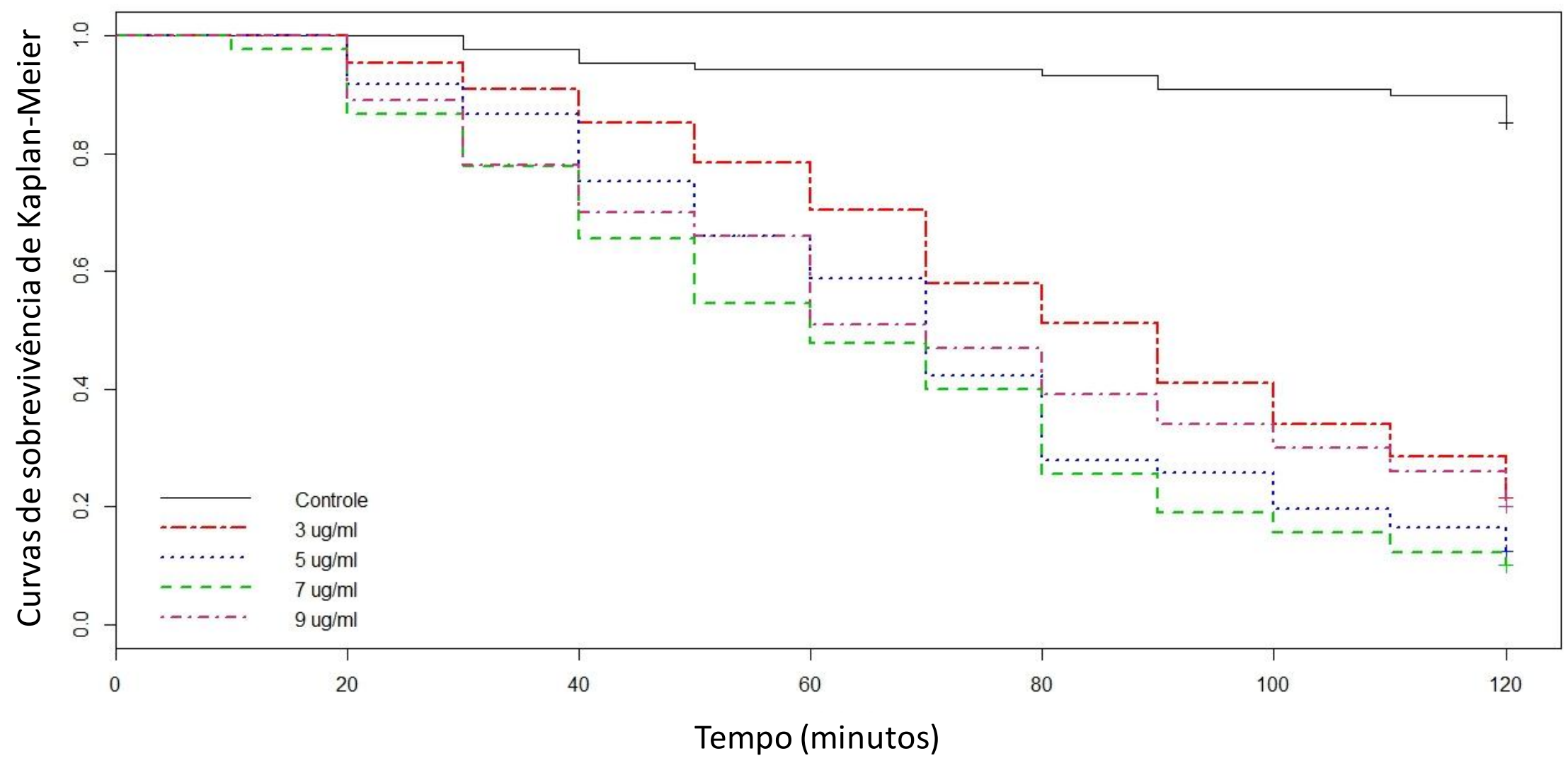

Figura 16. Curvas de sobrevivência de Kaplan-Meier para a população de flebotomíneos de Montes Claros, Minas Gerais. 


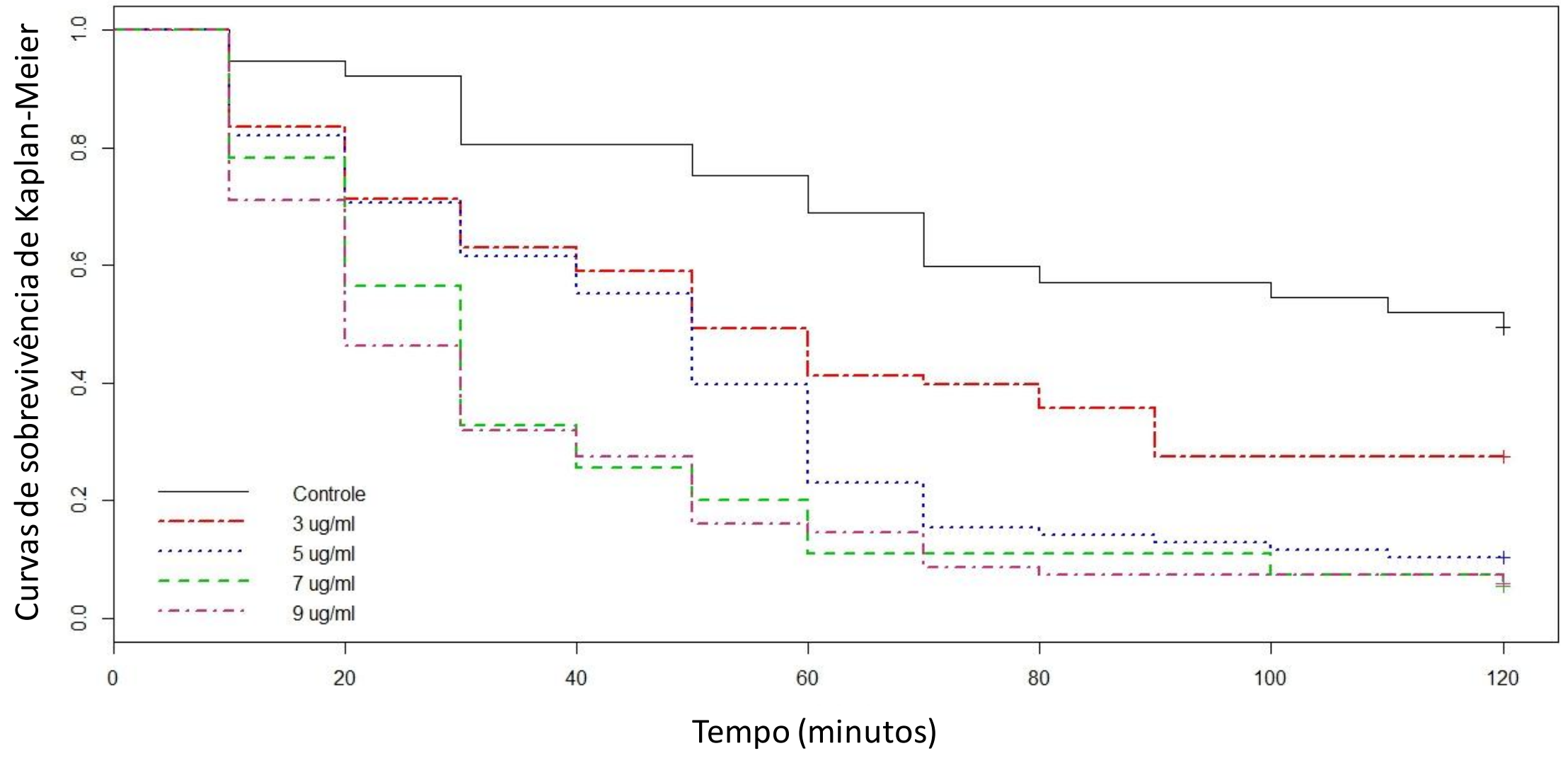

Figura 17. Curvas de sobrevivência de Kaplan-Meier para a população de flebotomíneos de Januária, Minas Gerais. 


\section{DISCUSSÃO}

Os flebotomíneos capturados em campo e utilizados nos experimentos com alfacipermetrina são espécimes comumente encontrados nessas localidades, não se tratando de novos registros para as mesmas ou para os Estados (Galati, 2015). Em um primeiro momento a espécie alvo do trabalho foi $\mathrm{Lu}$. longipalpis e para tal optou-se por coletas quando a densidade da mesma estivesse alta nos referidos municípios, segundo informações do órgãos de saúde locais. Como observado na Tabela 4 a espécie Lu. longipalpis predominou em todas as áreas, porém com baixa densidade em alguns municípios como Belo Horizonte, Januária e Pirenópolis não sendo suficientes para a realização das tréplicas experimentais propostas, utilizando de 10 a 20 espécimes para cada uma das cinco garrafas (ver item 4.3). Dessa forma optou-se por avaliar os tratamentos sobre Phlebotominae, dado que outras espécies, incluindo importantes vetores de espécies de leishmânia causadoras de LTA como $\mathrm{Ny}$. whitmani, $\mathrm{Ny}$. neivai e $\mathrm{Ny}$. intermedia também foram identificadas.

A espécie Lu. longipalpis correspondeu a $85 \%$ dos flebotomíneos utilizados nos bioensaios. De acordo com Brogdon e Chan (2010), caso 95\% dos espécimes testados forem de uma espécie predominante, o teste pode ser considerado válido para aquela determinada espécie. Caso não ocorra essa predominância, os autores sugerem que uma pré-identificação seja feita antes do bioensaio por meio de sedação dos insetos com acetato etílico. Após a identificação, os insetos seriam separados especificamente e testados. Porém, para identificação específica de flebotomíneos utiliza-se a morfologia interna e os mesmos devem ser montados entre lâmina e lamínula e visualizados com auxílio de microscopia ótica. Recomenda-se assim, nesse trabalho, que a avaliação de suscetibilidade de populações de flebotomíneos de campo a um determinado inseticida seja desenvolvida de 
forma geral e não específica como ocorre com outros insetos vetores, dado que a morfologia externa não pode ser utilizada para identificação segura de todas as espécies, principalmente fêmeas. Ainda que fosse possível essa pré-identificação, sedar os espécimes poderia levá-los à morte, antes mesmo dos experimentos, devido a sua fragilidade. Um número ideal para a realização dos testes seria próximo ao observado dos espécimes provenientes da UFMG e Montes Claros (Tabela 4). Diante disso todos os dados foram analisados e comparados, pois há pouca informação da literatura sobre o efeito de inseticidas, utilizando quaisquer dos critérios mensurados, fornecendo subsídios para estudos futuros que visem 0 controle químico de flebotomíneos.

Devido à dificuldade em se coletar um grande número de flebotomíneos no campo, durante os experimentos os flebotomíneos não foram sexados. Como somente as fêmeas são responsáveis pela transmissão de patógenos, parte dos poucos estudos de resistência com esse grupo de insetos não utilizam machos. Alexander et al. (2009) notaram que machos de Lu. longipalpis oriundos de Montes Claros e Lapinha, Minas Gerais, se mostraram mais suscetíveis do que fêmeas, para malation, permetrina e fenitrotion, já as fêmeas foram mais suscetíveis para deltametrina e lambda-cialotrina. Dinesh et al. (2008), na Índia, verificaram que machos de $P h$. argentipes se mostraram mais suscetíveis à permetrina do que flebotomíneos fêmeas. Essas diferenças poderiam influenciar na escolha de inseticida ideal para programas de saúde que visem o controle das leishmanioses, particularmente no caso de Lu. longipalpis onde se sabe que o macho atrai a fêmea para a cópula indicando por meio de sinais químicos (feromônios, batimento de asas) o local para hematofagia (Soares e Turco, 2003). No Velho Mundo, Li et al. (2015) avaliaram a suscetibilidade de $P h$. papatasi e Ph. duboscqi para cipermetrina, deltametrina, ciflutrina, lambda-cialotrina, permetrina, praletrina, clorpirifós, coumafós, diazinon e diclorvós, e indicaram o uso de machos em bioensaios de suscetibilidade. 
Como descrito anteriormente, dois critérios de mortalidade foram adotados: os flebotomíneos foram considerados mortos quando estavam totalmente imóveis (A) ou os flebotomíneos foram considerados mortos quando apresentavam perda das pernas (B). A perda das pernas em flebotomíneos foi relatada por Alexander et al. (2009) quando espécimes de Lu. longipalpis foram expostos a inseticidas piretróides e segundo os autores tal fenômeno acarretaria na incapacidade de se alimentarem e, no caso das fêmeas de transmitirem Leishmania. Possivelmente, tal fato acontece na natureza e esse dado biológico (perda de pernas) foi utilizado como critério de mortalidade nos experimentos com a alfacipermetrina. Observou-se que as taxas de mortalidade e, consequentemente, as $\mathrm{DL}_{50}, \mathrm{RR}_{50}, \mathrm{TL}_{50}$ e $T L_{95}$ seriam totalmente diferentes das apresentadas neste trabalho se o critério de mortalidade "B" fosse utilizado durante o presente estudo. Para as $\mathrm{DL}_{50} \mathrm{e}$ $\mathrm{RR}_{50}$ este critério não poderia ser avaliado, pois matou $100 \%$ dos insetos em vários municípios inviabilizando a análise dessas dosagens no programa Probit. Como essa observação foi sugerida somente após as avaliações nos municípios de Unaí e Paracatu, onde a perda de pernas do flebotomíneos foi frequente, os mesmos não puderam ser avaliados para o critério de mortalidade B.

$\mathrm{Na}$ literatura são raros os trabalhos científicos que relatam o critério de mortalidade adotado. O critério de mortalidade "A" foi preconizado por Brogdon \& Chan (2010), para avaliação da suscetibilidade a inseticidas em mosquitos e também foi utilizado por Delinger et al. (2015) em bioensaios com flebotomíneos. Critérios de mortalidade que consideram efeitos subletais, como a perda das pernas de flebotomíneos, foram adotados em avaliações de suscetibilidade de triatomíneos (Hemiptera: Reduviidae). Nestes trabalhos, triatomíneos com sinais de paralisia e falta de resposta a estímulos externos foram considerados mortos (Gomez et al.; Pessoa et al. 2015b). De acordo com a OPAS (2005) populações de triatomíneos com RR $>5$ são considerados resistentes a um determinado inseticida testado. Para as populações do mosquito Aedes aegypti a RR $>3$ permite classificar como 
sendo resistentes (Brasil, 2006b). Neste estudo, a maior RR foi encontrada na população de Pirenópolis, $R_{50}$ de 1,62. Até o presente momento, não existe uma definição clara e precisa de um valor de $R R_{50}$ que permita confirmar ou não um perfil de resistência estabelecida para populações de flebotomíneos, tal como para triatomíneos e Aedes aegypti, o que justifica a necessidade de estudos de várias populações para definir tais pontos de corte (Pessoa et al. 2015a).

Os flebotomíneos provenientes de Unaí, Januária e Pirenópolis apresentaram uma alta taxa de mortalidade para o controle de $30 \%, 39 \%$ e $44 \%$, respectivamente. Embora Brogdon e Chan (2010) recomendem, para culicídeos, o descarte de bioensaios cuja mortalidade observada no controle seja superior a $10 \%$, no presente estudo essa padronização foi ignorada devido ao baixo número de flebotomíneos coletados na maioria dos municípios, aliado a sua flutuação populacional, dificuldade de criação dos mesmos e dependência da rotina dos serviços de saúde. A acetona utilizada no grupo controle pode ter interferido na taxa de mortalidade dos espécimes, para as localidades acima citada, pois sabe que a mesma possui efeito anestésico sobre insetos, os quais se expostos durante muito tempo morreriam. Uma comparação entre esse produto e o álcool avaliando a suscetibilidade de Pi. evansi para os inseticidas deltametrina e lambdacialotrina mostrou repelência dos flebotomíneos às garrafas impregnadas com inseticidas diluídos com acetona. Garrafas impregnadas com os mesmos inseticidas diluídos em álcool não interferiram no comportamento dos insetos (Henriquez et al. 2009).

Como relatado acima, durante a execução do trabalho algumas limitações impediriam uma implementação eficaz e imediata dos resultados obtidos, ao mesmo tempo em que ofereceu ferramentas para futuros estudos visando o controle desses vetores. Os flebotomíneos de Pirenópolis, Goiás foram os únicos espécimes estudados que apresentaram valores de $\mathrm{DL}_{50}$ e $\mathrm{RR}_{50}$ maiores que da $\mathrm{LRS}\left(\mathrm{RR}_{50}>1\right)$ indicando maior tolerância a inseticida por parte dessa população. Em Pirenópolis a maioria dos 
flebotomíneos testados no bioensaio foram Lu. longipalpis, porém, o resultado da $R R_{50}$ de 1,62 pode ter sido influenciado pela presença de outras seis espécies detectadas após a identificação, tendo em vista que cada espécie possui mecanismos específicos no processo de absorção, penetração e detoxificação de inseticidas, baseados no tamanho, idade e sexo de cada espécie analisada. As populações de Paracatu, Montes Claros e Januária apresentaram valores de $\mathrm{DL}_{50}$ e $\mathrm{RR}_{50}$ menores que da $L R S\left(R_{50}\right.$ $<1)$. Uma hipótese para essa alta taxa de mortalidade das populações de campo pode estar ligada ao pouco tempo de aclimatação dos espécimes (2 horas) antes da realização dos experimentos. De Silans et al. (1998) avaliando populações de Lu. longipalpis de campo, deixaram os espécimes aclimatando por 12 horas. Hassan et al. (2012) e Maroli et al. (2002) avaliaram perfis de suscetibilidade de flebotomíneos do gênero Phlebotomus provenientes de campo, testando F1 e F3, respectivamente. As populações de flebotomíneos de Unaí e Belo Horizonte não tiveram seus valores de $\mathrm{DL}_{50}$ e $R_{50}$ calculados, talvez, por vieses pontuais ocorridos nestes municípios. No primeiro, o umedecimento de algumas garrafas fez com que alguns flebotomíneos permanecessem aderidos nas paredes dos frascos. Em Belo Horizonte, devido a um viés logístico, as armadilhas eram desinstaladas entre 8 h30 e 10 horas da manhã. O elevado tempo de exposição dos flebotomíneos aos raios solares, durante o período da manhã, poderia ter influenciado nas estimativas de mortalidade e sobrevivência neste município.

Maroli et al. (2002) avaliando TL em populações de Ph. papatasi e Ph. perniciosus para os inseticidas permetrina, lambda-cialotrina e DDT, verificou que o $\mathrm{TL}_{50}$ variou de 3 a 20 minutos de exposição, dependendo do inseticida e da espécie exposta. Para o $\mathrm{TL}_{95}$, os valores variaram de $43 \mathrm{a}$ 258 minutos. Neste estudo, o TL $L_{50}$ variou 10 a 100 minutos, dependendo do critério de mortalidade adotado, da dosagem utilizada e da população analisada. Para o $\mathrm{TL}_{95}$, essa variação foi de 20 a 120 minutos. A maioria dos estudos de suscetibilidade de flebotomíneos a inseticida visam encontrar a 
dose/mortalidade. Portanto, comparações de tempo/mortalidade são difíceis de serem avaliadas.

De forma geral, as curvas de sobrevivência de Kaplan-Meier para todas as populações mostraram uma maior mortalidade nas populações de campo, quando comparadas à população de referência. Pessoa et al. (2014) avaliando o perfil de suscetibilidade de Triatoma sordida (Hemiptera: Reduviidae) a deltametrina, registraram três populações de campo mais resistente do que a população de laboratório. Os autores acreditam que estes insetos já possuíam alelos de resistência quando foram coletados e que estes alelos foram mantidos e transferidos para as gerações seguintes. Este fato pode ter se repetido com a população de Lu. longipalpis da UFMG. Apesar do fato da LRS ser criada e mantida em colônia desde 2006, nota-se que a sua origem foi o estado do Piauí, especificamente do município de Teresina. Portanto, no passado essa população pode ter sofrido intensas exposições a inseticidas, considerando-se que são provenientes de áreas endêmicas de LV e LTA (Figuras 4 e 5). Dados futuros de biologia molecular com as fêmeas utilizadas no presente estudo poderão confirmar ou refutar essa hipótese.

A Organização Mundial de Saúde (1998) preconiza que uma taxa de mortalidade superior a $98 \%$ indica uma população suscetível. A mortalidade entre 80 e $97 \%$, sugere a possibilidade de resistência e recomenda novos estudos para confirmação. Mortalidade inferior a $79 \%$ sugere resistência dos insetos estudados. Essas classificações são baseadas e utilizada em bioensaios com mosquitos dos gêneros Aedes e Anopheles, porém foi adotada na classificação da resistência de algumas espécies de flebotomíneos (Delinger et al. 2015). Seguindo-a, com exceção da população de Belo Horizonte, o presente estudo mostrou indícios de resistência, ou seja, os municípios apresentaram populações de flebotomíneos com alterações na suscetibilidade, indicando provável tolerância, especificamente ao piretróide alfacipermetrina. Porém, a interpretação desses resultados exige cautela, necessitando de estudos 
complementares, como por exemplo, a realização de bioensaios de campo para avaliar a eficiência e o impacto das ações de controle químico nos municípios pesquisados.

Embora parte dos resultados seja inconclusiva em relação à resistência dos flebotomíneos testados, devido a possíveis problemas metodológicos expostos e discutidos acima, a condução dos experimentos pôde ser validada pela resposta dose-dependente ao inseticida alfacipermetrina, conforme mostra a Figura 10. Outro fator importante tratase da seleção de uma LRS, na qual seja considerada como padrão para futuros estudos que envolvam a suscetibilidade de flebotomíneos. Pessoa et al. (2015) recomendaram a utilização da população de flebotomíneos procedentes de caverna, localizada na Gruta da Lapinha, estado de Minas Gerais, Brasil. As populações de flebotomíneos da Jacobina, na Bahia e Espírito Santo do Pinhal, em São Paulo também apresentam potencial para serem consideradas LRS em futuros estudos.

O controle químico de flebotomíneos preconizado pelo MS do Brasil é, possivelmente, a ação mais laboriosa de se executar devido à diversidade das espécies, às escassas informações sobre biologia e variabilidade genética desses vetores, que se alteram em função de fatores bióticos e abióticos. A necessidade de financiamento de pesquisas no Brasil visando o controle químico, em parceria com órgãos de saúde competentes, é o primeiro passo para a discussão de novas estratégias a serem empregadas. Como exposto nesse estudo pioneiro, muitas perguntas deverão ser respondidas em laboratório e, principalmente, em condições de campo. Ainda sim, as informações contidas neste trabalho poderão, sem dúvida alguma, subsidiar o Programa Nacional de Controle das Leishmanioses do Ministério da Saúde do Brasil na implantação de uma rede de monitoramento de resistência de flebotomíneos aos inseticidas utilizados no seu controle, em nível de estado e, quem sabe, futuramente em nível de país. 
Relatórios contendo as informações a respeito do perfil de suscetibilidade dos flebotomíneos de cada município serão enviados para as Secretarias Estaduais e Municipais de Saúde após as correções e a impressão final deste documento. 


\section{CONCLUSÕES}

$\checkmark$ O método de bioensaio com garrafa do CDC mostrou-se uma técnica útil para mensurar possíveis alterações na suscetibilidade de flebotomíneos a inseticidas, porém necessita de ferramentas complementares, tais como, bioensaios bioquímicos, moleculares e de campo;

$\checkmark$ A estimativa da dose ideal para bioensaio foi de $\mathrm{DL}_{50}=2,38 \mathrm{ug} / \mathrm{ml}$ por garrafa e o tempo diagnóstico foi de 70 minutos para a dose de 3 $\mathrm{ug} / \mathrm{ml}, 60$ minutos para a dose de $5 \mathrm{ug} / \mathrm{ml}, 50$ minutos para a dose de $7 \mathrm{ug} / \mathrm{ml} \mathrm{e} 40$ minutos para a dose de $9 \mathrm{ug} / \mathrm{ml}$;

$\checkmark$ As populações de flebotomíneos oriundas dos municípios de Unaí, Paracatu, Belo Horizonte, Pirenópolis, Montes Claros e Januária, assim como a LRS apresentaram alterações nos perfis de suscetibilidade, indicando maior tolerância ao piretróide alfacipermetrina. 


\section{REFERÊNCIAS BIBLIOGRÁFICAS}

Aguiar GM, Medeiros WM 2003. Distribuição regional e habitats das espécies de flebotomíneos do Brasil. In Rangel EF, Lainson R (org.), Flebotomíneos do Brasil, Rio de Janeiro, Editora FIOCRUZ, 368 pp.

Alexander B, Barros VC, De Souza SF, Teodoro LP, Soares ZR, Gontijo NF, Reithinger R 2009. Suscetibility to chemical insecticides of two Brazilian populations of the visceral leishmaniasis vector Lutzomyia longipalpis (Diptera: Psychodidae). Trop Med Int Health 14:1272-1277.

Alexander B, Maroli M 2003. Control of phlebotomine sandflies. Med Vet Entomol 17(1): 1-18.

Alvar J, Aparicio P, Aseffa A. Den Boer M, Cañavete C, Dedet JP, Grandoni L, Ter Horst R, López-Vélez R, Moreno J 2008. The relationship between leishmaniasis and AIDS: the second 10 years. Clin Microbiol Rev 21:334359.

Alvar J, Velez ID, Bern C, Herrero M, Desjeux P, Cano J, Jannin J, Boer M 2012. Leishmaniasis worldwide and global estimates of its incidence. PLOS One 7:e35671.

Andrade-Coelho CA, Souza NA, Gouveia C, Silva VC, Gonzalez MS, Rangel EF 2009. Effect of fruit and leaves of Meliaceae plants (Azadirachta indica and Melia azedarach) on the development of Lutzomyia longipalpis larvae (Diptera: Psychodidae: Phlebotominae) under experimental conditions. $J$ Med Entomol 46: 1125-1130.

Bansal SK, Singh KV 1996. Susceptibility status of Phlebotomus papatasi and Sergentomyia punjabensis (Diptera: Psychodidae) to some insecticides in district Bikaner (Rajasthan). J Commun Diseases 28: 28-32. 
Barata RA, Michalsky EM, Fujiwara RT, França-Silva JC, RochaMF, Dias ES 2001. Assessment of sandfly (Diptera, Psychodidae) control using cypermethrin in an endemic area for visceral leishmaniasis, Montes Claros, Minas Gerais state, Brazil. Cad Saude Publica 27: 2117-2123.

Bern C, Maguire JH, Alvar J 2008. Complexities of assessing the disease burden attributable to Leishmaniasis. PLoS Negl Trop Dis 2: e313.

Borges BKA, Silva JA, Haddad JPA, Moreira EC, Magalhães DF, Ribeiro LM L, Fiúza VOP 2008. Avaliação do nível de conhecimento e de atitudes preventivas da população sobre a leishmaniose visceral em Belo Horizonte, Minas Gerais, Brasil. Cad Saúde Pública 24(4): 777-784.

Brasil. Ministério da Saúde 2015a. Leishmaniose Visceral. Disponível em: $<$ <ttp://portalsaude.saude.gov.br/index.php/o-

ministerio/principal/secretarias/svs/leishmaniose-visceral-Iv>. Acesso em 21 Dez. 2015.

Brasil. Ministério da Saúde 2015b. Leishmaniose Tegumentar Americana (LTA). Disponível em: <http://portalsaude.saude.gov.br/index.php/oministerio/principal/secretarias/svs/leishmaniose-tegumentar-americana-Ita> . Acesso em: 21 Dez. 2015.

Brasil. Ministério da Saúde 1999. Evolução temporal das doenças de notificação compulsória no Brasil de 1980 a 1998. Boletim Epidemiológico 3: 15-17.

Brasil. Ministério da Saúde 2006a. Secretaria de Vigilância em Saúde. Manual de Vigilância e Controle da Leishmaniose Visceral. 1ª. Edição. Brasília-DF: editora do Ministério da Saúde, 2006. 120p.- (Série A. Normas e Manuais Técnicos).

Brasil. Ministério da Saúde 2006b. Secretaria de Vigilância em Saúde. Coordenação geral do Programa Nacional do Controle de Dengue. Reunião 
Técnica paradiscutir o status de resistência de Aedes aegypti aos inseticidas. Brasília: Ministério da Saúde; p. 2.

Brasil. Ministério da Saúde 2010 Secretaria de Vigilância em Saúde. Manual da Vigilância da Leishmaniose Tegumentar Americana. 2ª . Edição. BrasíliaDF: editora do Ministério da Saúde, 180p.- (Série A. Normas e Manuais Técnicos).

Bray DP, Hamilton, JGC 2013. Insecticide-impregnated netting as a potential tool for long-lasting control of the leishmaniasis vector Lutzomyia longipalpis in animal shelters. Parasit Vectors 6:133.

Brogdon WG, Chan A 2010. Diretriz para avaliar a resistência a inseticida em vetores usando bioensaio com garrafas do CDC, Atlanta, EUA; 28 pp.

Bustamante-Teixeira MT, Faerstein E, Latorre MR 2002. Survival analysis techniques. Cad Saúde Pública 18: 579-594.

Courtenay O, Gillingwater K, Gomes PA, Garcez LM, Davies CR 2007. Deltamethrin-impregnated bednets reduce human landingrates of sandfly vector Lutzomyia longipalpis in Amazon households. Med Vet Entomol 21: 168-176.

Dantas-Torres F 2011. Ticks as vectors of Leishmania parasites. Trends Parasitol 27:155-159.

De Silans LN, Dedet JP, Arias JR 1998. Field monitoring of cypermethrin residual effect on the mortality rates of the Phlebotominae sand fly Lutzomyia longipalpis in the state of Paraiba, Brazil. Mem Inst Oswaldo Cruz 93: 339344.

Deane LM, Deane MP, Alencar JE 1955. Observações sobre o combate ao Phlebotomus longipalpis pela dedetização domiciliária em focos endêmicos de calazar, Ceará. Rev Bras Malariol Doenças Trop 7:131-141. 
Denlinger DS, Lozano-Fuentes S, Lawyer PG, Black WC 4th, Bernhardt SA 2015. Assessing Insecticide Susceptibility of Laboratory Lutzomyia longipalpis and Phlebotomus papatasi Sand Flies (Diptera: Psychodidae: Phlebotominae). J Med Entomol 52(5):1003-1012.

Dey A, Singh S 2006. Transfusion transmitted leishmaniasis: a case report and review of the literature. Indian J Med Microbiol 24:165-170.

Dhanda V, Shetty PS, Dhiman RC 1983. Studies on phlebotominae sandflies as vectors of kala-azar in Bihar. Proceedings of the Indo-UK Workshop on Leishmaniasis. Indian Co Med Res 128-137.

Dinesh DS, Das P, Picado A, Davies C, Speybroeck N, Ostyn B, Boelaert M, Coosemans M 2008. Long-lasting insecticidal nets fail at household level to reduce abundance of sandfly vector Phlebotomus argentipes in treated houses in Bihar (India). Trop Med Int Health 13(7):953-8.

Dinesh DS, Kumari S, Kumar V, Das P 2014. The potentiality of botanicals and their products as an alternative to chemical insecticides to sandflies (Diptera: Psychodidae): A review. J Vector Borne Dis 51(1): 1-7.

Dinesh DS, Kumar V, Das P 2011. Efficacy of DDT and deltamethrin on sand fly populations in an endemic village of Kalazar, Bihar, India. In: $7^{\text {th }}$ International Symposium on Phebotominae Sand flies, 25-30 april. Kusadasi - Turkey.

Dougall AM, Alexander B, Holt DC, Harris T, Sultan AH, Bates PA, Rose K, Walton SF 2011. Evidence incriminating midges (Diptera: Ceratopogonidae) as potential vectors of Leishmania in Australia. Int $J$ Parasitol 41:571-579.

Dougherty MJ. Ward RD 1991. Methods of reducing Ascogregarina chagasi parasitaemia in laboratory colonies of Lutzomyia longipalpis. Parassitologia 33: 185- 191.

Falcão AR, Pinto CT, Gontijo CMF 1988. Suscetibility of Lutzomyia longipalpis to deltametrin. Mem Inst Oswaldo Cruz 83(3): 395-396. 
Faraj C, Ouahabi S, Adlaoui el B, El Elkohli M, Lakraa L, El Rhazi M, Ameur B 2012. Insecticide susceptibility status of Phlebotomus (Paraphlebotomus) sergenti and Phlebotomus (Phlebotomus) papatasi in endemic foci of cutaneous leishmaniasis in Morocco. Parasit Vectors 5:51.

Forattini, OP 1973. Entomologia Médica. Psychodidae. Phlebotominae. Leishmanioses. Bartonelose. São Paulo: Ed. Edgard Blücher. 658p.

Galati EAB 1995. Phylogenetic systematics of Phlebotominae (Diptera, Psychodidae) with emphasis on American groups. Bol Dir Malariol Saneam Amb 35: 133-142.

Galati EAB 2003. Classificação de Phlebotominae. In EF Rangel, R Lainson, Flebotomíneos do Brasil, Fiocruz 2003; 23-51.

Galati, EAB 2015. Apostila de bioecologia e identificação de Phlebotominae (Diptera, Psychodidae) - Departamento de Epidemiologia p. 127, Faculdade de Saúde Pública da USP, São Paulo, Brasil. (http://www.fsp.usp.br/egalati) (acessado em: 21 Dez 2015).

Gomez MB, Pessoa GCD, Rosa ACL, Echeverria JE, Diotaiuti L 2015. Inheritance and heritability of deltamethrin resistance under laboratory conditions of Triatoma infestans from Bolivia. Parasit Vectors 8: 595.

Gontijo B, Carvalho MLR 2003. Leishmaniose Tegumentar Americana. Rev Soc Bras Med Trop 36(1):71-80.

Gontijo CMF, Melo MN 2004. Leishmaniose Visceral no Brasil: Quadro Atual, Desafios e Perspectivas. Rev Bras Epidemiol 7(3): 338-349.

Hassan MM, Widaa SO, Osman OM, Numiary MSM, Ibrahim MA, Abushama HM 2012. Insecticide resistance in the sand fly, Phlebotomus papatasi from Khartoum State, Sudan. Parasit Vectors 5:46.

Henriquez C, Pereira Y, Cochero S, Bejarano EE 2009. Dosis diagnóstica y umbral de resistencia de Lutzomyia evansi (Diptera: Psychodidae), a dos 
insecticidas utilizados en salud pública en Colombia: deltametrina y lambdacihalotrina. Rev Soc Entomol Argent 68(3-4): 287-294.

Joshi GC, Kaul SM, Wattal BL 1979. Susceptibility of sand flies to organochlorine insecticides in Bihar (India) - further reports. J Commun Diseases 11: 209-213.

Kaul SM, Wattal BL, Bhatnagar VN, Mathur KK 1978. Preliminary observations on the susceptibility status of Phlebotomus argentipes and $P$. papatasi to DDT in two districts of North Bihar (India). J Commun Diseases 10: 208-211.

Kaul SM, Sharma RS, Borgohain BK 1994. DDT resistance in Sergentomyia shorttii (Diptera: Psychodidae) in Kamrup, Assum-first report in Sergentomyia genus. J Commun Diseases 26: 100-102.

Killick-Kendrick $R$ 2010. Education is key to controlling visceral leishmaniasis. Bull World Health Organ 88: 11-12.

Killick-Kendrick R, Ward DH 1981. Transmition of leishmaniosis by the bait of phlebotomine sandfly: possible mechanism. Trans R Soc Trop Med Hyg 75(1): 152-154.

Lainson R, Rangel EF 2005. Lutzomyia longipalpis and the eco-epidemiology of American visceral leishmaniasis, with particular reference to Brazil - A Review. Mem Inst Oswaldo Cruz 100: 811-827.

Lainson R, Shaw JJ 1973. Leishmanias and leishmaniasis of the New World, with particular reference to Brazil. Bull Pan Am Health Org 7(4): 1-19.

Le Pont F, Padilla JM, Desjeux P, Richard A, Mouchet J 1989. Impact de pulverisations de deltamethrine dans un foyer de leishmaniose de Bolivie. Ann Soc Belg Med Trop 69: 223-232.

Li AY, Péres de Léon AA, Linthicum KJ, Britch SC, Bast JD, Debboun M 2015. Baseline Susceptibility to Pyrethroid and Organophosphate 
Insecticides in Two Old World Sand Fly Species (Diptera: Psychodidae). Us Army Med Dep J Jul-Sep: 3-9.

Lins RMMA, Souza NA, Peixoto AA 2008. Genetic divergence between two sypatric species of the Lutzomyia longipalpis complex in the paralytic gene, a locus associated with insecticide resistance and lovesong production. Mem Inst Oswaldo Cruz 103 (7): 736-740.

Luz ZMP, Pimenta DN, Schall VT, Rabello A 2003. Evaluation of informative materials on leishmaniasis distributed in Brazil: criteria and basis for the production and improvement of health education materials. Cad Saúde Pública 19(2): 561- 569.

Marceló C, Cabrera OL, Santamaria E 2014. Discriminating concentrations for three insecticides used in public health in a Lutzomyia longipalpis experimental strain from Colombia. Biomedica 34(4): 624-630.

Maciel MV, Morais SM, Bevilaqua CM, Silva RA, Barros RS, Sousa RN, Sousa LC, Machado LK, Brito ES, SouzaNeto MA 2010. In vitro insecticidal activity of seed Azadirachta indica oil on Lutzomyia longipalpis (Diptera: Psychodidae). Rev Bras Parasitol Vet 19(1): 7-11.

Marcondes, CB 2007. A proposal of generic and subgeneric abbreviations for phlebotomine sandflies (Diptera: Psychodidae: Phlebotominae) of the world. Entomological News 118: 351-356.

Marcondes CB, Nascimento JA 1993. Avaliação da eficiência de deltrametrina (K-Othrine $\mathrm{CE}$ ) no controle de Lutzomyia longipalpis (Diptera: Psychodidae) no município de Santa Rita, Paraíba, Brasil. Rev Soc Bras Med Trop 26: 15-18.

Maroli M, Cianchi T, Bianchi R, Khoury C 2002. Testing insecticide susceptibility of Phlebotomus perniciosus and P. papatasi (Diptera: Psychodidae) in Italy. Ann Ist Super Sanita 38(4):419-423. 
Maroli M, Feliciangeli MD, Bichaud L, Charrel RN, Gradoni L 2013. Phlebotomine sandflies and the spreading of leishmaniases and other diseases of public health concern. Med Vet Entomol 27:123-47.

Maroli M, Mizzon V, Siragusa C, D'oorazi A, Gradoni L 2001. Evidence for an impact on the incidence of canine leishmaniasis by the mass use of deltamethrinimpregnated dog collars in southern Italy. Med Vet Entomol 15(4): 358-363.

Mauricio IL, Stohard JR, Miles MA 2000. The strange case of Leishmania chagasi. Parasitol Today 16: 188-189.

Mazloumi Gavgani AS, Hodjati H, Mohite H, Davies CR 2002. Impact of insecticide impregnated dog collars on rate of zoonotic visceral leishmaniasis infection in children: matched community-based trial in Iran. Lancet 360(9330): 374-379.

Mazzarri MB, Feliciangeli MD, Maroli M, Hernandez A, Bravi A 1997. Susceptibility of Lutzomyia longipalpis (Diptera: Psychodidae) to selected insecticides in an endemic focus of visceral leishmaniasis in Venezuela. $J$ Am Mosq Control Assoc 13: 335-341.

Melander AL 1914. Can insects become resistant to sprays? J Econ Entomol 7: 167-172.

Mestre GLC, Fontes CJF 2007. A expansão da epidemia da leishmaniose visceral no Estado de Mato Grosso, 1998-2005. Rev Soc Bras Med Trop 40(1); $42-48$.

Monteiro EM, França-Silva JC, Costa RT, Costa DC, Barata RA, Paula EV, Machado-Coelho GLL, Rocha MF, Fortes-Dias CL, Dias ES 2005. Leishmaniose visceral: estudo de flebotomíneos e infecção canina em Montes Claros, Minas Gerais. Rev Soc Bras Med Trop 38(2): 147-152.

Monteiro PS, Lacerda MM, Arias JB 1994. Controle da leishmaniose visceral no Brasil. Rev Soc Bras Med Trop 27 (Suppl. 2): 67-72. 
Mukhopadhyay AK, Saxena NB, Narasimham MV 1992. Susceptibility of Phebotomus argentipes to DDT in some Kala-azar endemic districts of Bihar, India. Document WHO/LEISH/92.31, World Health Organization. Geneva.

Nery-Guimarães F, Bustamante FM 1954. Aplicação domicilaria de DDT como base da profilaxia das leishmanioses - Estudo de um foco de leishmaniose mucocutânea cinco anos depois da aspersão periódica com aquele inseticida. Rev Bras Malariol Doenças Trop 6: 127-130.

Oliveira-Filho AM, Melo MTV 1994. Vectors control importance on leishmaniasis transmission. Mem Inst Oswaldo Cruz 89: 451-6.

OMS. Organização Mundial de Saúde 1957. $7^{\text {th }}$ report of the World health expert comité on insecticides. (Série de Informes Técnicos, 125). Geneva.

OMS. Organização Mundial de Saúde 1998. Techniques to detect insecticide resistance mechanisms (field and laboratory manual). Geneva.

OMS. Organização Mundial de Saúde 1992. Vector resistence to pesticide. Expert Committee on vector biology and control (Série de Informes Técnicos, 818). Geneva.

OMS. Organização Mundial de Saúde 2010. Control of leishmaniases. Report of a meeting of the WHO Expert Committee on the Control of Leishmaniases. Tech Rep Ser 949: 1-186.

OMS. Organização Mundial de Saúde 2013. Leishmaniasis. Disponível em: <http://www.who.int/leishmaniasis/en/>. Acesso em: 07 de Jan. 2016.

OPAS. Organização Panamericana de Saúde 2005. II Reunion tecnica latinoamericana de monitoreo de resistencia a insecticidas em triatominos vectores de Chagas. Panamá, 11 a 13 de abril.

Owusu HF, Jancáryová D, Malone D, Müller P 2015. Comparability between insecticide resistance bioassays for mosquito vectors: time to review current methodology? Parasit Vectors 8:357. 
Pessoa FAC, Medeiros JF, Barrett TV 2007. Effects of timber harvest on phlebotomine sand flies (Diptera: Psychodidae) in a production forest: abundance of species on tree trunks and prevalence of trypanosomatids. Mem Inst Oswaldo Cruz 102(5): 593-599.

Pessoa GCD, Dias LS, Diotaiuti L 2014. Deltamethrin pyrethroid susceptibility characterization of Triatoma sordida Stål, 1859 (Hemiptera: Reduviidae) populations in the Northern Region of Minas Gerais, Brazil. Rev. Soc Bras Med Trop 47(4):426-429.

Pessoa GCD, Lopes JV, Rocha MF, Pinheiro LC, Rosa ACL, Michalsky EM, Dias ES 2015a. Baseline susceptibility to alpha-cypermethrin in Lutzomyia longipalpis (Lutz \& Neiva, 1912) from Lapinha Cave (Brazil). Parasit Vectors 8:469.

Pessoa GCD, Pinheiro LC, Ferraz ML, Mello BV, Diotaiuti L 2015b. Standardization of laboratory bioassays for the study of Triatoma sordida susceptibility to pyrethroid insecticides. Parasit. Vectors 8: 109.

Pugedo H Barata RA, França-Silva JC, Silva JC, Dias ES 2005. HP: an improved model of sucction light trap for the capture of small insects. Rev Soc Bras Med Trop 38: 70-72.

Rahman SJ, Wattal BL, Mathur KK, Joshi GC, Kumar K 1982. Suscetibility of laboratory reared strain of Phebotomus papatasi (Scopoli) to organochorine insecticides. J Commun Diseases 14: 122-124.

Ready PD 2013. Biology of phlebotomine sand flies as vectors of disease agents. Annu Rev Entomol 58: 227-50.

Ready PD 2014. Epidemiology of visceral leishmaniasis. Clin Epidemiol 6 147-154.

Reithinger R, Coleman PG, Alexander B, Vieira EP, Assis G, Davies CR 2004. Are insecticide-impregnated dog collars a feasible alternative to dog 
culling as a strategy for controlling canine visceral leishmaniasis in Brazil? Int J Parasitol 34(1): 55-62.

Romero GAS, Boelaert M 2010. Control of Visceral Leishmaniasis in Latin America - A Systematic Review. PLoS Negl Trop Dis 4(1): e584.

Robert LL, Perich MJ, Schlein Y, Jacobson JL, Wirtz RA, Lawyer PG, Githure J I 1997. Phlebotomine sand fly control using bait-fed adults to carry the larvicide's Bacillus sphaericus to the larval habitat. J Am Mosq Control 13(2); 140-144.

São Paulo. Cartilha. Manejo Ambiental para Controle de Leishmaniose Visceral Americana (LVA). 2012: 26 pp.

Scorza JV, Rosario CL, Scorza JVJR, Rojas E 1995. Susceptibilidad de hembras silvestres de Lutzomyia youngi de Trujillo, Venezuela, a insecticidas sinteticos. Bol Direc Malariol S Amb 35: 311 - 326.

Shaw JJ 2002. New World Leishmaniasis: the ecology of leishmaniasis and the diversity of leishmanial species in Central and South America. In Farrell J. World Class Parasites: Leishmania, 4, Kluwer Academic Publishers 11-31.

Sherlock IA 1996. Ecological interactions of visceral leishmaniasis in the State of Bahia. Mem Inst Oswaldo Cruz 91(6): 671-683.

Sherlock IA 2003. A importância dos flebotomíneos. In: Rangel EF, Lainson R. Flebotomíneos do Brasil. Rio de Janeiro: Fiocruz; 15-21.

Shimabukuro PHF, Andrade AJ, Galati EAB 2016. Phlebotominae in Catálogo Taxonômico da Fauna do Brasil. PNUD. Disponível em: <http://fauna.jbrj.gov.br/fauna/faunadobrasil/3297>. Acesso em: 07 Jan. 2016.

Singh R, Kumar P 2015. Susceptibility of the sandfly Phlebotomus argentipes Annandale and Brunetti (Diptera: Psychodidae) to insecticides in endemic areas of visceral leishmaniasis in Bihar, India. Jpn J Infect Dis 68(1): 33-37. 
Soares RPP, Turco SJ 2003. Lutzomyia longipalpis (Diptera: Psychodidae: Phlebotominae): a review. An Acad Bras Ciênc 75(3): 301-330.

Sudia WD, Chamberlain RW 1962. Battery operated light trap, an improved model, Mosquito News. 25: 172-182.

Tare V, Deshpande S, Sharma RN 2004. Susceptibility of two different strains of Aedes aegypti (Diptera: Culicidae) to plant oils. Journal of Economic Entomology 97(5): 1734-1736.

Thapar B, Joshi R, Rao J, Saxena N 1993. Susceptibility status of Phlebotomus papatasi to chlorinated hydrocarbons in Panchahal District of Gujarat State (India). J Commun Diseases 25:212-213.

Turchetti AP, Souza TD, Paixão TA, Santos RL 2014. Sexual and vertical transmission of visceral leishmaniasis. J Infect Dev Ctries 8:403-407.

Viegas Júnior C 2003. Terpenos com atividade inseticida: uma alternativa para o controle químico de insetos. Química Nova 26(3): 390-400.

Wahba MM, Labib IM, El Hamshary EM 1999. Bacillus thuringiensis var. israelensis as a microbial control agent against adult and immature stages of the sandfly, Phlebotomus papatasi under laboratory conditions. J Egyp Soc Parasitol 29(2): 587-597.

Warburg A 1991. Entomopathogens of phlebotomine sand flies: Laboratory experiments and natural infections. J Invertebr Pathol 58(2): 189-202.

Young DG, Duncan MA 1994. Guide to the identification and geographic distribution of Lutzomyia sand flies in Mexico, the West Indies, Central and South America (Diptera: Psychodidae). Mem Am Entomol Inst 54: 881 pp. 


\title{
Apêndice 1. Documento oficial da Universidade de Brasília enviada à Secretaria de Saúde de Goiás.
}

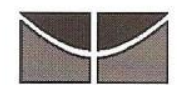 \\ Núcleo de Medicina Tropical \\ PROGRAMA DE PÓS-GRADUAÇÃO EM MEDICINA TROPICAL \\ Carta nº 002/2015 - PPGMT/FM/UnB \\ Brasília, 27 de março de 2015 . \\ À Senhora \\ Dra. Maria Bárbara Helou Rodrigues \\ Diretora Geral do Laboratório de Saúde Pública Dr. Giovanni Cysneiros \\ Goiânia - GO \\ Assunto: Solicitação de captura de flebotomíneos - vetores das \\ Leishmanioses
}

1. Dirijo-me a Vossa Senhoria para informar que poucos trabalhos têm sido realizados para detectar mudanças na susceptibilidade de populações flebotomínicas, em relação aos inseticidas utilizados no seu controle. A resistência a inseticidas é definida pela Organização Mundial de Saúde como sendo uma característica herdável, portanto genética, ao qual confere um aumento na tolerância a um pesticida, ou grupo de pesticidas, de modo que os indivíduos resistentes sobrevivem à concentração do(s) componente(s) que seriam normalmente letais para a maioria dos indivíduos de uma população da mesma espécie (suscetível).

2. Recentemente, sob a coordenação do Prof. Marcos T. Obara, da Universidade de Brasilia (UnB), foi aprovado o projeto, intitulado: "Monitoramento da Resistência de Lutzomyia longipalpis (Diptera: Psychodidae) - principal vetor da leishmaniose visceral, no Brasil", na Chamada Universal- MCTI/CNPQ $n^{\circ}$ 14/2014. Este projeto tem como objetivo caracterizar o perfil de suscetibilidade de diferentes populações naturais de Lu. longipalpis ao piretróide alfacipermetrina utilizado no Programa de Controle das Leishmanioses. A Secretaria de Estado da Saúde de Goiás será parte integrante desta pesquisa que visa promover e fomentar a melhoria contínua dos serviços prestados pelos Laboratórios de Entomologia Médica.

Núcleo de Medicina Tropical, Universidade de Brasília, CP 04517. Campus Universitário Darcy Ribeiro, Asa Norte, Brasilia, DF. Brasil 70904-970 Fone: +55-61-3107-0081; email: pgtropical@unb.br 


\section{W \\ Núcleo de Medicina Tropical \\ PROGRAMA DE PÓS-GRADUAÇÃO EM MEDICINA TROPICAL}

3. De um modo geral, o monitoramento consiste em:

a) Captura de flebotomíneos provenientes de áreas submetidas às ações de controle vetorial.

b) Um total de 300 espécimes de Lu. longipalpis oriundos de campo serão expostos, a pelo menos quatro diluições. Cada prova biológica terá três replicações, em diferentes momentos.

c) A intensidade da resistência será avaliada por meio da proporção de indivíduos suscetíveis e da relação entre a dose e o tempo diagnóstico.

d) A UnB enviará um relatório dos resultados obtidos para órgãos envolvidos, quanto à possível existência de focos de populações flebotomínicas resistentes.

4. O início do projeto de monitoramento está previsto para o mês de maio deste ano, a princípio para Lu. longipalpis. Diante do exposto, solicitamos o apoio para a realização de captura da espécie acima citada. As amostras entomológicas deverão ser enviadas até o laboratório local, de acordo com a metodologia, em anexo. Preferencialmente, recomenda-se a indicação de três (03) municípios com grande quantidade de Lu. longipalpis para a realização dos bioensaios.

5. Qualquer dúvida ou necessidade de orientação entrar em contato com Douglas de Almeida Rocha, pelo telefone (61) 8590-0569 ou pelo e-mail: dougalmeidarocha@gmail.com ou Marcos T. Obara, pelo telefone (61) 81321514 e e-mail: marcos.obara@gmail.com.

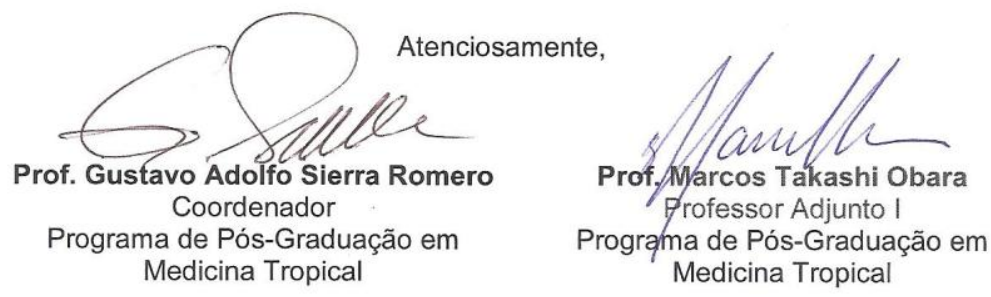

Núcleo de Medicina Tropical, Universidade de Brasilia, CP 04517. Campus Universitário Darcy Ribeiro, Asa Norte, Brasilia, DF. Brasil 70904-970 Fone: +55-61-3107-0081; email: pgtropical@unb.br 


\section{1 \\ Núcleo de Medicina Tropical \\ PROGRAMA DE PÓS-GRADUAÇÃO EM MEDICINA TROPICAL}

\section{PROTOCOLO DE CAPTURA DE FLEBOTOMÍNEOS}

- As populações de Lu. longipalpis provenientes do campo devem ser capturados por meio de armadilhas tipo CDC e/ou Shannon que serão instaladas em locais com maior probabilidade de ocorrência de flebotomíneos, tais como: galinheiros, canis, chiqueiros, entre outros. Serão instaladas um total de 10 armadilhas durante o período crepuscular e retiradas no início da manhã;

- As gaiolas de naylon devem ser retiradas cuidadosamente da parte superior das armadilhas CDCs para evitar a fuga dos flebotomíneos capturados. Após a separação, as gaiolas devem ser acondicionadas em caixas grandes de plástico ou de isopor para proteger as espécies contra ventos fortes, elevada temperatura, intensa luminosidade e quaisquer outros elementos que possam danificar 0 material entomológico;

- Na parte superior da gaiola deve-se colocar um pequeno chumaço de algodão umedecido com solução açucarada (10\%), a fim de alimentar os flebotomíneos durante o trajeto. Ainda, para manter a temperatura estável recomenda-se colocar no interior das caixas papéis toalha umedecido ou cobrir as gaiolas com toalha úmida.

- Todas as amostras enviadas devem apresentar fichas de registros padronizados, contendo os seguintes dados: local de coleta (município, região, Estado, País); data da coleta, nome do coletor e tipo de hábitat. 


\title{
Apêndice 2. Documento oficial da Universidade de Brasília enviada à Secretaria de Saúde de Minas Gerais.
}

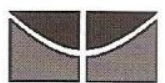 \\ Núcleo de Medicina Tropica \\ PROGRAMA DE PÓS-GRADUAÇÃO EM MEDICINA TROPICAL
}

Carta $n^{\circ}$ 003/2015 - PPGMT/FM/UnB

Brasília, 27 de março de 2015.

\author{
À Senhora \\ Dra. Marcela Lencine Ferraz \\ Diretora de Vigilância Ambiental \\ Secretaria de Estado da Saúde de Minas Gerais - SES/MG \\ Belo Horizonte - MG \\ Assunto: Solicitação de captura de flebotomíneos - vetores das \\ Leishmanioses
}

1. Dirijo-me a Vossa Senhoria para informar que poucos trabalhos têm sido realizados para detectar mudanças na susceptibilidade de populações flebotomínicas, em relação aos inseticidas utilizados no seu controle. A resistência a inseticidas é definida pela Organização Mundial de Saúde como sendo uma característica herdável, portanto genética, ao qual confere um aumento na tolerância a um pesticida, ou grupo de pesticidas, de modo que os indivíduos resistentes sobrevivem à concentração do(s) componente(s) que seriam normalmente letais para a maioria dos indivíduos de uma população da mesma espécie (suscetível).

2. Recentemente, sob a coordenação do Prof. Marcos T. Obara, da Universidade de Brasília (UnB), foi aprovado o projeto, intitulado: "Monitoramento da Resistência de Lutzomyia longipalpis (Diptera: Psychodidae) - principal vetor da leishmaniose visceral, no Brasil", na Chamada Universal- MCTI/CNPQ no 14/2014. Este projeto tem como objetivo caracterizar o perfil de suscetibilidade de diferentes populações naturais de Lu. longipalpis ao piretróide alfacipermetrina utilizado no Programa de Controle das Leishmanioses. A Secretaria de Estado da Saúde de Minas Gerais será parte integrante desta pesquisa que visa promover e fomentar a melhoria contínua dos serviços prestados pelos Laboratórios de Entomologia Médica.

Núcleo de Medicina Tropical, Universidade de Brasília, CP 04517. Campus Universitário Darcy Ribeiro, Asa Norte, Brasília, DF. Brasil 70904-970 Fone: +55-61-3107-0081; email: pgtropical@unb.br 


\section{De \\ Núcleo de Medicina Tropical \\ PROGRAMA DE PÓS-GRADUAÇÃO EM MEDICINA TROPICAL}

3.

De um modo geral, o monitoramento consiste em:

a) Captura de flebotomíneos provenientes de áreas submetidas às ações de controle vetorial.

b) Um total de 300 espécimes de Lu. longipalpis oriundos de campo serão expostos, a pelo menos quatro diluições. Cada prova biológica terá três replicações, em diferentes momentos.

c) A intensidade da resistência será avaliada por meio da proporção de indivíduos suscetíveis e da relação entre a dose e o tempo diagnóstico.

d) A UnB enviará um relatório dos resultados obtidos para órgãos envolvidos, quanto à possivel existência de focos de populações flebotomínicas resistentes.

4. O início do projeto de monitoramento está previsto para o mês de abril deste ano, a principio para Lu. longipalpis. Diante do exposto, solicitamos o apoio para a realização de captura da espécie acima citada. As amostras entomológicas deverão ser enviadas até o laboratório local, de acordo com a metodologia, em anexo. Preferencialmente, recomenda-se a indicação de três (03) municípios com grande quantidade de Lu. longipalpis para a realização dos bioensaios.

5. Qualquer dúvida ou necessidade de orientação entrar em contato com Douglas de Almeida Rocha, pelo telefone (61) 8590-0569 ou pelo e-mail: dougalmeidarocha@gmail.com ou Marcos T. Obara, pelo telefone (61) 81321514 e e-mail: marcos.obara@gmail.com.

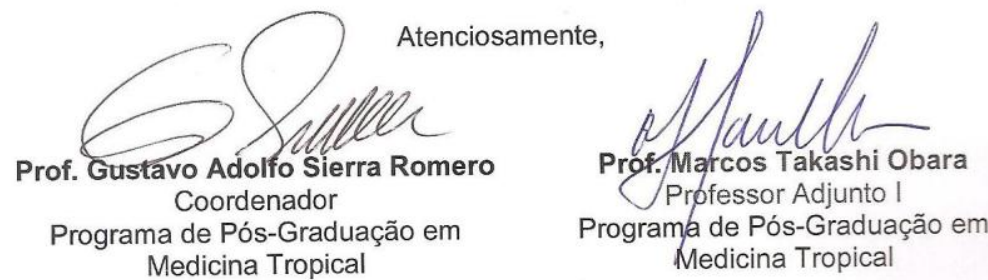

Núcleo de Medicina Tropical, Universidade de Brasília, CP 04517. Campus Universitário Darcy Ribeiro, Asa Norte, Brasília, DF. Brasil 70904-970 Fone: +55-61-3107-0081; email: pgtropical @unb.br 


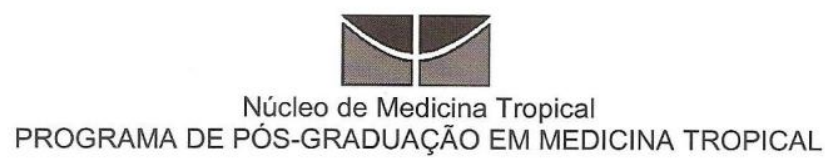

\section{PROTOCOLO DE CAPTURA DE FLEBOTOMÍNEOS}

- As populações de Lu. longipalpis provenientes do campo devem ser capturados por meio de armadilhas tipo CDC e/ou Shannon que serão instalados em locais com maior probabilidade de ocorrência de flebotomíneos, tais como: galinheiros, canis, chiqueiros, entre outros. Serão instaladas um total de 10 armadilhas durante o período crepuscular e retiradas no início da manhã;

- As gaiolas de naylon devem ser retiradas cuidadosamente da parte superior das armadilhas CDCs para evitar a fuga dos flebotomíneos capturados. Após a separação, as gaiolas devem ser acondicionadas em caixas grandes de plástico ou de isopor para proteger as espécies contra ventos fortes, elevada temperatura, intensa luminosidade e quaisquer outros elementos que possam danificar 0 material entomológico;

- Na parte superior da gaiola deve-se colocar um pequeno chumaço de algodão umedecido com solução açucarada (10\%), a fim de alimentar os flebotomíneos durante o trajeto. Ainda, para manter a temperatura estável recomenda-se colocar no interior das caixas papéis toalha umedecido ou cobrir as gaiolas com toalha úmida.

- Todas as amostras enviadas devem apresentar fichas de registros padronizados, contendo os seguintes dados: local de coleta (município, região, Estado, País); data da coleta, nome do coletor e tipo de hábitat.

Núcleo de Medicina Tropical, Universidade de Brasília, CP 04517. Campus Universitário Darcy Ribeiro, Asa Norte, Brasília, DF. Brasil 70904-970Ｆone: +55-61-3107-0081; email: pgtropical@unb.br 
Apêndice 3. Coordenadas geográficas dos pontos de capturas de flebotomíneos.

\begin{tabular}{|c|c|c|}
\hline Município / Bairro & Latitude & Longitude \\
\hline \multicolumn{3}{|l|}{ Unaí-MG } \\
\hline Sagarana & S 16을 $22.4^{\prime \prime}$ & W 046 53' 05.3" \\
\hline Novo Jardim & S 16을 $22^{\prime} 04.0^{\prime \prime}$ & W 0465' $01.3^{\prime \prime}$ \\
\hline Cachoeira & S 16음 $20^{\prime} 58.0^{\prime \prime}$ & W 046 53' 09.2" \\
\hline Água Branca & S 16을 $20^{\prime} 17.3^{\prime \prime}$ & W 046 53' 29.7" \\
\hline Mamoeiro & S 16우 $18^{\prime} 17.4^{\prime \prime}$ & W 046 54' 03.4" \\
\hline Santa Clara & S 16우 $17^{\prime} 15.7^{\prime \prime}$ & W 046 53' 50.4" \\
\hline Kamayurá & S 16을 $24^{\prime} 38.8^{\prime \prime}$ & W 046 54' 05.8" \\
\hline De Lourdes & S 16을 $10.4^{\prime \prime}$ & W 0465ㄴ 54' 11.2" \\
\hline \multicolumn{3}{|l|}{ Paracatu-MG } \\
\hline Nossa Senhora de Fátima & S 17우 13' 31.3" & W 0465 51' 34.6" \\
\hline Povoado São Domingos & S 17우 $12^{\prime} 25.8^{\prime \prime}$ & W 046 51' 38.5" \\
\hline Alto do Açude & S 17우 $12^{\prime} 37.3^{\prime \prime}$ & W 046 51' 35.9" \\
\hline $\mathrm{JK}$ & S 17우 $13^{\prime} 02.3^{\prime \prime}$ & W 046 51' 49.4" \\
\hline Vista Alegre & S 17운 $13^{\prime} 00.3^{\prime \prime}$ & W 046 51' 20.8" \\
\hline \multicolumn{3}{|l|}{ Belo Horizonte-MG } \\
\hline Salgado Filho & S 195' 56.1" & W 043 58' 38.0" \\
\hline Salgado Filho & S 1956' 53.7" & W 043 58' 37.9" \\
\hline Salgado Filho & S 195' $56^{\prime} 48.8^{\prime \prime}$ & W 043 58' 33.7" \\
\hline Salgado Filho & S 19 56' 48.0" & W 043ํㅗ $58^{\prime} 45.1^{\prime \prime}$ \\
\hline \multicolumn{3}{|l|}{ Pirenópolis-GO } \\
\hline Jardim Babilônia & S 15 $51^{\prime} 50.8^{\prime \prime}$ & W 048 58' 14.2" \\
\hline Vila Boa & S 15 $51^{\prime} 45.2^{\prime \prime}$ & W 048 58' 05.1" \\
\hline Vila Matutino & S 15ำ $50^{\prime} 54.5^{\prime \prime}$ & W 048 50' 05.7" \\
\hline Alto do Bonfim & S 15 $51^{\prime} 05.1^{\prime \prime}$ & W 048은 $56^{\prime} 45.1^{\prime \prime}$ \\
\hline Pedreirinha & S 15은 $42.4^{\prime \prime}$ & W 0485' $03.3^{\prime \prime}$ \\
\hline Bonfim & S 15ำ $51^{\prime} 18.5^{\prime \prime}$ & W 048 56' 20.3" \\
\hline Centro & S 15 $51^{\prime} 27.5^{\prime \prime}$ & W 048 57' 24.7" \\
\hline Tatersol & S 15은 $51^{\prime} 41.2^{\prime \prime}$ & W 048 58' 13.3" \\
\hline Caxambú & S 16우 $00^{\prime} 53.4^{\prime \prime}$ & W 049 $02^{\prime} 24.8^{\prime \prime}$ \\
\hline Carmo & S 15 $50^{\prime} 51.5^{\prime \prime}$ & W 048 57' 32.5" \\
\hline Frota & S 15 49' 22.1" & W 048오' 59'40.8" \\
\hline \multicolumn{3}{|l|}{ Montes Claros-MG } \\
\hline Morrinhos & S 16ㅇ' $44^{\prime} 04.7^{\prime \prime}$ & W 043 51' 42.3" \\
\hline Morrinhos & S 16우 $43^{\prime} 59.5^{\prime \prime}$ & W 043 51' 58.3" \\
\hline Maracanã & S 16 $45^{\prime} 40.9^{\prime \prime}$ & W 043 51' 50.0" \\
\hline Amazonas & S 16운 $41^{\prime} 52.9^{\prime \prime}$ & W 043ํ5' 53.0" \\
\hline \multicolumn{3}{|l|}{ Januária-MG } \\
\hline Coqueiro & S 15을 $25^{\prime} 5.6^{\prime \prime}$ & W 044 24' 39.7" \\
\hline Brejo do Amparo & S 15을 $26^{\prime} 31.4^{\prime \prime}$ & W 044 24' 06.6" \\
\hline Sítio & S 15은 $35^{\prime} 37.0^{\prime \prime}$ & W 044은 24. 24.4" \\
\hline Limeira & S 15을 $05.2^{\prime \prime}$ & W 044을 $23^{\prime} 04.5^{\prime \prime}$ \\
\hline
\end{tabular}


Apêndice 4. Ficha de resultados do bioensaio com garrafa.

Ficha de resultados do bioensaio com garrafa

Data:

Inseticida:

Local de coleta:

Dosagem:

Dados de campo:

\begin{tabular}{|c|c|c|c|c|c|c|c|c|c|c|}
\hline \multirow{2}{*}{$\begin{array}{c}\text { Tempo } \\
\text { (Min) }\end{array}$} & \multicolumn{2}{|c|}{ Controle } & \multicolumn{2}{c|}{ Frasco 1 } & \multicolumn{2}{c|}{ Frasco 2 } & \multicolumn{2}{c|}{ Frasco 3 } & \multicolumn{2}{c|}{ Frasco 4 } \\
\hline 0 & & & & & & & & & & \\
\hline 10 & & & & & & & & & & \\
\hline 20 & & & & & & & & & & \\
\hline 30 & & & & & & & & & & \\
\hline 40 & & & & & & & & & & \\
\hline 50 & & & & & & & & & & \\
\hline 60 & & & & & & & & & & \\
\hline 70 & & & & & & & & & & \\
\hline 80 & & & & & & & & & & \\
\hline 90 & & & & & & & & & & \\
\hline 100 & & & & & & & & & & \\
\hline 110 & & & & & & & & & & \\
\hline 120 & & & & & & & & & & \\
\hline 06 & & & & & & & & & & \\
\hline
\end{tabular}




\section{Caracterização da suscetibilidade de Phlebotominae (Diptera:}

Psychodidae) ao inseticida alfacipermetrina

Douglas de Almeida Rocha ${ }^{1}$, Andrey José de Andrade ${ }^{2}$, Luciana Moura Reinaldo ${ }^{3}$ e Marcos Takashi Obara ${ }^{1}$.

marcos.obara@gmail.com

1- Núcleo de Medicina Tropical, Universidade de Brasília; 2- Laboratório de Parasitologia Médica e Biologia de Vetores, Faculdade de Medicina, Universidade

de Brasília; 3- Departamento de Estatística - Instituto de Ciências Exatas, Universidade de Brasília

Apoio financeiro da Coordenação de Aperfeiçoamento de Pessoal de Nível Superior (CAPES).

\section{Resumo}

Caracterização da suscetibilidade de Phlebotominae (Diptera: Psychodidae) ao inseticida alfacipermetrina

As leishmanioses representam um conjunto de doenças infecciosas, que são transmitidas principalmente pela picada de flebotomíneos. Uma das medidas de controle dessas enfermidades é combate aos vetores por meio de inseticidas. Apesar das contínuas e intensivas campanhas de controle contra os flebotomíneos poucos estudos têm sido realizados para detectar mudanças na suscetibilidade de populações desses insetos, em relação aos inseticidas utilizados no seu controle. O objetivo do estudo foi caracterizar o 
perfil de suscetibilidade de populações naturais de flebotomíneos ao piretróide alfacipermetrina. Flebotomíneos de seis municípios brasileiros foram avaliados pela metodologia de garrafas do CDC para diferentes dosagens ( $3 \mathrm{ug} / \mathrm{ml}, 5 \mathrm{ug} / \mathrm{ml}, 7 \mathrm{ug} / \mathrm{ml}$ e $9 \mathrm{ug} / \mathrm{ml}$ ) do inseticida alfacipermetrina. Ao todo 2.198 flebotomíneos foram utilizados nos bioensaios. A espécie Lutzomyia longipalpis foi a mais capturada em todos os municípios. A dose ideal para diagnóstico nas alterações de suscetibilidade ao inseticida alfacipermetrina foi de 2,38 ug/ml. O tempo diagnóstico variou conforme as concentrações do inseticida sendo de 40 minutos para a dosagem de 9 $\mathrm{ug} / \mathrm{ml}, 50$ minutos para a dosagem de $7 \mathrm{ug} / \mathrm{ml}, 60$ minutos para a dosagem de $5 \mathrm{ug} / \mathrm{ml}$ e 70 minutos para a dosagem de $3 \mathrm{ug} / \mathrm{ml}$. As curvas de sobrevivência de KM apontaram que as populações de flebotomíneos de Montes Claros e Paracatu possuem maior tolerância a inseticidas, seguida da população de Pirenopolis e Unaí. Populações de flebotomíneos de Januária de Belo Horizonte mostraram menores taxas de sobrevivência. As populações de flebotomíneos oriundas dos municípios de Unaí, Paracatu, Belo Horizonte, Pirenópolis, Montes Claros e Januária, assim como a LSR apresentaram alterações nos perfis de suscetibilidade, indicando tolerância ao piretróide alfacipermetrina

Descritores: Flebotomíneos, Leishmanioses, Resistência, Bioensaios de garrafa, Piretróide.

Abstract 
Characterization of susceptibility Phlebotominae (Diptera: Psychodidae) to alphacypermetrin insecticide

Leishmaniases present a group of infectious diseases primarily transmitted by phlebotomine sand flies bites. One of the control measures of these diseases are chemical insecticides used against the vectors. Despite of the continuous and intensive control campaigns few studies have been carried out to detect changes in the susceptibility of sand flies by insecticides used in your control. Objective: Characterize the susceptibility profile of populations of sand flies to alphacypermetrin pyrethroid. Sand flies caught in six Brazilian municipalities and specimens of laboratory classified as Susceptible Strain Reference (SSR) were evaluated using CDC bottles trough different concentrations of alphacypermetrin ( $3 \mathrm{ug} / \mathrm{ml}, 5 \mathrm{ug} / \mathrm{ml}, 7 \mathrm{ug} / \mathrm{ml}$ and $9 \mathrm{ug} / \mathrm{ml}$ ). As control was used acetone P.A. A total of 2,198 sand fly specimens were used in bioassays and Lutzomyia longipalpis was the species most caught in all municipalities. Change in the susceptibility for alphacypermetrin was of $2.38 \mathrm{ug} / \mathrm{ml}$. Diagnosis time varied according to the insecticides concentrations: 40 minutes for $9 \mathrm{ug} / \mathrm{ml}, 50 \mathrm{~min}$. for $7 \mathrm{ug} / \mathrm{ml}, 60 \mathrm{~min}$. for 5 $\mathrm{ug} / \mathrm{ml}$ and $70 \mathrm{~min}$. for $3 \mathrm{ug} / \mathrm{ml}$. Sand fly populations of the municipalities of Unaí, Paracatu, Belo Horizonte, Pirenópolis, Montes Claros and Januária, as well as the SSR specimens showed changes in susceptibility profiles, indicating tolerance a alphacypermetrin. 
Key words: Phlebotomine sand flies, Leishmaniases, Resistence, Bottle bioassay, Pyrethroid.

\section{Introdução}

As leishmanioses representam um conjunto de doenças infecciosas, consideradas zoonoses, causadas por diferentes espécies de protozoários flagelados, os quais apresentam ciclo de vida heteroxênico, vivendo alternadamente em hospedeiros vertebrados (mamíferos e répteis) e insetos vetores, estes últimos, responsáveis pela transmissão das leishmânias (Lainson \& Shaw, 1973). São um grave problema de saúde pública, estando registradas em 98 países, onde 74 são endêmicos para Leishmaniose Visceral (LV) e 82 para Leishmaniose Tegumentar (LT), distribuídas por quatro continentes (Américas, Europa, África e Ásia). Atualmente, cerca de 350 milhões de pessoas estão expostas a essas enfermidades em todo mundo (Alvar et al., 2012).

Até o momento, não existe nenhuma vacina eficaz e segura contra as leishmanioses. Dessa forma as medidas de prevenção e controle baseiamse no diagnóstico precoce e tratamento dos casos humanos, realização de inquéritos sorológicos nas populações caninas seguidos da eliminação dos animais soropositivos e controle químico dos vetores (Brasil, 2006a).

No Brasil, as primeiras tentativas de controle químico de flebotomíneos, ocorreram durante uma campanha no ano de 1953, por meio de pulverização residual com o inseticida organoclorado dietildicloro difeniltricloroetano (DDT) (Monteiro et al., 1994). Em 1954, Nery-Guimarães 
\& Bustamante (1954) avaliaram o efeito da aplicação do DDT em um foco de LV, no estado do Rio de Janeiro. Este mesmo inseticida também foi usado nas ações de controle da espécie Lutzomyia longipalpis no estados do Ceará e Minas Gerais nas décadas de 50 e 60 (Oliveira-Filho \& Melo, 1994). Em 1964, o uso de inseticidas residuais foi interrompido, devido aos altos custos operacionais. Uma nova campanha recomeçou no início dos anos 80, quando um grande número de casos de LV foi notificado (Monteiro et al., 1994; Brasil, 1999). O DDT, devido aos diversos questionamentos, tais como: elevada toxicidade para o ser humano e animais domésticos, custo operacional relativamente alto, necessidade de replicações frequentes e sua inativação pelo barro das paredes foi, gradativamente, sendo substituído pelo uso dos piretróides, desde o fim dos anos 80 e início da década de 90, sendo aplicados principalmente, em locais que possa haver focos de flebotomíneos.

Com o aumento contínuo dos casos de leishmanioses, e um histórico de controle químico específico de mais de 60 anos, o monitoramento da suscetibilidade de flebotomíneos a inseticidas, principalmente em áreas endêmicas, torna-se fundamental para aprimorar as ações de controle vetorial, no Brasil. O objetivo deste trabalho foi caracterizar o perfil de suscetibilidade de populações naturais de flebotomíneos ao piretróide alfacipermetrina utilizados nos Programas de Controle Estaduais e Municipais das Leishmanioses.

\section{Material e métodos}




\section{Flebotomíneos}

Espécimes de Lu. longipalpis suscetíveis (sem possível resistência ao inseticida), foram provenientes de criações obtidas no Laboratório de Fisiologia de Insetos Hematófagos (LFIH) da Universidade Federal de Minas Gerais (UFMG) oriundas de Teresina, Piauí. Como preconizado da Organização Panamericana de Saúde (OPAS) (OPAS, 2005) esses espécimes atendiam os critérios para ser uma linhagem suscetível de referência (LSR).

Os flebotomíneos de campo foram capturados em áreas endêmicas tratadas com inseticidas, nas quais os Programas Estaduais de Controle das Leishmanioses realizam aplicações contínuas e sistemáticas com inseticidas de ação residual. A seleção dos municípios para as atividades de captura obedeceu aos seguintes critérios: i) a realização de um programa específico de controle de vetores; ii) antecedentes históricos de controle de outros vetores dentro da mesma área geográfica; iii) uso de inseticidas com finalidades agrícolas na mesma área, onde se localizam os vetores e iv) uso doméstico de inseticidas.

\section{Áreas de estudo}

Em Minas Gerais foram selecionados os municípios de Belo Horizonte

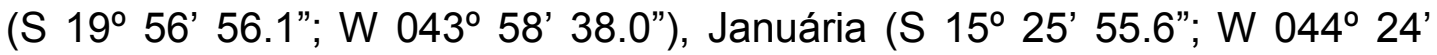

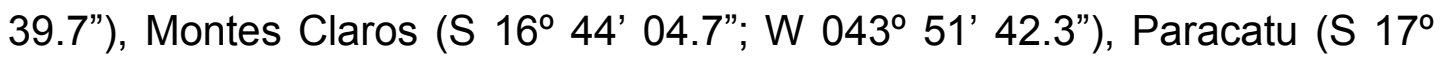
13' 31.3"; W $046^{\circ} 51^{\prime} 34.6^{\prime \prime}$ ) e Unaí (S $16^{\circ} 22^{\prime} 22.4^{\prime \prime}$; W $046^{\circ} 53^{\prime} 05.3^{\prime \prime}$ ) no estado de Goiás, o município de Pirenópolis (S 15 51' 50.8”; W $048^{\circ} 58^{\prime}$ 
14.2"). Os locais de coleta, em cada município, foram pré-selecionados pelos agentes de endemias da localidade, com base em casos humanos e caninos de LV e/ou na probabilidade de maior ocorrência de flebotomíneos.

\section{Captura dos flebotomíneos}

Gaiolas de nylon foram acopladas às armadilhas luminosas, dos tipos HP (Pugedo et al., 2005) e CDC (Sudia \& Chamberlain, 1962) instaladas no

crepúsculo e retiradas no início da manhã, acondicionadas para manter a umidade e transportadas para os pontos de apoio disponíveis em cada um dos municípios estudados.

Os flebotomíneos foram contabilizados e separados em cinco capturadores de castro, fechados com algodão embebidos em água com açúcar (30\%) e mantidos no escuro por duas horas, para aclimatação dos insetos até o bioensaio.

\section{Ensaios biológicos}

Os ensaios biológicos foram realizados conforme a metodologia de garrafas de Brogdon \& Chan (2010). Garrafas do tipo Wheaton de $250 \mathrm{ml}$, foram revestidas com $1 \mathrm{ml}$ de acetona (controle) ou de inseticida nas dosagens de $3 \mathrm{ug} / \mathrm{ml}, 5 \mathrm{ug} / \mathrm{ml}, 7 \mathrm{ug} / \mathrm{ml}$ e $9 \mathrm{ug} / \mathrm{ml}$, e os frascos foram girados de modo que todo seu interior tenha sido revestido pelas soluções. Após a impregnação, as garrafas foram abertas, para evitar condensação, e ficaram armazenadas em locais protegidos da luz durante 24 horas. 
Os flebotomíneos machos e fêmeas foram introduzidos nas garrafas com auxílio de pequenos funis para evitar o escape dos insetos. Em média, 18 insetos foram testados por frasco para avaliação da taxa de mortalidade. Após a introdução dos insetos no frasco controle e em cada frasco teste, se deu início uma contagem de $2 \mathrm{~h}$ de exposição. A cada 10 minutos, os frascos foram avaliados para contagem de quantos flebotomíneos permaneciam vivos. Para cada localidade, os bioensaios biológicos foram repetidos três vezes e a leitura de mortalidade foi realizada por um único pesquisador.

Em quatro municípios (Belo Horizonte, Pirenópolis, Montes Claros e Januária) e na população de referência, após os bioensaios, os flebotomíneos foram transferidos para potes com presença de algodão umedecido e solução açucarada (30\%), por 24 horas, para avaliação de possíveis efeitos "knock-down".

\section{Identificação dos flebotomíneos}

Após os testes, os flebotomíneos foram armazenados em álcool 70\% e levados ao Laboratório de Parasitologia Médica e Biologia de Vetores da Faculdade de Medicina da Universidade de Brasília para posterior identificação. Machos e fêmeas foram montados e clarificados, segundo Forattini (1973) e identificados utilizando a proposta de Galati (2015). A abreviação dos gêneros seguiu a proposta de Marcondes (2007).

As fêmeas foram dissecadas e partes do corpo (asa, tórax, pernas e parte do abdômen) foram estocadas para futuras análises genéticas de 
resistência (dados não apresentados). Todos os espécimes encontram-se no referido laboratório da UnB.

\section{Análise estatística}

As doses letais que matam $50 \%\left(\mathrm{DL}_{50}\right)$ dos flebotomíneos expostos e a razão de resistência $\left(R_{50}\right)$ de cada localidade foram estimadas utilizando o programa Basic Probit Analisys. Os tempos letais (TL) para cada população foram inferidos por meio da análise das taxas de mortalidade. As curvas de sobrevivência das populações de flebotomíneos foram inferidas pela análise de Kaplan-Meier (KM) (2002), utilizando o programa estatístico R 3.0.2.

\section{Resultados}

Ao todo 2.198 flebotomíneos foram utilizados nos ensaios biológicos com garrafas distribuídos em oito gêneros e 16 espécies. A espécie $L u$. longipalpis foi a mais frequente em todos os municípios (Tabela 1).

A $\operatorname{DL}_{50}$ da população de referência (UFMG) foi de $2,38 \mathrm{ug} / \mathrm{ml}$ de alfacipermetrina. Em Montes Claros a $D_{50}$ foi $1,03 \mathrm{ug} / \mathrm{ml}$, em Paracatu foi de 1,31, em Januária foi de 2,53 e em Pirenópolis, a $\mathrm{DL}_{50}$ foi de $3,87 \mathrm{ug} / \mathrm{ml}$. Montes Claros, Paracatu e Januária tiveram $R_{50}$ menor que $1\left(R_{50}<1\right)$, ou seja, menores que a $\mathrm{RR}_{50}$ da população de referência. Pirenópolis teve $R R_{50}$ de $1,62\left(R R_{50}>1\right)$ (Tabela 2). 
O TL variou entre as dosagens de cada população e entre as populações das diferentes localidades. Na população da UFMG, os flebotomíneos alcançaram o TL $L_{50}$ entre 40 e 100 minutos de exposição. Em Belo Horizonte, o TL 50 variou entre 20 e 50 minutos. No município de Pirenópolis, a variação do $\mathrm{TL}_{50}$ foi de 40 a 100 minutos. Em Montes Claros, o $\mathrm{TL}_{50}$ foi alcançado com 60 e 90 mintuos de exposição. Em Januária, essa variação foi de 20 a 60 minutos. Somente a população de Belo Horizonte alcançou o $\mathrm{TL}_{95}$ e este variou de 60 a 90 minutos de exposição (Tabela 3).

As curvas de sobrevivência de $\mathrm{KM}$ demonstram o perfil de suscetibilidade em relação à somatória de todos os flebotomíneos expostos e as dosagens utilizadas, conforme mostra a Figura 1. A população de flebotomíneos da UFMG obteve a maior taxa de sobrevivência, seguida das populações de Paracatu, Montes Claros, Pirenópolis, Unaí, Januária e Belo Horizonte. Na Figura 2 estão representadas as taxas de sobrevivência de todas as populações, em relação às doses de $3,5,7$, e $9 \mathrm{ug} / \mathrm{ml}$, incluindo o grupo controle. Nessa mesma figura, é possível observar um aumento gradativo da mortalidade, a medida que as dosagens elevam-se, confirmando a validade do experimento. Esse comportamento das curvas se manteve por todo o período de exposição, havendo sobreposição das curvas em alguns momentos.

\section{Discussão}

Em um primeiro momento a espécie alvo do trabalho foi Lutzomyia longipalpis e para tal optou-se por coletas quando a densidade da mesma 
estivesse alta nos referidos municípios, segundo informações do órgãos de saúde locais. Como observado na Tabela 1, à espécie Lu. longipalpis predominou em todas as áreas, porém com baixa densidade em alguns municípios como Belo Horizonte, Januária e Pirenópolis não sendo suficientes para a realização das tréplicas experimentais propostas. Dessa forma optou-se por avaliar os tratamentos sobre Phlebotominae, dado que outras espécies, incluindo importantes vetores de espécies de leishmânia causadoras de LT como Nyssomyia whitmani, Ny. neivai e Ny. intermedia também foram identificadas.

Brogdon \& Chan (2010) afirmaram que se 95\% dos espécimes testados forem de uma espécie predominante, o teste pode ser considerado válido para aquela determinada espécie. Caso não ocorra essa predominância, os autores sugerem que uma pré-identificação seja feita antes do bioensaio por meio de sedação dos insetos com acetato etílico. Após a identificação, os insetos seriam separados especificamente e testados. Porém, para identificação específica de flebotomíneos utiliza-se a morfologia interna e os mesmos devem der montados entre lâmina e lamínula e visualizados com auxílio de microscopia ótica. Recomenda-se assim que a avaliação de suscetibilidade de populações de flebotomíneos de campo a um determinado inseticida seja desenvolvida de maneira geral e não específica como ocorre com outros insetos vetores, dado que a morfologia externa não pode ser utilizada para uma identificação taxonômica segura e precisa. 
Durante os experimentos os flebotomíneos não foram sexados. Como somente as fêmeas são responsáveis pela transmissão de patógenos, parte dos poucos estudos de resistência com esse grupo de insetos não utilizam machos. Alexander et al. (2009) notaram que machos de Lu. longipalpis se mostraram mais suscetíveis do que fêmeas, para malation, permetrina e fenitrotion, já as fêmeas foram mais suscetíveis para deltametrina e lambdacialotrina. Dinesh et al. (2008), verificaram que machos de Ph. argentipes se mostraram mais suscetíveis à permetrina do que flebotomíneos fêmeas. Essas diferenças poderiam influenciar na escolha de inseticida ideal para programas de saúde que visem o controle das leishmanioses, particularmente no caso de Lu. longipalpis onde se sabe que o macho atrai a fêmea para a cópula indicando por meio de sinais químicos (feromônios, batimento de asas) o local para hematofagia (Soares \& Turco, 2003). No Velho Mundo, Li et al. (2015) avaliaram a suscetibilidade de machos de Ph. papatasi e Ph. duboscqi para cipermetrina, deltametrina, ciflutrina, lambdacialotrina, permetrina, praletrina, clorpirifós, coumafós, diazinon e diclorvós, e indicam o uso de machos em bioensaios de suscetibilidade.

No presente estudo, os flebotomíneos foram considerados mortos quando estavam totalmente imóveis. Porém, foi observada frequentemente a perda das pernas dos flebotomíneos durante os bioensaios, fenômeno relatado por Alexander et al. (2009) quando espécimes de Lu. longipalpis foram expostos a inseticidas piretróides.

O critério de mortalidade adotado neste estudo foi preconizado por Brogdon \& Chan (2010), para avaliação da suscetibilidade a inseticidas em 
mosquitos e também foi utilizado por Delinger et al. (2015) em bioensaios com flebotomíneos. Critérios de mortalidade que consideram efeitos subletais foram adotados em avaliações de suscetibilidade de triatomíneos (Hemiptera: Reduviidae). Nestes trabalhos, triatomíneos com sinais de paralisia e falta de resposta a estímulos externos foram considerados mortos (Gomez et al.,; Pessoa et al., 2015).

De acordo com a OPAS (2005) populações de triatomíneos com RR > 5 são considerados resistentes a um determinado inseticida testado. Para as populações do mosquito Aedes aegypti a RR $>3$ permite classificar como sendo resistentes (Brasil, 2006b). Ressalta-se que não há classificação de RR específica para os vetores de Leishmania que possa definir com precisão uma possível resistência a inseticidas, tornando-se indispensáveis estudos de várias populações para estabelecer uma linha de base para comparação entre suscetível e resistente. Neste estudo, a maior RR foi encontrada na população de Pirenópolis, $\mathrm{RR}_{50}$ de 1,62, sendo considerada, por este parâmetro, como suscetível ao inseticida alfacipermetrina.

Os flebotomíneos provenientes de Unaí, Januária e Pirenópolis apresentaram uma alta taxa de mortalidade para o controle de $30 \%, 39 \%$ e 44\%, respectivamente. Embora Brogdon e Chan (2010) recomendem, para culicídeos, o descarte de bioensaios onde a mortalidade observada no controle seja superiores a 10\%, no presente estudo essa padronização não foi considerada devido ao baixo número de flebotomíneos coletados nos municípios, particularmente devido à sua flutuação populacional, à dificuldade de criação e à dependência da rotina dos serviços de saúde. A 
acetona utilizada como diluente no grupo controle pode ter interferido na taxa de mortalidade dos espécimes para as localidades acima citadas, pois sabe que a mesma possui efeito anestésico sobre insetos, os quais se expostos durante muito tempo morreriam. Garrafas impregnadas com deltametrina e lambda-cialotrina diluídas em acetona mostraram repelência em pesquisa de suscetibilidade para a espécie Pi. evansi. Porém, as garrafas impregnadas com os mesmos inseticidas misturados em álcool não interferiram no comportamento dos insetos (Henriquez et al., 2009).

Como relatado acima, durante a execução do trabalho algumas limitações impediriam uma implementação eficaz e imediata dos resultados obtidos, ao mesmo tempo em que oferece ferramentas para futuros estudos visando o controle desses vetores. Os flebotomíneos provenientes de Pirenópolis, foram os únicos espécimes estudados que apresentaram valores de $D L_{50}$ e $R R_{50}$ maiores que da população de referência $\left(R R_{50}>1\right)$, mostrando-se pela $\mathrm{RR}$, aparentemente, mais resistentes à alfacipermetrina do que os flebotomíneos usados como referência (UFMG). Em Pirenópolis a maioria dos flebotomíneos testados no bioensaio foram Lu. longipalpis, porém, o resultado da $\mathrm{DL}_{50}$ de 1,62 pode ter sido influenciado pela presença de outras sete espécies detectadas após a identificação. As populações de Paracatu, Montes Claros e Januária tiveram valores de $\mathrm{DL}_{50}$ e $\mathrm{RR}_{50}$ menores que da população de referência $\left(R_{50}<1\right)$. Essa alta taxa de mortalidade das populações de campo pode estar ligada ao pouco tempo de aclimatação dos espécimes (2 horas) antes da realização dos experimentos. De Silans et al. (1998) avaliando populações de Lu. longipalpis de campo, deixou os 
espécimes aclimatando por 12 horas. Hassan et al. (2012) e Maroli et al. (2002) avaliaram perfis de suscetibilidade de flebotomíneos do gênero Phlebotomus, testando f1 e f3, respectivamente. As populações de flebotomíneos de Unaí e Belo Horizonte não tiveram seus valores de $\mathrm{DL}_{50}$ e $\mathrm{RR}_{50}$ calculados, talvez, por vieses pontuais ocorridos nestes municípios. No primeiro, o umedecimento de algumas garrafas fez com que alguns flebotomíneos ficassem aderidos nas paredes dos frascos. Para a população de Belo Horizonte, devido a um viés logístico, as armadilhas eram desinstaladas entre 8 h30 e 10 horas da manhã. O elevado tempo de exposição dos flebotomíneos aos raios solares, durante o período da manhã, poderia ter influenciado nas estimativas de mortalidade e sobrevivência neste município.

Maroli et al. (2002) avaliando TL em populações de Ph. papatasi e $P h$. perniciosus para os inseticidas permetrina, lambda-cialotrina e DDT, verificou que o $\mathrm{TL}_{50}$ variou de 3 a 20 minutos de exposição, dependendo do inseticida e da espécie exposta. Para o $\mathrm{TL}_{95}$, os valores variaram de 43 a 258 minutos. Neste estudo, o $\mathrm{TL}_{50}$ variou 20 a 100 minutos, dependendo da dosagem utilizada e da população analisada. Para o TL ${ }_{95}$, essa variação foi de 60 a 110 minutos. A maioria dos estudos de suscetibilidade de flebotomíneos a inseticida visam encontrar a dose/mortalidade. Portanto, comparações de tempo/mortalidade são difíceis de serem avaliadas.

De forma geral, as curvas de sobrevivência de Kaplan-Meier para todas as populações mostraram uma maior mortalidade nas populações de 
campo, quando comparadas à população de referência. Pessoa et al. (2014), avaliando o perfil e suscetibilidade de Triatoma sordida a deltametrina, registraram três populações de campo mais resistente do que a população de laboratório. Os autores acreditam que estes insetos já possuíam alelos de resistência quando foram coletados, e que estes alelos foram mantidos nas gerações seguintes. Este fato pode ter se repetido com a população de Lu. longipalpis da UFMG. Apesar do fato da LSR ser criada e mantida em colônia desde 2006, nota-se que a sua origem foi o estado do Piauí, especificamente do município de Teresina. Portanto, no passado essa população pode ter sofrido intensas exposições a inseticidas, considerandose que são provenientes de áreas endêmicas de LV e LTA.

A Organização Mundial de Saúde (1998) preconizou que uma taxa de mortalidade superior a $98 \%$ indica uma população suscetível. A mortalidade entre 80 e 97\%, sugere a possibilidade de resistência e recomenda novos estudos para confirmação. Mortalidade inferior a $79 \%$ sugere resistência dos insetos estudados. Essa classificação é baseada e utilizada em bioensaios de mosquitos dos gêneros Aedes e Anopheles, porém foi adotada na classificação da resistência de algumas espécies de flebotomíneos (Delinger et al., 2008). Seguindo essa classificação, com exceção da população de Belo Horizonte, o presente estudo mostrou indícios de resistências, ou seja, os municípios apresentaram populações de flebotomíneos com alterações na suscetibilidade, indicando provável tolerância, especificamente ao piretróide alfacipermetrina. Porém, a interpretação desses resultados exige cautela, necessitando de estudos complementares, como por exemplo, a 
realização de bioensaios de campo para avaliar a eficiência e o impacto das ações de controle químico nos municípios pesquisados.

\section{Conclusões}

As populações de flebotomíneos oriundas dos municípios de Unaí, Paracatu, Belo Horizonte, Pirenópolis, Montes Claros e Januária, assim como a LSR apresentaram alterações nos perfis de suscetibilidade, indicando tolerância ao piretróide alfacipermetrina. Esses resultados poderão subsidiar o Programa Nacional de Controle das Leishmanioses do Ministério da Saúde do Brasil na implantação de uma rede de monitoramento de resistência de flebotomíneos a inseticidas utilizados no progama de controle vetorial.

\section{Agradecimentos}

Ao Dr. Rodrigo Gurgel Gonçalves e à Dra. Liléia Gonçalves Diotaiuti pela disponibilização dos laboratórios para a realização dos bioensaios de garrafas e análise da fauna flebotomínica. À Secretaria de Saúde de Minas Gerais e as Gerências de Saúde de Unaí, Paracatu, Belo Horizonte, Montes Claros e Januária, como também, à Secretaria de Saúde de Goiás e a Gerência de Saúde de Pirenópolis por viabilizarem as coletas de flebotomíneos e disponibilizarem laboratórios para realização dos bioensaios. À Dra. Grasielle Caldas D'Ávila Pessoa pelos auxílios e ensinamentos durante a realização dos bioensaios.

\section{Referências}


Alexander B, Barros VC, De Souza SF, Teodoro LP, Soares ZR, Gontijo NF, Reithinger R. Suscetibility to chemical insecticides of two Brazilian populations of the visceral leishmaniasis vector Lutzomyia longipalpis (Diptera: Psychodidae). Trop Med Inter Health 14:1272-1277, 2009.

Alvar J, Velez ID, Bern C, et al. Leishmaniasis worldwide and global estimates of its incidence. PLoS One 7:e35671, 2012.

Brasil. Ministério da Saúde. Secretaria de Vigilância em Saúde. Manual de Vigilância e Controle da Leishmaniose Visceral. 1a․ Edição. Brasília-DF: editora do Ministério da Saúde, 2006. 120p.- (Série A. Normas e Manuais Técnicos), 2006a.

Brasil. Ministério da Saúde. Secretaria de Vigilância em Saúde. Coordenação geral do Programa Nacional do Controle de Dengue. Reunião Técnica paradiscutir o status de resistência de Aedes aegypti aos inseticidas. Brasília: Ministério da Saúde, 2006b.

Brasil. Ministério da Saúde. Evolução temporal das doenças de notificação compulsória no Brasil de 1980 a 1998. Boletim Epidemiológico 3: 15-17, 1999.

Brogdon WG, Chan A. Diretriz para avaliar a resistência a inseticida em vetores usando bioensaio com garrafas do CDC 28 pp, 2010.

Bustamante-Teixeira MT, Faerstein E, Latorre MR. Survival analysis techniques. Cad Saúde Pública 18: 579-594, 2002.

De Silans LN, Dedet JP, Arias JR. Field monitoring of cypermethrin residual effect on the mortality rates of the Phlebotomine sand fly Lutzomyia longipalpis in the state of Paraiba, Brazil. Mem Inst Oswaldo Cruz 93: 339344, 1998.

Deane LM, Deane MP, Alencar JE. Observações sobre o combate ao Phlebotomus longipalpis pela dedetização domiciliária em focos endêmicos de calazar, Ceará. Rev Bras Malariol Doenças Trop 7:131-141, 1955. 
Denlinger DS, Lozano-Fuentes S, Lawyer PG, Black WC 4th, Bernhardt SA. Assessing Insecticide Susceptibility of Laboratory Lutzomyia longipalpis and Phlebotomus papatasi Sand Flies (Diptera: Psychodidae: Phlebotominae). J Med Entomol 52(5):1003-1012, 2015.

Dinesh DS, Das P, Picado A, Davies C, Speybroeck N, Ostyn B, Boelaert $M$, Coosemans $M$. Long-lasting insecticidal nets fail at household level to reduce abundance of sandfly vector Phlebotomus argentipes in treated houses in Bihar (India). Trop Med Int Health 13(7):953-8, 2008.

Forattini, OP. Entomologia Médica. Psychodidae. Phlebotominae. Leishmanioses. Bartonelose. São Paulo: Ed. Edgard Blücher 658p, 1973.

Galati, EAB. 2015. Apostila de bioecologia e identificação de Phlebotominae (Diptera, Psychodidae) - Departamento de Epidemiologia p. 127, Faculdade de Saúde Pública da USP, São Paulo, Brasil. (http://www.fsp.usp.br/egalati) (acessado em: 21 Dez 2015).

Gomez MB, Pessoa GCD, Rosa ACL, Echeverria JE, Diotaiuti L. Inheritance and heritability of deltamethrin resistance under laboratory conditions of Triatoma infestans from Bolivia. Parasit Vectors 8: 595, 2015.

Hassan MM, Widaa SO, Osman OM, Numiary MSM, Ibrahim MA, Abushama HM. Insecticide resistance in the sand fly, Phlebotomus papatasi from Khartoum State, Sudan. Parasit Vectors 5:46, 2012.

Henriquez C, Pereira Y, Cochero S, Bejarano EE. Dosis diagnóstica y umbral de resistencia de Lutzomyia evansi (Diptera: Psychodidae), a dos insecticidas utilizados en salud pública en Colombia: deltametrina y lambdacihalotrina. Rev Soc Entomol Argent 68(3-4): 287-294, 2009.

Lainson R, Shaw JJ. Leishmanias and leishmaniasis of the New World, with particular reference to Brazil. Bull Pan Am Health Org 7(4): 1-19, 1973.

Li AY, Péres de Léon AA, Linthicum KJ, Britch SC, Bast JD, Debboun M. Baseline Susceptibility to Pyrethroid and Organophosphate Insecticides in 
Two Old World Sand Fly Species (Diptera: Psychodidae). Us Army Med Dep J Jul-Sep: 3-9, 2015.

Marcondes, CB. A proposal of generic and subgeneric abbreviations for phlebotomine sandflies (Diptera: Psychodidae: Phlebotominae) of the world. Entomological News 118: 351-356, 2007.

Maroli M, Cianchi T, Bianchi R, Khoury C. Testing insecticide susceptibility of Phlebotomus perniciosus and P. papatasi (Diptera: Psychodidae) in Italy. Ann Ist Super Sanita 38(4):419-423, 2002.

Monteiro PS, Lacerda MM, Arias JB. Controle da leishmaniose visceral no Brasil. Rev Soc Bras Med Trop 27 (Suppl. 2): 67-72, 1994.

Nery-Guimarães F, Bustamante FM. Aplicação domicilaria de DDT como base da profilaxia das leishmanioses - Estudo de um foco de leishmaniose mucocutânea cinco anos depois da aspersão periódica com aquele inseticida. Rev Bras Malariol Doenças Trop 6: 127-130, 1954.

Oliveira-Filho AM, Melo MTV. Vectors control importance on leishmaniasis transmission. Mem Inst Oswaldo Cruz 89: 451-6, 1994.

OMS. Organização Mundial de Saúde. Test procedures for insecticide resistance monitoring in malaria vectors, bioefficacy and persistence of insecticides on treated surfaces. WHO/CDS/CPC/MAL/98.12, Geneva, pp. 43, 1998.

OPAS. Organização Pan Americana de Saúde. II Reunion tecnica latinoamericana de monitoreo de resistencia a insecticidas em triatominos vectores de Chagas. Panamá, 11 a 13 de abril de 2005.

Pessoa GCD, Dias LS, Diotaiuti L. Deltamethrin pyrethroid susceptibility characterization of Triatoma sordida Stål, 1859 (Hemiptera: Reduviidae) populations in the Northern Region of Minas Gerais, Brazil. Rev Soc Bras Med Trop 47(4):426-429, 2014. 
Pessoa GCD, Pinheiro LC, Ferraz ML, Mello BV, Diotaiuti L. Standardization of laboratory bioassays for thestudy of Triatoma sordida susceptibility to pyrethroid insecticides. Parasit Vectors 8: 109, 2015.

Pugedo H, Barata RA, França-Silva JC, Silva JC, Dias ES. HP: an improved model of sucction light trap for the capture of small insects. Rev Soc Bras Med Trop 38: 70-72, 2005.

Soares RPP, Turco SJ. Lutzomyia longipalpis (Diptera: Psychodidae: Phlebotominae): a review. An Acad Bras Ciênc 75(3): 301-330, 2003.

Sudia WD, Chamberlain RW. Battery operated light trap, an improved model. Mosq News 25: 172-182, 1962.

Tabela 1. Flebotomíneos coletados e utilizados nos bioensaios de suscetibilidade.

\begin{tabular}{|c|c|c|c|c|c|c|c|c|c|c|c|c|c|c|c|}
\hline \multirow{4}{*}{ Espécies } & \multicolumn{14}{|c|}{$\begin{array}{l}\text { Estados e Municípios } \\
\end{array}$} & \multirow{4}{*}{ Total } \\
\hline & \multirow{2}{*}{\multicolumn{6}{|c|}{$\begin{array}{c}\text { Minas Gerais } \\
\text { Belo Horizonte }\end{array}$}} & \multirow{2}{*}{\multicolumn{2}{|c|}{ Montes Claros }} & & & & & & & \\
\hline & & & & & & & & & \multicolumn{2}{|c|}{ Januária } & \multicolumn{2}{|c|}{ Pirenópolis } & \multicolumn{2}{|c|}{ Colônia - UFMG } & \\
\hline & $8 \pi$ & 우우 & $3 \hat{0}$ & 우우 & $80^{2}$ & 우우 & $\delta \delta^{2}$ & 우암 & $3 \hat{0}$ & 우오 & & \multicolumn{2}{|c|}{ 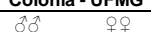 } & \\
\hline Lutzomyia longipalpis & 176 & 56 & 223 & 19 & 99 & 39 & 364 & 119 & 116 & 71 & 106 & 30 & 357 & 107 & 1882 \\
\hline Lutzomyia ischnacantha & 0 & 0 & 0 & 0 & 0 & 0 & 0 & 0 & 47 & 33 & 0 & 0 & 0 & 0 & 80 \\
\hline Nyssomyia whitmani & 15 & 5 & 8 & 8 & 0 & 0 & 0 & 0 & 0 & 0 & 18 & 9 & 0 & 0 & 63 \\
\hline Lutzomyia renei & 0 & 0 & 0 & 0 & 0 & 0 & 0 & 0 & 18 & 32 & 0 & 0 & 0 & 0 & 50 \\
\hline Nyssomyia intermedia & 25 & 15 & 0 & 0 & 0 & 0 & 0 & 0 & 0 & 0 & 0 & 0 & 0 & 0 & 40 \\
\hline Evandromyia lenti & 2 & 1 & 0 & 3 & 0 & 0 & 0 & 0 & 2 & 6 & 0 & 2 & 0 & 0 & 16 \\
\hline Evandromyia sallesi & 0 & 5 & 0 & 2 & 0 & 2 & 0 & 0 & 0 & 0 & 0 & 0 & 0 & 0 & 9 \\
\hline Micropygomyia villelai & 0 & 0 & 0 & 0 & 0 & 0 & 0 & 0 & 7 & 2 & 0 & 0 & 0 & 0 & 9 \\
\hline Evandromyia bacula & 0 & 0 & 0 & 0 & 0 & 0 & 0 & 0 & 2 & 0 & 0 & 1 & 0 & 0 & 3 \\
\hline Micropygomyia acanthopharynx & 0 & 0 & 0 & 0 & 0 & 0 & 0 & 0 & 0 & 0 & 0 & 2 & 0 & 0 & 2 \\
\hline Pintomyia kuscheli & 0 & 0 & 0 & 0 & 0 & 0 & 0 & 0 & 0 & 0 & 2 & 0 & 0 & 0 & 2 \\
\hline Martinsmyia oliveirai & 0 & 0 & 0 & 0 & 0 & 0 & 0 & 0 & 0 & 0 & 1 & 1 & 0 & 0 & 2 \\
\hline Nyssomyia neivai & 2 & 0 & 0 & 0 & 0 & 0 & 0 & 0 & 0 & 0 & 0 & 0 & 0 & 0 & 2 \\
\hline Brumptomyia avellari & 0 & 0 & 0 & 0 & 0 & 0 & 0 & 0 & 2 & 0 & 0 & 0 & 0 & 0 & 2 \\
\hline Psathyromyia sp. & 0 & 0 & 0 & 1 & 0 & 0 & 0 & 0 & 0 & 0 & 0 & 0 & 0 & 0 & 1 \\
\hline Não identificados & 0 & 0 & 0 & 1 & 0 & 0 & 0 & 1 & 5 & 25 & 0 & 3 & 0 & 0 & 35 \\
\hline \multirow{2}{*}{ Total } & 220 & 82 & 231 & 34 & 99 & 41 & 364 & 120 & 199 & 169 & 127 & 48 & 357 & 107 & 2198 \\
\hline & \multicolumn{2}{|c|}{302} & \multicolumn{2}{|c|}{265} & \multicolumn{2}{|c|}{140} & \multicolumn{2}{|c|}{484} & \multicolumn{2}{|c|}{368} & \multicolumn{2}{|c|}{175} & \multicolumn{2}{|c|}{464} & 2198 \\
\hline
\end{tabular}


Tabela 2. $\mathrm{DL}_{50}, \mathrm{RR}_{50}$ e slope da população de referência e das populações de campo.

\begin{tabular}{ccccc}
\hline População & $\mathrm{n}$ & slope & DL50 & RR50 \\
\hline UFMG & 344 & 1,37 & $2,38(0,74 \pm 3,37)$ & 1 \\
Montes & & & & \\
Claros & 363 & 1,47 & $1,03(0,00 \pm 2,14)$ & 0,43 \\
Paracatu & 264 & 1,40 & $1,31(0,00 \pm 2,50)$ & 0,55 \\
Januária & 361 & 2,53 & $2,33(0,99 \pm 3,18)$ & 0,98 \\
Pirenópolis & 110 & 3,06 & $3,87(0,25 \pm 5,80)$ & 1,62 \\
Unaí & 261 & - & - & - \\
Belo & & & - & - \\
Horizonte & 134 & - & &
\end{tabular}

Tabela 3. $T L_{50}$ e TL $L_{95}$ da população referência e das populações de campo para os dois critérios de mortalidade (A e B).

\begin{tabular}{cccc}
\hline População & Dose & TL50 & TL95 \\
\hline & Controle & - & - \\
& $3 \mathrm{ug} / \mathrm{ml}$ & $100 \mathrm{~min}$ & - \\
UFMG & $5 \mathrm{ug} / \mathrm{ml}$ & $80 \mathrm{~min}$ & - \\
& $7 \mathrm{ug} / \mathrm{ml}$ & $50 \mathrm{~min}$ & - \\
& $9 \mathrm{ug} / \mathrm{ml}$ & $40 \mathrm{~min}$ & - \\
\hline \multirow{4}{*}{ Belo Horizonte } & Controle & - & - \\
& $3 \mathrm{ug} / \mathrm{ml}$ & $50 \mathrm{~min}$ & - \\
& $5 \mathrm{ug} / \mathrm{ml}$ & $40 \mathrm{~min}$ & $90 \mathrm{~min}$
\end{tabular}




\begin{tabular}{|c|c|c|c|}
\hline & $\begin{array}{l}7 \mathrm{ug} / \mathrm{ml} \\
9 \mathrm{ug} / \mathrm{ml}\end{array}$ & $\begin{array}{l}30 \mathrm{~min} \\
20 \mathrm{~min}\end{array}$ & $\begin{array}{c}110 \mathrm{~min} \\
60 \mathrm{~min}\end{array}$ \\
\hline \multirow{5}{*}{ Pirenópolis } & Controle & 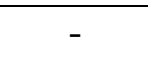 & - \\
\hline & $3 \mathrm{ug} / \mathrm{ml}$ & $100 \mathrm{~min}$ & - \\
\hline & $5 \mathrm{ug} / \mathrm{ml}$ & $70 \mathrm{~min}$ & - \\
\hline & $7 \mathrm{ug} / \mathrm{ml}$ & $60 \mathrm{~min}$ & - \\
\hline & $9 \mathrm{ug} / \mathrm{ml}$ & $40 \mathrm{~min}$ & - \\
\hline \multirow{5}{*}{ Montes Claros } & Controle & - & - \\
\hline & $3 \mathrm{ug} / \mathrm{ml}$ & $90 \mathrm{~min}$ & - \\
\hline & $5 \mathrm{ug} / \mathrm{ml}$ & $70 \mathrm{~min}$ & - \\
\hline & $7 \mathrm{ug} / \mathrm{ml}$ & $60 \mathrm{~min}$ & - \\
\hline & $9 \mathrm{ug} / \mathrm{ml}$ & $70 \mathrm{~min}$ & - \\
\hline \multirow{5}{*}{ Januária } & Controle & - & - \\
\hline & $3 \mathrm{ug} / \mathrm{ml}$ & $60 \mathrm{~min}$ & - \\
\hline & $5 \mathrm{ug} / \mathrm{ml}$ & $30 \mathrm{~min}$ & - \\
\hline & $7 \mathrm{ug} / \mathrm{ml}$ & $30 \mathrm{~min}$ & - \\
\hline & $9 \mathrm{ug} / \mathrm{ml}$ & $20 \mathrm{~min}$ & - \\
\hline \multirow{5}{*}{ Unaí } & Controle & - & - \\
\hline & $3 \mathrm{ug} / \mathrm{ml}$ & $50 \mathrm{~min}$ & - \\
\hline & $5 \mathrm{ug} / \mathrm{ml}$ & $50 \mathrm{~min}$ & - \\
\hline & $7 \mathrm{ug} / \mathrm{ml}$ & $60 \mathrm{~min}$ & - \\
\hline & $9 \mathrm{ug} / \mathrm{ml}$ & $60 \mathrm{~min}$ & - \\
\hline \multirow{5}{*}{ Paracatu } & Controle & & - \\
\hline & $3 \mathrm{ug} / \mathrm{ml}$ & $50 \mathrm{~min}$ & - \\
\hline & $5 \mathrm{ug} / \mathrm{ml}$ & $90 \mathrm{~min}$ & - \\
\hline & $7 \mathrm{ug} / \mathrm{ml}$ & $70 \mathrm{~min}$ & - \\
\hline & $9 \mathrm{ug} / \mathrm{ml}$ & $70 \mathrm{~min}$ & - \\
\hline
\end{tabular}




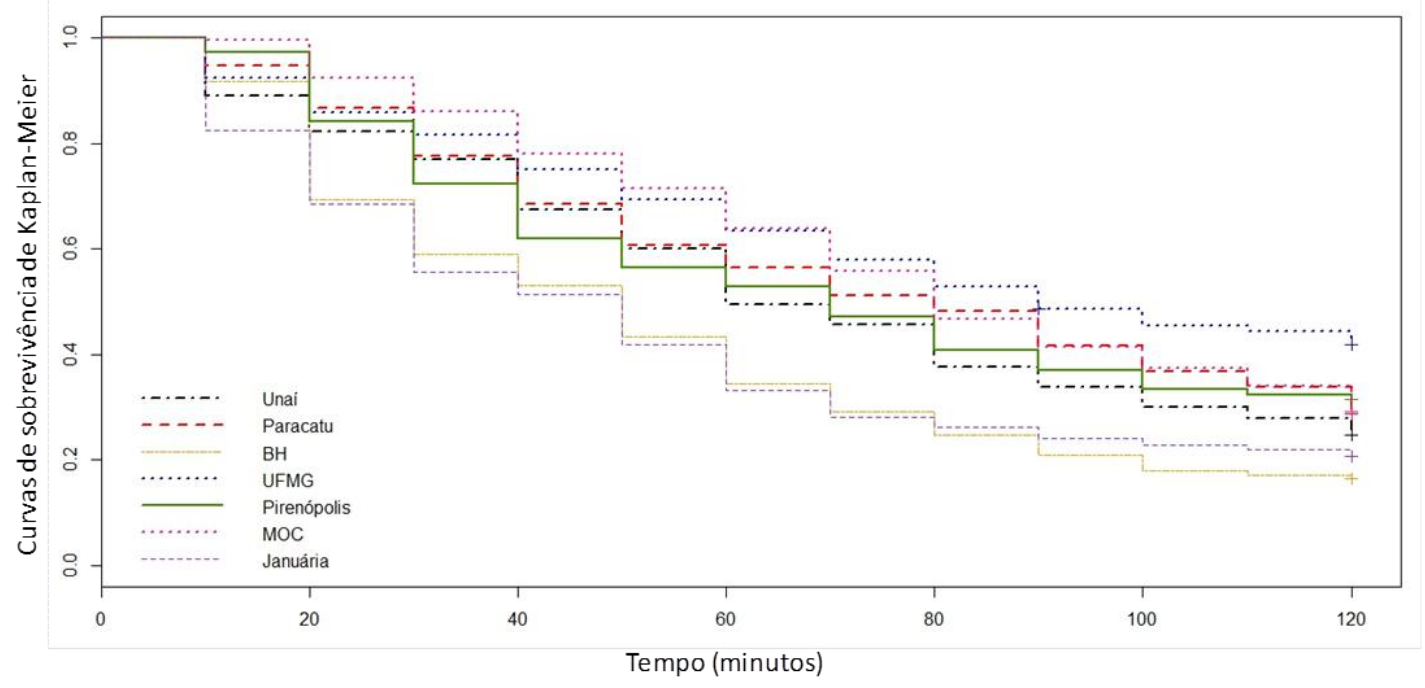

Figura 1. Estimativas de Kaplan-Meier para a função de sobrevivência por localidade.

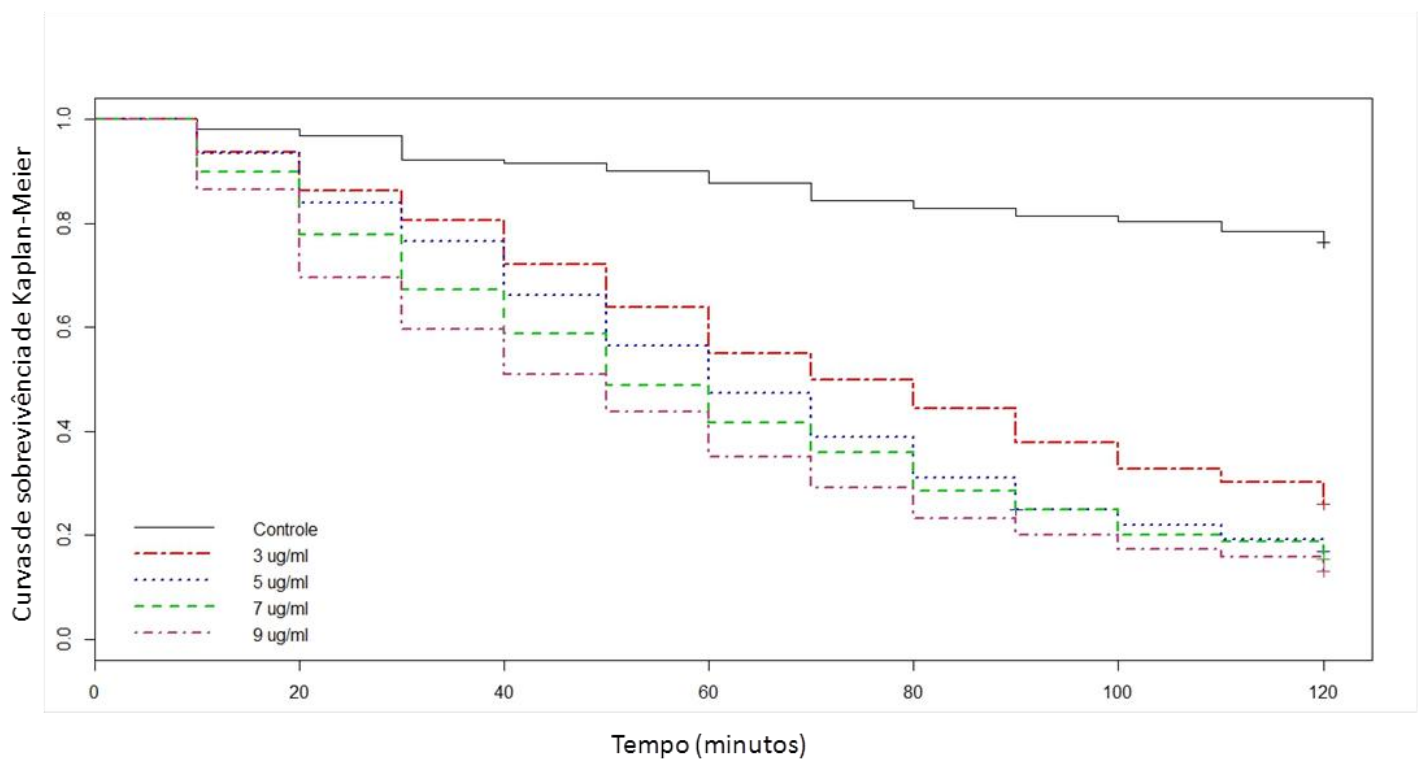

Figura 2. Curvas de sobrevivência Kaplan-Meier para as dosagens de todos os municípios. 
Potenciais Revisores:

1) Dr. José Dilermando Andrade Filho

Email: jandrade@cpqrr.fiocruz.br

2) Dr. Edelberto Santos Dias

Email: edel@cpqrr.fiocruz.br

3) Dra. Grasielle Caldas D'Ávila Pessoa

Email: grasielle@cpqrr.fiocruz.br 


\section{DECLARACÃO}

Declaramos, para os devidos fins que a publicação, intitulada: "Caracterização da suscetibilidade de Phlebotominae (Diptera: Psychodidae) ao inseticida alfacipermetrina" não apresenta conflitos de interesses de ordem financeira, pessoal ou de relações com pessoas ou organizações que possam influenciar no teor do manuscrito. Além disso, reafirmamos de que o material não foi publicado nem está sendo submetido a outro periódico e concordamos em transferir direitos de reprodução em todas as mídias e formatos para a Revista de Patologia Tropical.

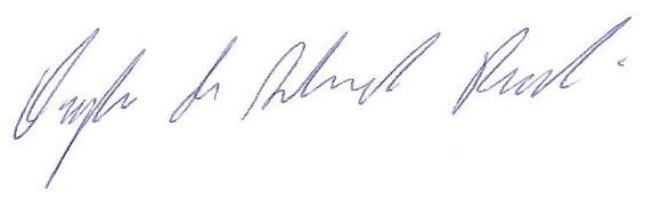

Douglas de Almeida Rocha

E-Mail: dougalmeidarocha@gmail.com

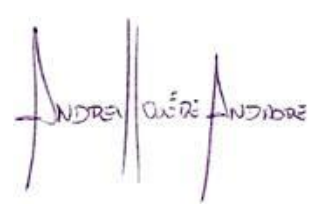

Andrey José de Andrade

E-mail: bioandrey@gmail.com 
buciana Slowra Reinaldo

Luciana Moura Reinaldo

E-mail: luciana.atuaria@gmail.com

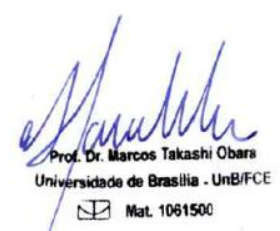

Marcos Takashi Obara

E-mail: marcos.obara@gmail.com 


\section{RPT - Agradecimento pela submissão MS1259}

1 mensagem

Revista de Patologia Tropical <revpatoltrop@yahoo.com.br

11 de fevereiro de 2016 11:35

Responder a: Revista de Patologia Tropical <revpatoltrop@yahoo.com.br

Para: "dougalmeidarocha@gmail.com" <dougalmeidarocha@gmail.com>, "bioandrey@gmail.com"

<bioandrey@gmail.com>, "luciana.atuaria@gmail.com" <luciana.atuaria@gmail.com>,

"marcos.obara@gmail.com" <marcos.obara@gmail.com>

Prezados autores,

O seu manuscrito "CARACTERIZAÇÃO DA SUSCETIBILIDADE DE PHLEBOTOMINAE (DIPTERA: PSYCHODIDAE) AO INSETICIDA ALFACIPERMETRINA" foi recebido e cadastrado como MS1259.

Agradecemos por considerar nossa revista como meio de compartilhar seu trabalho.

Em caso de dúvidas, entre em contato via e-mail

Atcs,

Rosângela Souza

Revista de Patologia Tropical 